\title{
MOTHERS INSIDE LOVING KIDS: AN EVALUATION OF A PARENTING SUPPORT PROGRAM FOR INMATE MOTHERS
}

\author{
A Dissertation \\ Presented to \\ The Faculty of the Curry School of Education \\ University of Virginia \\ In Partial Fulfillment \\ of the Requirements for the Degree of \\ Doctor of Philosophy \\ by \\ Elizabeth Coleman, M.Ed.
}

August, 2017 
(C) Copyright by Elizabeth Coleman

All Rights Reserved

August 2017 


\section{Department of Human Services \\ Curry School of Education \\ University of Virginia \\ Charlottesville, Virginia}

\section{APPROVAL OF THE DISSERTATION}

This dissertation, "Mothers Inside Loving Kids: An Evaluation of a Parenting Support Program for Inmate Mothers," has been approved by the Graduate Faculty of the Curry School of Education in partial fulfillment of the requirements for the degree of Doctor of Philosophy.

Dr. Ann B. Loper (Chair)

Dr. Nancy Deutsch

Dr. Edith (Winx) Lawrence

Dr. Peter Sheras 


\section{ACKNOWLEDGEMENTS}

Thank you to the members of the MILK programs at the Virginia Correctional Center for Women and the Fluvanna Correctional Center for Women who generously opened their lives to me. I have been so impressed by the incredible strength I have seen in each of you. To the VCCW and FCCW staff who assisted me in this process, thank you for your help. Special thanks to Sharon Dunn who made so much of this work possible. I can only hope that this evaluation is as helpful to all of you as you have been to me.

This dissertation would not have been possible without the guidance and support of my advisor, Ann Loper. Over the past four and half years, you have been a constant champion supporting me no matter the direction I chose. You were always there when I needed you with wisdom and perspective. Thank you. I am truly honored to be your last official mentee and will carry your wisdom with me throughout my career.

Thank you to the other members of my committee for the role you have each played in my professional development. To Nancy Deutsch: I would have been lost without your generosity and guidance on this project. Thank you for allowing me access to your amazing mind and your lab. To Winx Lawrence: Thank you for your excellent ideas, which dramatically strengthened this study. I am also truly grateful to have had you as a clinical mentor. I will always hold you as a standard of excellence as I pursue a career in family psychology. And to Peter Sheras who has served as a research, clinical, and personal mentor throughout my graduate school career. Thank you for your supervision and guidance. I have learned so much from you.

Thank you to Eleanor Nowak who spent hours in the car to assist with countless days of interviews. It was a pleasure to work with you as a colleague and a friend. Thank you for being so generous with your time. I could not have done it without you.

To my lab mates, thank you for your help and support. To Rachel Kappel, Kelsey Bowman, Carol Bernate, and Sierra Swisher, my willing and able research assistants: Thank you so much for your help. Thank you for doing the not-so-fun parts of this project with constant positivity and energy. To the Lovely Ladies of the Loper Lab: Joanna Will, Logan Rowe, Tory Phillips, and Emily Nichols. Thank you for making it seem possible and for helping me along the way.

Lastly, thank you to those of you who made sure Liz the person was taken care of while I worked on Liz the psychologist. To Trevor, who kept me sane and fed: thank you for being silly when I was stressed, for being kind when I was sad, and for being you when I was me. To Sadie, thank you for your friendship. It was a surprise that made this whole journey manageable, not to mention fun! To my parents, thank you for the many forms of

support you have given without hesitation as I've pursued my goals. Thank you for supporting my decisions even when they made you nervous and for being proud of me no matter what.

Thank you all for the guiding lights you shown, the hands you held, and the shoulders you leant. I will always be grateful. 
TABLE OF CONTENTS

ACKNOWELDGEMENTS ..._. Page
LIST OF TABLES
LIST OF FIGURES
LIST OF APPENDICES

ELEMENTS

I. EXECUTIVE SUMMARY _____________.... 9

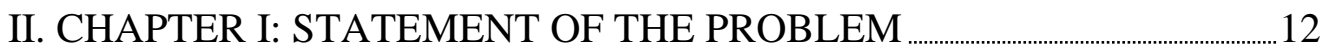

III. CHAPTER II: REVIEW OF THE LITERATURE

IV. CHAPTER III: METHOD _ _ 64

V. CHAPTER IV: RESULTS …﹎.._________..... 76

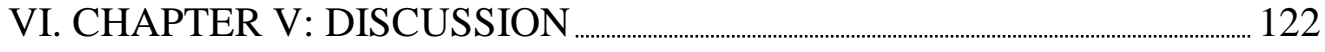

VII. REFERENCES _ _ 150 


\section{LIST OF TABLES}

Page

1. Parenting Attitudes of Participants Per the Adult-Adolescent Parenting Inventory (AAPI-2) 79

2. Self-reported Visit Participation and Changes in Visit Frequency 87

3. MILK Participant Self-reports of Relationships with Children's Caregivers 89

4. Self-reported Changes in Parenting Stress Since Joining MILK 106

5. Self-reported Behavior Change Among MILK Participants 111 


\section{LIST OF FIGURES}

Page

1. Makariev and Shaver's (2010) Model of Attachment Disruption in Children of Incarcerated Mothers

2. Hypothesized Theory of Change Model for Multi-systemic Intervention for Incarcerated Mothers and Their Families

3. Hypothesized Mechanism of Change 1: Healthier Mother-child Relationship via Improved and Increased Mother-child Contact

4. Hypothesized Mechanism of Change 2: Improved Mother-caregiver Alliance via Improved and Increased Mother-caregiver Contact.

5. Hypothesized Mechanism of Change 3: Reduced Maternal Parenting Stress via Increased Perceived Parenting Competence, Increased Parenting Support, and Healthier Mother-child Relationship.

6. Hypothesized Mechanism of Change 4: Improved In-prison Behavior via Program Requirements and Reduced Parenting Stress.

7. Hypothesized Mechanism of Change 5: Institutional Benefits via Improved Inmate Behavior, Improved Inmate Mental Health, Reduced Recidivism, and Shorter Sentences

8. Model of Factors Contributing to Perceived Changes in Mother-child Relationships According to Inmate MILK Participants.

9. Model of Factors Contributing to Perceived Changes in Mother-caregiver Relationships According to Inmate MILK Participants

10. Model of Factors Contributing to Perceived Changes in Wellbeing According to Inmate MILK Participants

11. Model of Factors Contributing to Perceived Changes in Behavior According to Inmate MILK Participants.

12. Revised Theory of Change Model for MILK Program Based on Inmate MILK Participant Reports 


\section{LIST OF APPENDICES}

Page

1. A: Staff Interview Protocol................................................ 168

2. B: Initial Inmate Interview Protocol.......................................... 173

3. C: Inmate Interview Protocol Revised.......................................179

4. D: Background and Program Questionnaire..................................184

5. E: Adult-Adolescent Parenting Interview (AAPI-2)............................ 188 


\title{
Executive Summary
}

\author{
Advisor: Ann B. Loper
}

With the advent of harsher mandatory sentencing laws in the 1980s, the number of incarcerated mothers in the US grew dramatically leaving a large group of vulnerable children behind (Glaze \& Maruschak, 2008). A considerable body of research has found that these children are at increased risk for negative developmental outcomes including internalizing and externalizing behavior problems as well as academic difficulties and even failure (Murray, Farrington, \& Sekol, 2012; Trice \& Brewster, 2004). Given the number of known risk factors that are associated with incarceration (e.g., poverty, substance abuse, criminal activity; Connell \& Goodman, 2002; Greenfeld \& Snell, 1999; Zuckerman, 1994), it remains unclear whether a mother's incarceration itself contributes to these outcomes or simply serves as a marker for children who were already at-risk. Nevertheless, Attachment Theory (Bowlby, 1969) and well-supported theories of accumulated risk (Gerard \& Beuhler, 2004), teach that the sudden absence of a primary caregiver from a child's life is likely to undermine healthy development and this is likely to be particularly true for children already facing adversity. As such, whether the relationship between maternal incarceration and negative developmental outcomes is primarily causal or correlational in nature, repairing and strengthening the mother-child attachment system is likely to contribute to resiliency among this vulnerable group of children.

With this in mind, and bolstered by findings indicating that improved relationships with family contribute to better outcomes for inmates, including fewer behavior and mental health problems (Bales \& Mears, 2008; Hlavka, Wheelock, \& Jones, 
2015), some correctional communities have developed programs designed to strengthen relationships between incarcerated parents and their children. This study used mixed methods to evaluate the efficacy of one such program in two state correctional facilities in Virginia as perceived by inmate participants and institutional staff. The Mothers Inside Loving Kids (MILK) program aims to foster healthy mother-child relationships by creating a context for parent-child interactions that is more conducive to healthy, attachment-building dynamics than the typically inflexible and intimidating visitation environment. MILK includes three components: regularly scheduled, child-friendly visits, parent training, and group support. Given the multiple components and potential for many areas of impact, I developed a comprehensive theory of change model to detail the numerous hypothesized mechanisms of change. I then evaluated perceptions of changes in three primary domains: the mother-child relationship, the relationship between mothers and their children's caregivers, and inmate behavior and wellbeing.

Results suggest that the majority of inmate participants perceived improvement in relationships with their children as a result of participating in MILK, which they attributed primarily to the enhanced visits, and this perception was also held by staff members. The aspects of the specialty visits most often cited as contributing to improved mother-child relationships were child-friendly activities, one-on-one interactions with children, and physical contact with children. There was more limited evidence to support the efficacy of the parent training and group support components of the program in improving relationships with children. With regard to mother-caregiver relationships, a majority of participants perceived improvements as a result of participating in MILK, including improved connection with caregivers and a stronger sense of parenting alliance. 
Again, staff reported similar perceptions in this area. As compared to the mother-child relationship improvements, participants attributed changes in the mother-caregiver relationship to the group support and parent training components as well as to the enhanced visits noting that they learned more about their caregiver's perspective and how to interact with them more effectively through these program components. Lastly, results also supported the hypothesis that program participation would contribute to improved behavior and wellbeing among participants. The majority of MILK participants reported improved behavior since joining the program which included fewer infractions and increased engagement in prosocial activities and this was confirmed by staff perceptions. Additionally, a majority of women reported improvements in mental health as a result of participating in MILK. Women described gaining self-esteem and a more positive mood as a result of working towards becoming a better parent and more directly from enjoyable interactions with children. These results provide support for programs working to enhance interactions between incarcerated mothers and their children and offer insight into the factors that are most likely to contribute to healthier relationships. 


\section{Chapter I}

\section{Statement of the Problem}

As of last count in 2007, 65,600 mothers were incarcerated in US prisons, leaving an estimated 147,400 children behind (Glaze \& Marushcak, 2008). The challenges facing these children are numerous and put children at risk for a host of negative outcomes including mental health issues, antisocial behavior (Murray, Farrington, \& Sekol, 2012), and academic failure (Trice \& Brewster, 2004). Attachment theory provides a useful lens for understanding the difficulties these children face. According to Bowlby's (1969) seminal theory, having a "secure attachment schema," in which relationships are seen as predictable sources of support and comfort, is an essential building block of healthy development without which children are at risk for many of the negative outcomes listed above. Children develop secure attachment schemas through continuous contact with adults who provide consistent care in response to their needs (Bowlby, 1969). For most children, mothers are their primary caregivers and have the greatest bearing on their attachment schemas (Steele, Steele, \& Fonagy, 1996), and this holds for children of incarcerated women (Block \& Potthast, 1998; Glaze \& Maruschak, 2008). Research has shown that the sudden absence of a primary attachment figure often leads to the development of insecure attachment schemas in which children do not see intimate others as reliable providers of support (Bowlby, 1982). As such, a mother's sudden absence due to incarceration is likely to undermine a child's attachment schema placing him or her on a risky developmental path. Accordingly, research has demonstrated that children of incarcerated mothers are more likely than not to have insecure attachment representations of mothers and caregivers (Poehlmann, 2005b). 
Moreover, the threat to the attachment system posed by a mother's sudden departure is compounded by issues that are often present in the lives of incarcerated mothers and their children prior to the incarceration itself. Incarcerated mothers report high rates of pre-incarceration drug use, mental health problems, and poverty (Murray \& Murray, 2010), and, as is often the case among parents struggling with these issues (Connell \& Goodman, 2002; Zuckerman, 1994), they report elevated rates of ineffective parenting marked by low support and inappropriate discipline (Dannerback, 2005;

Kjellstrand \& Eddy, 2011), as well as child neglect and abuse (Phillips, Burns, Wagner, Kramer, \& Robbins, 2002). As such, the attachment disruption caused by a mother's incarceration often occurs within a context of accumulating risk that poses considerable threat to children's well-being and ability to form healthy attachment schemas (Bowlby, 1982; Gerard \& Beuhler, 2004). This makes children of incarcerated mothers a particularly high-risk group and speaks to the need for interventions that improve dynamics between incarcerated mothers and their children.

However, given the pre-existing issues documented in the lifestyle and parenting habits of incarcerated women, some have argued that separation from an incarcerated mother may be a boon to children rather than an additional risk factor (Eddy \& Reid, 2003; Edin, Nelson, \& Paranal, 2004). While some research provides support for this notion amongst children of incarcerated fathers (Geller, Cooper, Garfinkel, SchwartzSoicher, \& Mincy, 2012), little is known about the veracity of this claim amongst children with incarcerated mothers whose circumstances often differ considerably from those of children with incarcerated fathers (Glaze \& Maruschak, 2008). Moreover, the majority of incarcerated women expect to resume primary caretaking duties for their 
children upon release (Gaudin \& Sutphen, 1993), making a discussion of whether or not it is best for children to maintain a relationship with their incarcerated mothers moot.

Given the accumulation of risk factors facing incarcerated mothers and their children, effectively strengthening the bond between them requires a multifaceted approach. One potential avenue for intervention is through an increase in the frequency of contact between the dyad. While the majority of contact between incarcerated mothers and their children typically occurs via phone calls and letters (Loper, Carlson, Levitt, \& Scheffel, 2009), there is reason to focus attention on in-person visitation as it provides the most direct form of the dyadic interactions that are essential to healthy attachment (Poehlmann, Dallaire, Loper, \& Shear, 2010). As such, children who do not visit their incarcerated parents report increased feelings of alienation from them (Shlafer \& Poehlmann, 2010). Moreover, prison systems are motivated to work on visitation experiences as in-person contact with children is related to a host of positive outcomes for inmates, including improved behavior and mood (Roxburgh \& Fitch, 2013) as well as decreased recidivism (Bales \& Mears, 2008; Hairston, 1988; Harm \& Phillips, 2001; Loper et al., 2009). However, due to a variety of barriers, most incarcerated mothers receive visits from children infrequently, and more than half of all parents in state and federal prisons never visit with a child (Glaze \& Maruschak, 2008).

But scientific studies sound a caveat suggesting that enacting interventions to increase the frequency of visits without addressing the quality would be insufficient. Findings indicate that some parents (Bales \& Mears, 2008; Loper et al., 2009) and children (Poehlman et al., 2010; Shlafer \& Poehlmann, 2010) experience significant distress related to in-person visits and may exhibit emotional and behavioral problems in 
their wake. Some evidence suggests that more visits with an incarcerated parent are associated with children's insecure attachment representations of that parent (Poehlmann, 2005b). These mixed findings likely result from widely varying visitation conditions as well as dramatic differences in incarcerated parents' abilities to facilitate positive interactions within the visitation environment. Surveys of visitation procedures reveal a lack of child-friendly environments that have the potential to foster positive parent-child interactions - families often meet in crowded, public spaces, and may be separated by glass (Boudin, Stutz, \& Littman, 2014; Poehlmann et al., 2010). And, even when incarcerated parents are not separated from children, they may be prohibited from touching them (Arditti, 2003). In addition, children are often exposed to frightening body searches and close monitoring by guards, and many incarcerated parents express distress over worries that children will inadvertently violate strict prison rules (Park \& ClarkeStewart, 2002). These difficult circumstances in combination with the faulty parenting skills many incarcerated mothers are known to possess (Dannerback, 2005; Kjellstrand \& Eddy, 2011; Phillips et al., 2002), make for an experience that may be more harmful than helpful to the mother-child relationship without intervention.

With these findings in mind, and bolstered in particular by the potential for improved mother-child relationships to improve inmate behavior and reduce recidivism (Loper et al., 2009; McClure et al., 2015), some institutions have developed specialty visitation programs designed to improve the quantity and quality of visits between incarcerated mothers and children. While there is a general sense of optimism in the research community surrounding these programs, to date, few have been formally evaluated, or even described for potential replication in other facilities (Shlafer, Loper, \& 
Schillmoeller, 2015). This study represents an effort at such documentation and evaluation. The Mothers Inside Loving Kids (MILK) program - a multi-systemic program in two Virginia correctional facilities for women - is a multifaceted intervention that combines longer, child-friendly visits with parent training and support in an effort to improve the bond between incarcerated mothers, their children, and their children's caregivers. In the next chapter, I will review the literature on the challenges facing incarcerated mothers and their children and the role of attachment in the development and resolution of these difficulties. I will then use this attachment perspective to illustrate a comprehensive theory of change model for parent training plus specialty visitation programs, followed by a review of studies examining the efficacy of such programs. I will then introduce the MILK program and the aims of the current study-a mixedmethods evaluation of the program evaluating its efficacy in each proposed area of change as perceived by incarcerated mothers participating in the program and institutional staff. In Chapter III, I will describe the methods used to conduct the evaluation in a sample of 39 MILK participants and 5 staff members. The results of this evaluation are examined in Chapter IV, followed by interpretation of the results and practical implications discussed in Chapter V. 


\section{CHAPTER II}

\section{Review of the Literature}

The purpose of this investigation is to evaluate a program combining parent training, interparent support, and specialty visitation for incarcerated mothers and their children. The importance of an investigation of this nature is grounded in the following underlying assumptions: (1) maternal incarceration is associated with problems for children; (2) maternal incarceration is likely to lead to these problems in part through disrupted mother-child connection and attachment; and (3) interventions aimed at improving the quality of contact between incarcerated mothers and their children can influence these relationship dynamics. In this chapter, I will review the existing literature associated with each of these assumptions. Using this review, I will develop a theory of change model for combined parent training, interparent support and specialty visitation programs that outlines the mechanisms through which these interventions are likely to benefit incarcerated mothers and their children. Lastly, I will provide a review of findings on such programs, followed by a description of the program under evaluation-Mothers Inside Loving Kids (MILK) — and the research questions this study hopes to answer.

\section{Children of Incarcerated Mothers: A High-risk Population}

The advent of mandatory sentencing laws and the use of incarceration for drugrelated offenses in the 1990s led to rapid growth in the number of women in U.S. prisons (Hanlon, Blatchley, Bennett-Sears, O’Grady, Rose, \& Callaman, 2005). These policies have broad implications as the majority of these incarcerated women- $56 \%$ in federal and $65 \%$ in state prisons - reported having at least one child (Glaze \& Maruschak, 2008). 
As a result, the number of children with a mother incarcerated in U.S. state and federal prisons increased 131\% between 1991 and 2007 (Glaze \& Maruschak, 2008) to an estimated 147,000. Moreover, when the population of mothers housed in jails is considered, estimates suggest that as of 2010, 300,000 minor children in the U.S. had a mother in jail or prison on any given day. While policy changes in the past several years have led to decreased rates of incarceration (Glaze \& Parks, 2011), and presumably this has resulted in fewer children with incarcerated mothers (although no data is available to confirm this), these children, even if smaller in number, remain of national concern given their high-risk status. Research has consistently shown a strong link between parental incarceration and a host of negative emotional and behavioral outcomes for children (Geller et al., 2012; Geller, Garfinkel, Cooper, \& Mincy, 2009; Murray \& Farrington, 2005; Murray et al., 2012; Phillips et al., 2002; Poehlmann, 2005b) including substance abuse (Kinner, Alati, Najman, \& Williams, 2007), delinquency (Murray et al., 2012), low academic achievement (Nichols, Loper, \& Meyer, 2015; Trice \& Brewster, 2004), and increased rates of internalizing disorders (Murray \& Farrington, 2008b). As such, interventions aimed at promoting resiliency in this group are of growing importance. Such interventions first require a nuanced understanding of the challenges these children face.

While the majority of the research on children of incarcerated parents has focused on paternal incarceration, or on parental incarceration more generally (Dallaire, 2007), much can be learned about the children of incarcerated mothers from this body of work. If anything, studies that focus exclusively on or include incarcerated fathers may underestimate the risks associated with maternal incarceration, which, for a variety of 
reasons, may pose a greater threat to children's well-being (Cho, 2010; Glaze \& Maruschak, 2008; Young \& Smith, 2000). Children's living arrangements are more likely to be disrupted, sometimes multiple times (Cho, 2010), following a mother's incarceration; incarcerated mothers, as compared to incarcerated fathers, are more likely to have been living with their children prior to incarceration, and they are almost three times as likely to have been their children's primary caretaker (Glaze \& Maruschak, 2008). As such, when a child's mother is incarcerated, the child is likely to face a significant change in who is providing his or her daily care. Moreover, caretakers who step in are likely to be less familiar to children than in the case of paternal incarceration. According to Glaze and Maruschak's 2008 survey of state prisoners, while $88 \%$ of children of incarcerated fathers remain in the care of their mothers, only $37 \%$ of children of incarcerated mothers live with their fathers, while $42 \%$ are cared for by grandparents and the remainder live with other relatives $(23 \%)$ or foster parents $(11 \%$; percentages sum to more than $100 \%$ because some prisoners had multiple children living with multiple caregivers). Furthermore, children of incarcerated mothers may be at greater risk than children of incarcerated fathers even before their parents' incarceration: As compared to the children of incarcerated fathers, they are more likely to have experienced maternal drug use and mental health problems (Murray \& Murray, 2010), and are more likely to have witnessed criminal activity (Dallaire \& Wilson, 2010). They are also more likely to have been relying on public assistance before the arrest than the children of incarcerated fathers (Murray \& Murray, 2010), which places children at considerable risk for a host of negative outcomes (Sameroff, Gutman, \& Peck, 2003). 
The aforementioned findings are part of a large body of evidence indicating that children of incarcerated parents, and especially children of incarcerated mothers, represent a high-risk group independent of their parents' incarceration. These children are more likely to have young parents with little education who are of low socioeconomic status (Geller et al., 2009; Huebner \& Gustafson, 2007; Murray \& Farrington, 2005). They are also more likely to live with parents struggling with substance use and mental illness: In a national study of incarcerated parents, $85 \%$ reported that they had a history of substance abuse, and 54\% reported that they were using drugs in the month before their arrest (Mumola, 2000). This same study found that 25\% of the entire female prison population in the U.S. received medication for a mental illness, and another study estimated that incarcerated adults were five times more likely to have a mental illness than adults in the general population (Kupers, 1999). Likely due at least in part to these issues, research into the parenting styles of incarcerated parents has demonstrated that they are more likely to use ineffective parenting techniques marked by low support and inappropriate discipline (Dannerback, 2005; Kjellstrand \& Eddy, 2011). Moreover, investigators have observed increased rates of child neglect and abuse among incarcerated parents (Phillips et al., 2002). Given the well-established importance of supportive and effective parenting in children's healthy development and ability to withstand adversity (Rothbaum \& Weisz, 1994), and the known link between child abuse and later hardship (Wiebush, Freitag, \& Baird, 2001), this evidence paints a clear picture of a vulnerable group of youth.

Because children of incarcerated mothers often have lives marked by such significant adversity, it is unclear whether or not maternal incarceration uniquely 
contributes to the negative outcomes seen in these children or is more often a proxy for these adversities. In an effort to answer this question, the latest research in this area has focused heavily on teasing out the causal effects of parental incarceration, if any, above and beyond these associated risk factors (Murray et al., 2012). However, whether or not the relationship between maternal incarceration and negative child outcomes is causal or correlational does not change these children's need for support. Regardless of whether or not children would have faced the same issues had their parents avoided incarceration, once these mothers are in prison an opportunity to intervene in a family system that is almost certainly in need of help is provided. As such, this review will give equal weight to child outcomes likely to be correlated with but not caused by maternal incarceration in order to develop the most comprehensive understanding of appropriate targets for intervention.

Antisocial behavior. The link between parental incarceration and increased antisocial and delinquent behavior among children is the most robustly supported of all child outcomes. This relationship was most clearly illustrated by Murray, Farrington and Sekol's 2012 meta-analysis of 50 rigorous studies examining outcomes associated with parental incarceration. Antisocial behavior, which included lying and cheating as well as more explicit criminal activities, was significantly related to parental incarceration even after controlling for a comprehensive list of covariates, and the size of the effect was fairly large. Moreover, Murray and Farrington (2005) had previously demonstrated that this association was stronger than the relationship between antisocial behavior and separation from a parent due to death, hospitalization, or divorce. This finding is 
particularly concerning given the relationship between antisocial behavior in childhood and later offending and possible incarceration (Gendreau, Little, \& Goggin, 1996).

In fact, evidence suggests that the antisocial behavior seen in children of incarcerated parents at young ages does often translate into justice system involvement (Dannerback, 2005; Huebner \& Gustafson, 2007; Tennessee Department of Corrections, 1995). Maternal incarceration specifically has been shown to increase the likelihood that a child will become involved with the justice system and may in fact be a stronger predictor than paternal incarceration. A 1995 survey of incarcerated parents-including 260 incarcerated mothers - conducted by the Tennessee Department of Corrections found that adolescent children of incarcerated mothers were significantly more likely to be involved with the justice system than children of incarcerated fathers. They also found that the intergenerational cycle of crime started early: $17 \%$ of the adolescents of incarcerated mothers in their study had already been in legal trouble or held in a juvenile detention center, and this number may be an underestimate as information was provided exclusively by the incarcerated women, some of whom had little information on their children. In order to address this issue, Trice \& Brewster (2004) sampled the guardians of adolescents with incarcerated mothers and compared their reports to reports from the guardians of the adolescents' best friends - a comparison group with similar profiles of risk other than the experience of parental incarceration. Based on these reports, $34 \%$ of the adolescents of incarcerated mothers had been arrested in the previous 12 months, as compared to $15 \%$ of the best friends.

While these findings are notable, small sample sizes preclude generalizability. As such, Huebner and Gustafson sought to investigate the generalizability of these findings 
in a 2007 study. They analyzed data from the National Longitudinal Survey of Youth 1979 and found that maternal incarceration was a robust predictor of children's later involvement with the justice system. The predictive value of maternal incarceration for later justice system involvement held after considering other maternal characteristics and correlates of criminal activity, suggesting that maternal incarceration itself rather than simply its associated risk factors increased children's chance of arrest. This points to an intergenerational cycle of crime and imprisonment that is troublesome given the vast number of parents who have been incarcerated in recent decades and the already overburdened correctional system (Pitts, Griffin, \& Johnson, 2013). Research also suggests that justice system involvement is not only more frequent among children of incarcerated parents, but also more chronic and severe. In a study of youth involved in the justice system in Missouri, Dannerback (2005) found that those with a history of parental incarceration were more likely to have a more serious history of offending marked by earlier age of first referral, greater number of referrals, and more serious offenses.

Internalizing problems. In addition to antisocial behaviors, often referred to as “externalizing problems," maternal incarceration has also been linked to internalizing problems in children. In a 2008 study of boys who experienced the incarceration of a parent during childhood, Murray and Farrington found that they were more than three times as likely to struggle with anxiety and depression in adolescence and adulthood as compared to a group who had experienced other forms of separation from parents including divorce and death. These findings are bolstered by anecdotal reports from incarcerated parents that reflect experiences in line with these statistics. Through 
interviews with incarcerated mothers, Block and Potthast (1998) found that mothers perceived more depressive symptoms and anger in their daughters after their imprisonment. Additionally, they reported increased rates of nocturnal enuresis (bedwetting) among their daughters since their incarceration, which provides a more objective measure of emotional disturbance in children (Equit, Klein, Braun-Bither, Gräber, \& Gontard, 2013).

Evidence also suggests that children of incarcerated parents are at increased risk of experiencing symptoms of post-traumatic stress (Bokneck, Sanderson, \& Britner, 2009; Kampfner, 1995; Phillips \& Zhao, 2010). Researchers investigating this possibility suggest that children's experience of a parent's arrest and sudden departure is often traumatic, and symptoms of post-traumatic stress may emerge as a result (Bokneck et al., 2009; Kampfner, 1995). This idea stems from findings that $40 \%$ of parents say children were present at their arrest and in $27 \%$ of those cases they report that weapons were drawn (Braman, 2004). Moreover, $70 \%$ of mothers report that police handcuffed them in sight of their children (Braman, 2004). Other researchers (Myers, Smarsh, AmlundHagen, \& Kennon, 1999; Phillips \& Zhao, 2010) suggest that children of incarcerated parents are likely to experience post-traumatic stress due to an accumulation of traumatic experiences associated with parental incarceration such as abuse, neglect, chronic poverty, exposure to violence, and multiple separations from caretakers (Dallaire, 2007; Phillips et al., 2002; Wildeman, 2009). Using qualitative interviews from 36 children participating in a visitation program at a women's prison, Kampfner (1995) found that $75 \%$ of the children she interviewed exhibited symptoms consistent with post-traumatic stress, including flashbacks of their mother's arrest, depressed mood, insomnia, and 
concentration difficulties. In a similarly small study of 35 children participating in an after-school program for children with incarcerated parents, Bokneck, Sanderson, and Britner (2009) found that $77 \%$ reported clinically significant symptoms of post-traumatic stress on a standardized measure. In an attempt to increase the generalizability of these findings, Phillips and Zhao (2010) analyzed data from the National Survey of Child and Adolescent Wellbeing, a nationally representative survey of 5501 children who were known victims of maltreatment. Due to limitations of the data, they were only able to identify children who were likely to have witnessed a parent's arrest by finding those that reported witnessing the arrest of a household member, and also reported the recent arrest of a parent. Their analyses revealed that being in the group of children who were likely to have witnessed a parent's arrest was a "distinct predictor" of symptoms of post-traumatic stress in children after controlling for a variety of other risk factors. As noted above, the fact that they controlled for other risk factors suggests that the lived experience of posttraumatic stress in these children may actually be more prevalent and/or severe than their findings indicate.

Despite these findings, general consensus in the field is that the existence of a significant relation between maternal incarceration and internalizing problems in offspring remains unclear (Murray et al., 2012). This notion stems mainly from Murray et al.'s (2012) widely cited meta-analysis, which found no significant relation between parental incarceration and internalizing problems among children. However, these findings must be interpreted cautiously. The meta-analysis included outcomes measured during childhood and adolescence as well as during adulthood, and, because they found no main effect, they did not investigate the possible moderating effect of age at outcome. 
Therefore, a weaker relationship between parental incarceration and internalizing problems during childhood and adolescence may have masked the significant relationship between parental incarceration and internalizing problems in adulthood that was previously documented by the authors themselves (Murray \& Farrington, 2008b). Moreover, given the ongoing debate in the field, the meta-analysis aimed to parse out the causal relations between parental incarceration and child outcomes from those that were exclusively correlational in nature. As such, they only reported the relation between parental incarceration and internalizing problems in offspring after accounting for the effect of related risk factors, which does not reflect the actual rates of these issues among the children studied. The actual experiences and needs of children in their study would be better reflected in the rate and severity of internalizing problems among the cohort, regardless of the factors believed to have caused them; however, this figure is yet unknown.

Academic performance. Findings linking maternal incarceration to academic difficulties and school drop-out are convincing. This is not surprising given evidence that these children are more likely to experience behavioral problems and mental health issues all of which are risk factors for academic difficulties and failure (Fergusson $\&$ Woodward, 2002; McIntosh, Horner, Chard, Dickey, \& Braun, 2008). Among the sample of 260 mothers interviewed by the Tennessee Department of Corrections (1995), 31\% reported that at least one of their children had been held back a grade. Evidence also suggests that suspension and expulsion rates are elevated among these children. Among youth seeking mental health services, those who had experienced a parent's incarceration were significantly more likely to be expelled or suspended from school during the six- 
month study period (Phillips et al., 2002). Furthermore, in Trice and Brewster's (2004) study comparing adolescent children of incarcerated mothers to their best friends, the adolescents with incarcerated mothers were significantly more likely to be suspended than their friends with $40 \%$ and $14 \%$ suspension rates respectively. The adolescents of incarcerated mothers were also more likely to be receiving a failing grade than their friends with $45 \%$ of their guardians reporting as much in comparison to $20 \%$ of their friends' guardians. Murray and Farrington (2008a) found similar results in a sample of sons of incarcerated parents in England. Of the 23 boys studied, $68 \%$ had failed out of school by age 14 , which was significantly more than had failed out among the comparison group of boys who had been separated from parents for other reasons (e.g., hospitalization). Moreover, investigations of much larger, nationally representative samples have revealed similar findings. In a 2012 analysis of data from the National Longitudinal Study of Adolescent Health, Hagan and Foster found that paternal incarceration was a significant predictor of lower academic achievement and college attainment after controlling for a host of associated risk factors. Using the same data set, Nichols, Loper, and Meyer (2015) expanded their investigation to children experiencing both paternal and maternal incarceration and found that parental incarceration was positively correlated with truancy, and negatively correlated with both cumulative academic achievement and highest attained level of education. Notably, while parental incarceration was a unique predictor of truancy after controlling for a multitude of associated individual- and school-level risk factors, these risk factors accounted for the associations between parental incarceration and the two measures of achievement (cumulative academic achievement and highest attained level of education). 
There are many possible mechanisms through which maternal incarceration may threaten children's academic outcomes. Findings suggest that children of incarcerated parents may be at a disadvantage in academics based on their intellectual abilities: Poehlmann (2005b) found that children of incarcerated parents in her study on average demonstrated below-average levels of cognitive functioning. This may stem from genetic predisposition as below-average cognitive abilities are the norm among prisoners (Yun \& Lee, 2013), but may also be exacerbated or induced by the stress and trauma these children are likely to face, including the incarceration itself (Lupien, McEwen, Gunnar, \& Heim, 2009). Furthermore, the upheaval caused by parental incarceration may impact school placement and therefore performance. Changing schools may undermine children's success as maintaining a stable connection to school and the adults within it, a construct often referred to as "school bonding," is a known protective factor for at-risk youth, which has been linked to reduced rates of future incarceration (Catalano, Haggerty, Oesterle, Fleming, \& Hawkins, 2004; Henry, Oeting, \& Slater, 2009; Maddox \& Prinz, 2003). Children of incarcerated mothers may be particularly at risk in this area given the increased likelihood that they will relocate following their mother's arrest (Cho, 2010; Glaze \& Maruschak, 2008).

Taken together, research on the children of incarcerated mothers paints a complex portrait of risk in which children are often fighting an uphill battle to stay out of prison themselves. This intergenerational cycle of crime threatens not only the children and families involved in it directly but also society as a whole through increased crime rates and resulting demands on the justice system. As such, intervention is needed to interrupt this cycle, which requires an in-depth understanding of the mechanisms that put children 
of incarcerated mothers at risk. In the next section, I will argue that children of incarcerated mothers are likely to develop maladaptive attachment schemas as a result of the myriad adversities they face, and this attachment dysfunction is a key factor in the many negative outcomes outlined above. And, as such, the attachment schemas of these children represent a ripe target for intervention.

\section{An Attachment Perspective on Maternal Incarceration}

Attachment theory (Bowlby, 1969) provides a well-researched and amplysupported framework that illuminates the risks posed to children of incarcerated mothers and how these risk factors are perpetuated through the life cycle. This review will provide a brief overview of attachment theory, followed by a comprehensive model of the role attachment disruption plays in the intergenerational cycle of hardship and crime.

Attachment theory. The fundamental tenet of attachment theory as originally detailed by Bowlby (1969) is that children develop a sense of safety in the world through interactions with caregivers who reliably and consistently meet their needs. According to Bowlby (1969), this sense of security is essential to children's cognitive and social development, as their expectation of being able to return to a reliable caregiver allows them to feel safe exploring an unfamiliar world. Attachment theory posits that early experiences with caregivers create an internal working model, also referred to as an attachment schema, which dictates children's sense of safety in relationships and the greater world. In her seminal work, Ainsworth (1979) observed interactions between infants and their mothers and identified three patterns of attachment (i.e., attachment schemas) that characterized the majority of children: secure, insecure-anxious, and insecure-avoidant. Each of these schemas describes a particular pattern of responding to 
children's needs among caregivers and a corresponding pattern of interacting with caregivers in children.

Children with secure attachment schemas receive consistent and appropriate (i.e., warm yet not overbearing) responses to bids for affection and feel safe and competent to explore their world as a result. Children with insecure-anxious attachment schemas receive inconsistent responses to requests for support from caregivers who are often anxious and preoccupied by their own difficulties. As a result, children with this schema view the world as unpredictable and anxiety provoking and are often hesitant to engage in the exploration of the unfamiliar that facilitates healthy development. Children with insecure-avoidant attachment schemas have caregivers who respond consistently, yet poorly, to their bids for help, which encourages them to suppress their own needs and emotions. These caregivers tend to be uncomfortable with their own emotions and respond to children's distress in various unfavorable ways (e.g., ignoring their distress, physical punishment, or verbal chastising), which encourages children to rely exclusively on themselves for comfort. Following Ainsworth's work, Main and Solomon (1990) identified a fourth attachment pattern, which is likely to be particularly relevant to children of incarcerated mothers given its association with neglect, abuse, and poverty (Lyons-Ruth \& Jacobvitz, 2008). Insecure-disorganized attachment schemas result from caregivers who lack any strategy for dealing with children's needs. As a result, instead of seeing their caregivers as comforting and supportive, children with insecure-disorganized schemas often express fear of caregivers leading to considerable internal conflict.

Attachment theory has maintained such prominence in developmental psychology because each of these attachment schemas, which are reliably identifiable in children as 
young as 12 months of age (Ainsworth, 1979), are robust predictors of a constellation of personality characteristics and outcomes later in life (Bakermans-Kranenburg \& van IJzendoorn, 2009). While children with secure attachment schemas are likely to develop into adults with sound emotion regulation and impulse control abilities, children with insecure attachment schemas are likely to struggle with anxiety, depression, aggression, mental disorganization, and substance abuse in adulthood (Bakermans-Kranenburg \& van IJzendoorn, 2009; Bretherton \& Munholland, 2008). As such, attachment theory provides a comprehensive model for understanding the intergenerational transmission of risk as the dynamics that characterize the interactions of insecurely attached children and their caregivers are likely to be perpetuated when children with these maladaptive attachment schemas and resulting difficulties become parents themselves (Benoit \& Parker, 1994).

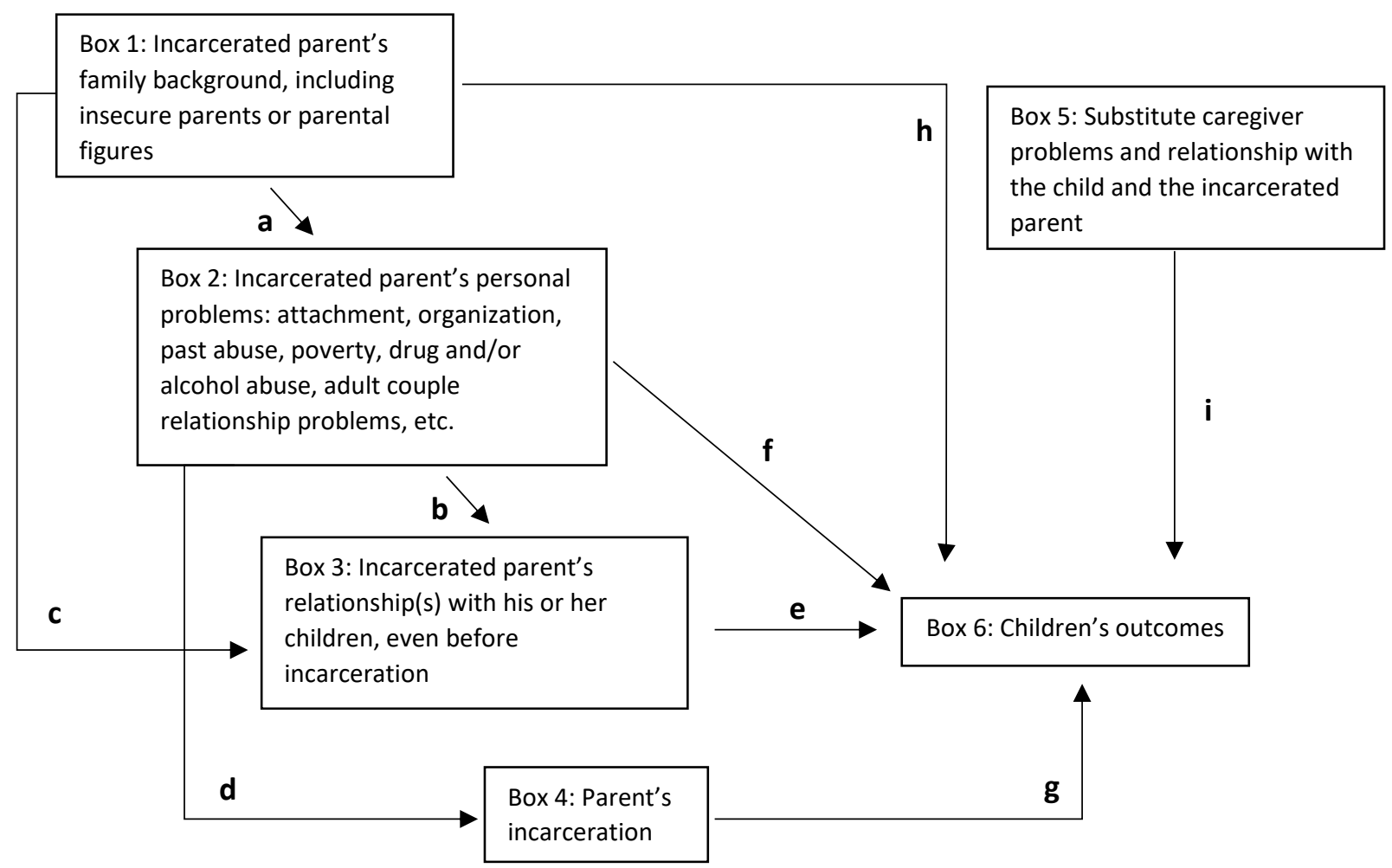

Figure 1. Makariev and Shaver's (2010) model of the multi-level attachment disruption experienced by children of incarcerated mothers. 
Attachment and maternal incarceration. In light of the findings outlined above, attachment theory provides a useful lens for understanding the complex processes involved in the transmission of adversity from incarcerated mothers to their children. In a special issue of Attachment and Human Development focusing on the challenges facing the children of incarcerated parents, Makariev and Shaver (2010) proposed a comprehensive model, illustrated in Figure 1, which details the numerous factors that threaten the attachment schemas of children of incarcerated parents and how they interact. They suggest that threats to the attachment schemas of these children are likely to occur across both time and setting leading to an accumulation of risk that predicts an insecure attachment system and thereby puts children at risk. Little research into the attachment schemas of children of incarcerated mothers is available to validate Makariev and Shaver's assertions; however, the research that has been done supports their theory. In her 2005 (b) study of young children (ages 2.5-7.5) with incarcerated mothers, Poehlmann found that $63 \%$ of the 54 children who participated expressed insecure attachment schemas related to both incarcerated mothers and caregivers in responses to attachment-related story stems.

Maternal history. Makariev and Shaver's (2010) model points to a complex interplay of risk factors acting on children of incarcerated mothers and illustrates how the influence of these factors on the familial attachment system predicts a domino effect of negative outcomes for incarcerated mothers and their offspring. These risks begin well before the child's birth with his or her grandparents. Box 1 in Figure 1 represents the family history of an incarcerated mother, including the attachment patterns and behaviors of her parents. Research on incarcerated mothers suggests that the family history 
represented by Box 1 is likely to be characterized by adversity. Incarcerated mothers are likely to have grown up in poor families headed by parents with significant problems including substance abuse and mental illness (Murray \& Murray, 2010). As such, many incarcerated women had maladaptive relationships with their parents as children-more than $50 \%$ of women incarcerated in the US report abuse by a parent (Arditti \& Few, 2006). Through these childhood circumstances, women are likely to develop insecure attachment schemas themselves and are at particular risk of developing insecuredisorganized schemas, which have been linked to early experiences of neglect and abuse as well as poverty (Lyons-Ruth \& Jacobvitz, 2008). As illustrated by Arrow “a,” given the well-documented connection between insecure attachment schemas and a host of difficulties in adulthood (Lyons-Ruth \& Jacobvitz, 2008), the potential attachment disruption resulting from these early adversities is a likely causal factor in the development of the various problems incarcerated mothers are known to experience (Box 2) including poverty, substance abuse, relationship instability, and mental illness (Glaze \& Maruschak, 2008; Mumola, 2000; Roxburgh \& Fitch, 2013).

The mother-child relationship. The pathway from Box 2 to Box 3 (Arrow " $\mathrm{b}$ ") represents the impact of these maternal problems on a mother's relationship with her own child. Maternal depression, substance abuse, criminal activity, and poverty are all associated with maladaptive parenting styles in which children's needs are met in problematic ways including with actual neglect and abuse (Connell \& Goodman, 2002; Greenfeld \& Snell, 1999; Zuckerman, 1994). Prior substance abuse and mental illness among incarcerated mothers are particularly serious risk factors for children as living with a substance-abusing parent increases a child's risk of being maltreated four-fold 
(Greenfeld \& Snell, 1999). Additionally, parents often derive their parenting skills from the way in which their parents interacted with them (Simons, Whitbeck, Conger, \& Wu, 1991). As such, given the neglect and abuse experienced by many incarcerated mothers during their childhoods (Chipman, Olsen, Klein, Hart, \& Patterson, 2000), many of these women may have limited parenting skills due to a lack of good role models.

While the evidence that incarcerated mothers are likely to experience adversities known to undermine appropriate parenting is plentiful, few studies have actually assessed the parenting of incarcerated mothers directly. In one of the few studies that has examined parenting among incarcerated parents, Kjellstrand and Eddy (2011) assessed the parenting styles of 21 mothers and 53 fathers who had been incarcerated at some time prior to their child's tenth birthday. They studied several aspects of parenting as reported by parents themselves: monitoring — a measure of supervision —involvement — a measure of parent-child interaction quantity — quality of the parent/child relationship — a measure of parent-child interaction quality_-praise - a measure of the amount of praise given to the child — inappropriate discipline — a measure of a parent's likelihood to use one of a host of overly punishing disciplinary techniques — and, inconsistent discipline — a measure of the consistency with which disciplinary action was applied. As compared to parents who had never been incarcerated, previously incarcerated parents reported significantly greater use of inappropriate and inconsistent discipline; no significant differences were found between the two groups on any of the other parenting measures. However, the lack of differences in other areas of parenting should be interpreted cautiously given the potential influence of social desirability effects on parents' self- 
reports. Furthermore, given that the majority of the incarcerated parents studied were men, the implications of this study for incarcerated mothers is unclear.

Per attachment theory and supporting research, these unhealthy interactions with mothers are likely to create insecure attachment schemas in children (Lyons-Ruth \& Jacobvitz, 2008), which are thought to undermine their ability to develop adaptive social and cognitive skills, (Bowlby, 1982) putting them at risk for many of the negative outcomes associated with maternal incarceration (Patterson, DeBaryshe, \& Ramsey, 1989). Arrow "e" represents this well-documented pathway between insecure attachment schemas and the negative child outcomes represented by Box 6 (Bakermans-Kranenburg \& van IJzendoorn, 2009; Bretherton \& Munholland, 2008). This theory elegantly demonstrates how a mother's incarceration often occurs within the context of a multitude of other negative influences already acting on children. According to research on accumulated risk, this likely amplifies the negative impact of the imprisonment itself, as children who have experienced multiple hardships are often armed with less resilience to overcome additional adversities (Gerard \& Beuhler, 2004).

Separation through incarceration. A mother's incarceration (Box 4) is likely to put children at risk through several mechanisms (Murray \& Murray, 2010), as represented by Arrow “g." Given their grounding in attachment theory, Markariev and Shaver (2010) focus on the additional disruption in a child's attachment schema that is likely to occur following a mother's incarceration. According to attachment theory, this disruption is caused most directly through the loss of contact with a mother imposed by her incarceration. From the beginning, attachment theory has stressed the importance of contact between children and their caregivers in the development of healthy attachments, 
while underscoring the negative repercussions of separation from caregivers (Bowlby, 1969). Given his theory that children develop a sense of security based on caregiver availability, Bowlby (1982) saw physical proximity to caregivers as fundamental to the creation of healthy attachment schemas. As such, ample research has demonstrated a relation between separation from caregivers and negative outcomes for children both during childhood and later in life (Bowlby, 1953; Dozier, 2005). The impact of separation is particularly salient to children of incarcerated mothers, as compared to children of incarcerated fathers, as the majority of incarcerated mothers report that they were living with their children (Block \& Potthast, 1998) and were their primary caretaker prior to incarceration (Glaze \& Maruschak, 2008). While mothers do often have contact with their children while in prison, the vast majority of this contact is through letters and phone calls (Loper et al., 2009), which provide little amelioration to the trauma of forced physical separation. In-person visitation is available to inmates, but nearly half of all incarcerated mothers report that they have never received a visit from a child (Glaze \& Maruschak, 2008), and those that do report receiving visits infrequently (Loper et al., 2009). Moreover, even when children do visit incarcerated parents, some evidence suggests that a lack of child-friendly visitation contexts limits the positive impact of this contact on children's wellbeing (Poehlmann, 2005a; Schlafer \& Poehlmann, 2010).

Caregivers as new attachment figures. Box 5 illustrates a second avenue through which a mother's incarceration may impact children's attachment schema. Following a mother's incarceration, the majority of children must adjust to a new primary caregiver (Glaze \& Maruschak, 2008). The child's relationship with this caregiver provides a new attachment context that can serve as a boon or a blow to the child's attachment schema 
and related wellbeing. Accordingly, Mackintosh, Myers, and Kennon (2006) found that children who reported experiencing greater warmth and acceptance from caregivers following their mother's incarceration also reported fewer psychological and behavioral problems.

Unfortunately, research indicates that this experience might be the exception rather than the rule for children of incarcerated mothers given findings that the majority of these children exhibit insecure attachment relationships with caregivers (Poehlmann, 2005b). This may result from strained relationships between caregivers and children of incarcerated mothers due to the stress that is likely to fall on caregivers who suddenly, and often unexpectedly, take over these children's care. According to a 2004 survey, $51.9 \%$ of all incarcerated mothers and $88.6 \%$ of mothers who lived with their children prior to incarceration were the sole financial provider for their children before leaving for prison (Glaze \& Maruschak, 2008). As a result, caregivers who take over for incarcerated mothers are often asked to shoulder sole financial responsibility for children (Geller, Garfinkel, \& Western, 2011). Furthermore, grandparents, who are most often tasked with caring for children during a mother's incarceration (Glaze \& Maruschak, 2008), may be older and have more difficulty keeping up with and responding patiently to children. And, evidence suggests that many of the grandparents caring for the children of incarcerated mothers have conflicted relationships with these mothers (who are most often their daughters), and may resent having to assume their parenting responsibilities (Bachman \& Chase-Lansdale, 2005). Given these circumstances, caregivers may experience considerable stress related to caring for children of incarcerated mothers, which is known to undermine their ability to provide children with appropriate 
supervision and support (Crnic \& Low, 2002; Deater-Deckard, 2005). Moreover, the stress experienced by caregivers may be exacerbated by the transactional influence of the behavioral and emotional difficulties children of incarcerated mothers might bring with them into the new situation.

The soundness of Makariev and Shaver's (2010) theory, and the research supporting it, suggests that improving the attachment schemas of children of incarcerated mothers is a worthy intervention target. However, as the model illustrates, this task is not simple and therefore requires a multi-pronged approach. The model suggests that an effective intervention would target three primary mechanisms: problematic parenting by incarcerated mothers, disrupted contact between incarcerated mothers and their children, and children's relationships with substitute caregivers who may struggle to provide high quality care. In the next section, I will provide a more in-depth discussion of these potential intervention targets to illuminate the most promising pathways to change.

\section{Intervention Targets}

Improving parent-child interactions. As detailed above, there is ample indirect evidence, and some direct evidence, suggesting that incarcerated mothers are likely to parent in problematic ways. As such, the need for parent training in this population is convincing. In response to this need, a majority of prison systems offer parenting classes to inmates (Eddy, Kjellstrand, Martinez, \& Newton, 2010). However, reviews of such programs have revealed that programs are often developed in-house by a parenting instructor and have little backing in the scientific literature (Eddy et al., 2008). As such, curricula vary widely in content (e.g., empirically supported parent training programs vs. informal discussion and support groups), frequency of meetings (e.g., once weekly for ten 
weeks vs. a one-week intensive course), instructor qualifications (e.g., trained psychologists vs. volunteers from religious groups), and targeted populations (e.g., mothers vs. fathers, inmates approaching release vs. those with extended sentences; Loper \& Novero, 2010). Despite these differences, a 2010 review by Loper and Novero found that most interventions targeted similar outcomes: increasing knowledge and attitudes about childrearing, improving emotional well-being, reducing parenting stress, and changing parenting behaviors (e.g., increased contact with children). Improving knowledge and parenting attitudes was the most common outcome measured by studies of in-prison parenting programs. Of the 13 studies reviewed that included incarcerated mothers, eight reported pre-test, post-test improvements in parents' understanding of child development and appropriate parenting as reflected by one or more of the following outcomes: more appropriate expectations of child behavior, better understanding of effective behavior management techniques including decreased endorsement of corporal punishment, and improved understanding of appropriate parent/child roles (i.e., reduced likelihood of inappropriate role reversal). Three of these studies documented improved feelings towards parenthood as measured by increased parenting confidence, improved self-esteem related to being a parent, and/or decreased parenting stress. Actual changes in parenting behaviors were only measured by two of these programs (Kennon, 2003; Loper \& Tuerk, 2010) and changes were only observed in one of these studies (Loper \& Tuerk, 2010), which found an increase in phone and mail contact between mothers and their children after the completion of a parenting course designed specifically to address the needs of incarcerated mothers (i.e., improving communication during incarceration was a main focus of the program). 
These findings suggest that parent training is likely to be an effective means of increasing incarcerated mothers' knowledge of child development and effective parenting; however, the mechanisms of change responsible for these outcomes remain largely unknown given the considerable variation in training and lack of studies identifying proximal outcomes. Loper and Novero (2010) noted that a few standardized programs did exist and had been widely disseminated to prisons at the time of publication (e.g., the Prison Parents' Education Project developed and disseminated by the Center for Children and Incarcerated Parents), but none had been formally evaluated.

In response to the lack of empirically-validated parent training programs in U.S. prisons, Eddy and his colleagues (2008) developed an evidence- and theory-based program in conjunction with the Oregon Department of Corrections, which they called Parenting Inside Out (PIO). During the design phase of the intervention, the authors surveyed incarcerated parents regarding their wishes for a parent training program and found that inmates expressed the most interest in learning parenting skills specific to the prison situation (e.g., how to write an effective letter and how to interact with children's caregivers). PIO consists of group classes that meet for two and a half hours three times per week for 12 weeks. Course content includes instruction in child development, positive parenting techniques, and child health and safety in addition to prison-specific content including how to communicate with children's caregivers, decision-making around romantic relationships upon release, and communicating with children through letters, phone calls and prison visits. Content is conveyed through a combination of presentations, video clips, group projects, extensive role plays, group discussion, and skill building exercises. In addition, participants meet individually with instructors mid- 
program to discuss unique circumstances. During the course, participants are encouraged to discuss program material with children's caregivers and caregivers are provided with course materials if requested.

In a randomized-control trial of this program, Eddy and his colleagues (2013) documented post-intervention improvements in parenting stress, parent depressed mood, and positive parent-child interactions as reported by inmates. Moreover, their evaluation suggested that the inclusion of a discussion-based support group for parents was necessary as without this outlet, many instructors struggled to balance covering course material with providing parents an opportunity to discuss their particular situations and receive support from the group.

Contact. In order for newly improved parenting skills to impact children, incarcerated mothers and their children must have opportunities for interaction. Contact between incarcerated parents and their children occurs through three primary means: letters, phone calls, and in-person visits (Loper et al., 2009). Increased contact between incarcerated parents and their children has been associated with benefits for children (Trice \& Brewster, 2004) and incarcerated mothers (Loper et al,. 2009; Poehlmann et al., 2010) alike. Evidence suggests that children who have more frequent contact with their incarcerated parents via phone calls, letters, and in-person visits exhibit lower rates of school drop-out and suspension (Dallaire et al., 2010; Trice \& Brewster, 2004). Incarcerated mothers who have more frequent contact with their children through letters and phone calls report less stress related to parenting competence (Loper et al., 2009), which has larger implications as parenting stress has been linked to an increase in depression, anxiety, and disciplinary issues among incarcerated women (Houck \& Loper, 
2002; Loper et al., 2009). In addition, incarcerated mothers who speak to their children on the phone more frequently report improved relationships with them (Poehlmann, 2005a). While phone calls and letters are the most common forms of contact between incarcerated parents and their children, those interested in influencing attachment systems in these families have set their sights on facilitating and improving visitation experiences (Poehlmann et al., 2010), given the potential for in-person contact to provide the most proximal form of the parent-child interactions that foster healthy attachment (Bowlby, 1982).

While studies investigating the impact of contact generally (i.e., without distinguishing between calls, letters, and visits) have demonstrated clear benefits for incarcerated parents and their children, the role that in-person visits play in this is unclear. In contrast to findings specifically highlighting the benefits of written and phone contact between incarcerated women and their children, findings on the impact of inperson visits are more mixed. Research on the relation between visits with children and the wellbeing of incarcerated parents clearly indicates that visiting with children is beneficial to parents during their incarceration. Incarcerated mothers who receive more in-person visits from children report significantly fewer depressive symptoms and less distress (Poehlmann, 2005a), and anecdotal reports from incarcerated mothers and staff working with them indicate that visits with children are highly coveted by inmates and often described as highlights of their sentences (Casey-Acevedo \& Bakken, 2002). Moreover, incarcerated parents who receive more visits from children report greater levels of attachment to children after release (La Vigne, Naser, Brooks, \& Castro, 2005). This increased attachment has the potential to decrease incarcerated parents' risk of 
recidivating given research showing that prisoners who feel connected to family upon release are more likely to stay out of prison (Bales \& Mears, 2008; Hlavka et al., 2015).

In contrast, findings on the implications of visits for children are less clearly positive. Evidence suggests that children who do not visit their incarcerated parents feel more alienated from them than those who do attend in-person visits (Shlafer \& Poehlmann, 2010); however, researchers have documented associations between visits with incarcerated parents and negative child outcomes. Dallaire, Ciccone, and Wilson (2010) found an increase in children's behavioral problems in school following visits with incarcerated parents. Moreover, in a later study by these same authors (Dallaire, Ciccone, \& Wilson, 2012) found that more frequent visitation with jailed parents was associated with more "role reversal" themes in children's family drawings. Furthermore, Dallaire, Zeman, and Thrash (2015) extended this research by studying the impact of visitation on children of jailed mothers specifically and found that more frequent visits with jailed mothers was associated with increased internalizing problems in children. They found no association between visit frequency and externalizing problems.

Taken together, these findings question the utility of interventions targeting inperson contact experiences between children and their incarcerated mothers; however, given that the majority of research in this area has examined visitation with incarcerated parents generally without distinguishing between mothers and fathers, the meaning of these findings for visitation between children and their incarcerated mothers is unclear. And, given that children are more likely to have been living with mothers prior to their incarceration and that mothers are more likely to have been children's primary caretaker (Glaze \& Maruschak, 2008), there is reason to suspect that visitation with incarcerated 
mothers may have a distinct impact on children as compared to visitation with incarcerated fathers.

Moreover, experts in the field (see Poehlmann et al., 2010) contend that it is not the act of visitation with incarcerated parents itself that leads to negative outcomes, but rather the context within which the visit occurs. Visitation policies vary widely among US state and federal prisons: while some prisons allow inmate parents to touch children and move around, allowing for physical comfort as well as age-appropriate play, others prohibit any movement or touch, and may even require inmates to meet families through plexiglass (Boudin, Stutz, \& Littman, 2012; Shlafer et al., 2015). These conditions make child-friendly, attachment-enhancing interactions difficult. Moreover, conditions that feel dangerous may actually damage the attachment system; children's concerns for parents' safety may be exacerbated rather than assuaged, and the physical distance imposed by some visitation restrictions may prevent inmate parents from providing comfort and reassurance in the face of these fears.

Anecdotal reports from incarcerated parents and their children's caregivers suggest that they are aware of these potential problems and worry that children will be upset by visitation conditions (e.g., separation by plexiglass) and regulations (e.g., required body searches; Arditti, 2003). And, interviews with children visiting incarcerated parents suggest that the fears expressed by parents and caregivers are wellfounded: Nesmith and Ruhland (2008) interviewed 34 children with incarcerated parents and found that fear was a common theme among their descriptions of visiting prison. For instance, one boy noted: "It wasn't safe there because there were a lot of people that just looked like, just looked real bad and this and that. There was a lot of arguing with other 
people" (p.1126). In addition, the duration of visits varies widely between institutions and may even vary within the institution depending on the number of visitors on any given day. As such, children may have limited, and sometimes unpredictable, time in which to interact with parents and work through emotional responses while in their presence. Interviews with jailed mothers confirm that a majority felt that visits were too short to connect with children emotionally (Arditti \& Few, 2006).

In light of these findings, Poehlmann et al. (2010) argue that while children visiting incarcerated parents under frightening conditions may react negatively to the experience, children may benefit from visiting incarcerated parents when conditions are child-friendly and allow them to see that parents are safe. In support of this theory, Poehlmann et al. (2010) note that of the seven studies in their review investigating the link between in-person visits with incarcerated parents and child outcomes, the two that included enhanced, more child-friendly visitation documented benefits to children including improved self-esteem (Landreth \& Lobaugh, 1998) and emotional well-being as well as reduced behavior problems (Block \& Potthast; 1998); however, statistical comparison to a control group was not possible in either study. These findings, and the known benefit of visitation for incarcerated parents, speak to the importance of interventions aimed at improving the quality of visits between incarcerated mothers and their children. Improving the quality of visits may have the added benefit of increasing the frequency with which incarcerated mothers see their children. Surveys of inmates' families suggest that many families visit infrequently due to the time and expense of traveling to facilities that are often quite far from family homes (Christian, Mellow, \& Thomas, 2006). It may be especially difficult for families to justify spending this time 
and money to visit incarcerated family members when visits are unpredictable and/or short in duration, and interactions with inmates are unsatisfying or even frightening. Furthermore, if children enjoy visits with incarcerated parents more and exhibit fewer behavioral issues in their wake, caregivers are likely to have fewer concerns about the negative effects of visitation on children (Arditti, 2003), and may be more likely to bring them to visits.

Facilitating healthy attachment with caregivers. Given the influence of children's new caregiving contexts on their attachment schemas, finding ways to improve relationships between children and their new caregivers is an essential piece of the puzzle. While providing training directly to caregivers to influence their parenting would be the most direct, and perhaps most effective, means of intervention in this area, the feasibility of this is limited. As such, I will focus on a potential avenue through which incarcerated mothers may be able to help foster healthy relationships between children and their caregivers: strengthening of the parenting alliance. The importance of helping mothers maintain or develop positive relationships with their children's caregivers stems from a considerable body of research connecting child wellbeing to the quality of the relationship between co-caregivers (Adamsons \& Pasley, 2006; Gasper, Stolberg, Macie \& Williams, 2008). Weissman and Cohen (1985) introduced the idea of "parenting alliance" to capture the elements of the co-caregiver relationship that are most important to healthy child development. They described caregivers with a high degree of alliance as those who were mutually invested in children, valued each other's involvement with children and judgments related to them, and communicated with each other about childrearing in healthy ways. 
Research on the relationship between incarcerated mothers and their children's caregivers is limited, but the little evidence that is available suggests that children of incarcerated mothers experience a similar benefit from a stronger alliance between their caregivers and their mothers as do children in the general population (Loper, Phillips, Nichols, \& Dallaire, 2012). A study by Poehlmann, Schlafer, Maes, and Hanneman (2008), sheds some light on the particular importance of caregiver alliance for children of incarcerated mothers. Their findings suggest that a stronger alliance between children's caregivers and their incarcerated mothers is associated with greater stability of children's living arrangements during their mother's imprisonment, the benefit of which was established by Poehlmann's 2005(b) study demonstrating that children who stayed with one caregiver during their mother's incarceration were more likely to have secure attachment schemas. Moreover, a stronger parenting alliance between incarcerated mothers and caregivers is associated with more mail and phone contact between mothers and their children during the incarceration period (Loper et al., 2009; Poehlmann et al., 2008). And, incarcerated mothers who report a stronger parenting alliance with their children's caregivers report fewer symptoms of depression (Loper et al., 2009).

However, these benefits may elude many children as incarcerated mothers and their children's caregivers face significant obstacles to building and/or maintaining a healthy parenting alliance. Successful co-parenting requires constant, productive communication; however, communication between incarcerated mothers and caregivers is limited by a third party and often not conducive to co-parenting discussions. Frequency of visits is often limited by long distances and associated travel costs, and the structure of visitation rarely provides opportunities for incarcerated mothers and caregivers to speak 
independently of children (Arditti \& Few, 2008); phone calls are often limited by costs that far outpace typical call rates (Greene, 2013); and letters, while less limited in frequency, require necessary delays in information such that life events discussed in one letter (e.g. a teenager's prom) can be old news to the family by the time the inmate responds. Furthermore, strong co-parenting alliances are strengthened by a sense of shared responsibility (Weissman \& Cohen, 1985), which is far from the lived reality of incarcerated mothers and caregivers given obvious discrepancies in actual parenting duties.

Equally important to the strength of the parenting alliance is caregivers' understanding of the challenges faced by their parenting ally (Johnson \& Greenberg, 1985). For incarcerated mothers, it may be particularly difficult to understand the parenting challenges facing caregivers given their absence from children's lives. Moreover, caregivers of children of incarcerated mothers are often faced with helping children understand and overcome their mother's absence, which is a particularly difficult task that most incarcerated mothers have not themselves had to manage. Accordingly, research comparing perceptions of incarcerated mothers and their children's caregivers suggests that incarcerated mothers often have skewed views that minimize challenges facing children and their caregivers at home (Loper et al., 2009). Lastly, given the personal problems often faced by incarcerated mothers and their families, the relationship between caregivers and incarcerated mothers may be damaged long before the incarceration, if not by the incarceration itself. 


\section{Multi-systemic Interventions}

Targeting the three key influences on children's attachment schemas outlined above - the quantity and quality of contact with incarcerated mothers, the nature of interactions between incarcerated mothers and their children, and the parenting alliance between incarcerated mothers and children's caregivers-requires a multifaceted approach. Some corrections systems have attempted to address these needs with programs that combine parent training and support with specialized, extended visits between incarcerated mothers and their children. These programs aim to facilitate attachment-strengthening, parent-child interactions as well as opportunities for communication between incarcerated parents and caregivers.

Theory of change models offer a comprehensive yet efficient means of understanding how interventions are hypothesized to lead to desired outcomes. These models provide theoretically-based depictions of potential mechanisms of change and the way in which they interact to produce intervention outcomes. A theory of change model is well-suited to an intervention of this kind given the interactive and transactional nature of the hypothesized mechanisms of change. The following theory of change model details the specific, multi-faceted, mechanisms through which programs of this nature are thought to benefit incarcerated mothers and their families.

Theory of change model. Using Makariev and Shaver's (2010) model of the multilevel threats to the attachment schemas of children of incarcerated mothers, the model provided in Figure 2 illustrates how a parent training and specialty visitation program is well suited to intervene at each level of possible dysfunction. Moreover, the model demonstrates the transactional nature of the changes predicted to stem from a 
program of this nature by highlighting multiple pathways through which change is likely to occur. The primary mechanism of change in an intervention of this type, represented by Pathway A in Figure 2, is the improvement of the mother-child relationship through healthier and more frequent dyadic interactions, which are the backbone of a secure attachment dynamic. The intervention aims to improve mother-child interactions by teaching incarcerated mothers what to expect of children and how to parent in consistent and appropriate ways and then providing opportunity to practice newly learned skills during extended and more child-friendly visits. Moreover, more child-friendly visits in which children can see that parents are safe and in which parents are able to provide physical comfort to children have the potential to improve children's attachment schemas by fostering a greater sense of security in their parents' well-being and presence in their lives. The bi-directional arrow linking more frequent visits to visits of better quality represents the potential recursive influence of visit quality on visit frequency. It is likely that children and caregivers will be more inclined to visit when interactions with incarcerated mothers are more pleasant and satisfying. And, the comfort level of incarcerated mothers and their children during visits, and thus the visit quality, is likely to improve as they have these in-person contact experiences more frequently. Additionally, as Pathway A illustrates, parent training and specialty visitation also have the potential to facilitate improved interactions between incarcerated mothers and children's caregivers. This may occur as a result of more relaxed and extended visits that provide greater opportunity for positive interactions between incarcerated mothers and caregivers. In addition, incarcerated mothers may develop increased understanding of caregivers' challenges by spending more time with children and through explicit instruction and 
discussion with other incarcerated mothers. These interactions are likely to improve the parenting alliance between incarcerated mothers and caregivers, which has the potential to facilitate secure attachment representations of caregivers in children given its association with more stable caregiving and living situations. Pathway B represents a potential secondary, transactional pathway through which the intervention improves maternal wellbeing, which in turn has an additional positive influence on mother-child

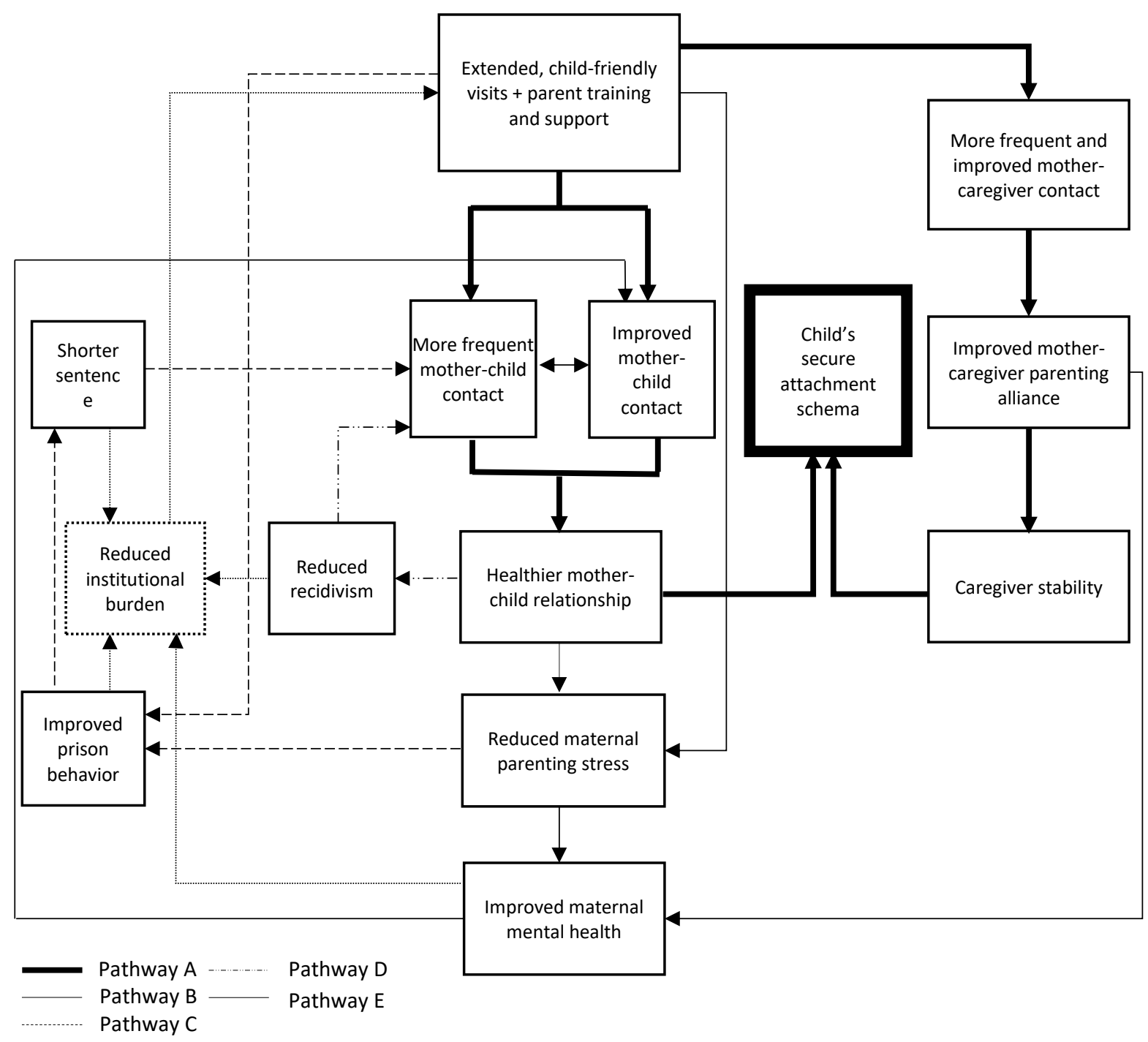

Figure 2. Model of hypothesized treatment effects of a multi-systemic intervention for incarcerated mothers and their families combining parent training and support for mothers with extended, child-friendly visits. Primary and non-primary pathways are represented by distinct line types as described in the legend. 
interactions and the ensuing benefits outlined in Pathway A. As discussed previously in this chapter, research has linked increased contact with children, improved relationships with children, and stronger parenting alliance with children's caregivers to reduced parenting stress in incarcerated women. In turn, this reduced parenting stress has been linked to more appropriate parenting as well as improved maternal mental health (Loper et al., 2009), and is therefore likely to improve mother-child interactions. As such, the impact of the intervention on mothers' parenting stress represents a recursive pathway through which some improvement in mothers' relationships with their children may lead to even more relationship improvement via the impact it has on maternal wellbeing.

Pathway $\mathrm{C}$ represents an additional, and more indirect, pathway through which an intervention of this nature may facilitate improvements in the mother-child relationship. In most institutions, participation in such a program is a privilege that inmates earn through good behavior, which they must continue in order to maintain their status within the program. As such, an intervention of this type has the potential to improve the inprison behavior of incarcerated mothers. Furthermore, reduced parenting stress among inmates has been linked to fewer in-prison rule violations. Given the use of "good time" - a program that rewards good behavior with sentence reductions - in many correctional systems, as well as the potential for rule violations to lead to additional charges and time in prison, improvements in inmate behavior have the potential to lead to more rapid family reunification. As such, this pathway represents a potential pathway to increased contact between incarcerated mothers and their children through earlier release.

Similarly, Pathway D represents another potential avenue through which an intervention of this kind may lead to increased contact between children and incarcerated 
mothers outside of prison. Given research showing that strong familial relationships are powerful protective factors against recidivating (Bales \& Mears, 2008; Hlavka et al., 2015), incarcerated mothers who feel more connected to their children upon release are more likely to stay out of prison, leading to another form of increased contact and the associated mother and child benefits illustrated by pathways A through C.

Lastly, Pathway E represents the potential for an intervention of this nature to have institutional benefits. The potentially improved in-prison behavior and mental health of mothers participating in such a program represent institutional cost-savings related to reduced staffing requirements and inmate medical needs. Moreover, shorter sentences and reduced recidivism open up beds in facilities that are notoriously overcrowded (Pitts et al., 2013). While these institutional benefits may not have a direct impact on children, they may indirectly lead to improved child outcomes if facilities are more likely to start and/or continue these programs because they experience economic benefits (as represented by the large arrow linking "reduced institutional burden" to the key intervention components).

Existing programs. As the theory of change model outlined above demonstrates, these programs hold promise in their potential to address the multi-pronged threats to children's attachment schemas during a mother's incarceration; however as is the case with many prison-based interventions, little is known about their efficacy. Nevertheless, the little work that has been done in this area suggests that incarcerated mothers find these programs helpful in rebuilding relationships with their children. Snyder, Carlo, and Mullins (2001) conducted qualitative interviews with 31 incarcerated mothers participating in a "mother-child visitation program" (MCVP) in a Mid-Western women's 
prison and compared their responses to those of 27 waitlist controls. This particular program was sponsored by community donations and run by community volunteers. Before entering MCVP, mothers were required to complete a parenting course, the contents of which were not disclosed. Mothers then had monthly visits in a large room that had been converted into a child-friendly play area (e.g., pictures of Barney on the walls and child-sized furniture). Visits included a combination of organized activities (e.g., crafts) and time for children and parents to interact freely. The length of visits was not provided. Volunteers from local churches and businesses assisted children in attending visits by providing free transportation. The authors' analyses of these interviews suggest that participation in the MCVP program was associated with reports of improved relationships with children, improved child coping related to the incarceration, and increased phone and mail contact with children.

Additionally, in a 2008 study, Sandifer provided a quantitative evaluation of another combination program in a southern correctional institution for women. This program combined the Rebonding and Rebuilding parenting curriculum (Meyer \& Moriarty, 1995), which met for three hours, two times per week for twelve weeks, with extended visits with a similar breakdown of structured activities and free time as that documented by Snyder et al. (2001). The frequency of visits was not provided. Using a pretest-postest non-equivalent comparison group, quasi-experimental design, Sandifer (2008) found that incarcerated mothers who participated in the program were better able to identify age-appropriate child behavior and reported being more accepting of it. They were also less likely to endorse corporal punishment as an effective means of discipline, and were more likely to report that they would assume an adult role in crises indicating a 
reduction in parenting attitudes reflecting role reversal. No differences were found in parenting confidence, self-esteem, or parent-child communication skills. Moreover, no information was gathered on mothers' perceptions of the program's influence on children. Furthermore, the significant changes they did observe must be interpreted with caution. In her discussion, Sandifer noted an "interruption of two interactive components of the parenting program resulting in a lack of availability of face-to-face parent-child interaction opportunities." It is unclear whether or not any specialized visitation occurred, or if they were curtailed in frequency towards the end of the study. Given this lack of clarity, it is unclear if these results are best interpreted as findings on the efficacy of a parent training program alone.

Given the promise held by these programs as a result of the many transactional mechanisms of change they are predicted to facilitate, and the considerable lack of evidence on their efficacy, additional studies are needed to a) investigate the soundness of the theory of change model used to promote such programs and b) provide more thorough program descriptions to allow for a more careful study of program efficacy, as well as potential replication. In an effort to address this scientific need, this study aims to achieve these goals through an evaluation of the Mothers Inside Loving Kids (MILK) program in two Virginia correctional institutions for women.

\section{The Present Study}

Mothers Inside Loving Kids (MILK). The Mothers Inside Loving Kids (MILK) program has been ongoing in two Virginia correctional centers for women since the early 1980s. The program was started in 1981 by three inmates and the chaplain at the Virginia Correctional Center for Women (VCCW) under the sponsorship of Parents Anonymous 
of Virginia, an external non-profit group, which is no longer involved in the program. The program is currently running at VCCW as well as at the Fluvanna Correctional Center for Women (FCCW) and it is fully funded by the institutions themselves. Given its longevity, the program has experienced many revisions over the years; however, it has consistently included an initial phase in which mothers who qualify based on good behavior and type of offense (i.e., no child-related offenses) participate in a parenting course, and a second phase in which mothers meet with each other regularly and participate in extended, child-centric visits with their children and their children's caregivers four to six times per year. While these fundamental components remain the same, the program has changed some since its inception and varies in structure between the two institutions.

Parent training. Initially, all mothers participating in MILK were taught the same nine-week, eighteen-hour, parenting curriculum. Per a 1998 evaluation of this training program (Moore \& Clement, 1998), the training spent ten hours on parenting and eight hours on child development. The parenting component focused on discipline, which was taught using Systemic Training for Effective Discipline (STED) techniques, and effective communication. Moore and Clement (1998) compared pre- and post-training parenting beliefs and self-esteem of 20 women participating in the program to 20 wait-list controls and found that women in the training group showed significantly greater growth in their understanding of behavioral management techniques, but not in their overall parenting knowledge as measured by the Adult-Adolescent Parenting Inventory (AAPI; Bavolek, 1990), or in their self-esteem. 
Currently, women in the MILK program are eligible for the support group and visits if they can prove completion of any parent training course sponsored by a correctional institution. As such, the parent training is no longer considered part of MILK, but rather a pre-requisite for entry into the program. The result is that women in MILK have completed different courses with different emphases. The most popular course focuses primarily on the legal ramifications of incarceration on mothers and their children and is taught by a former inmate. However, some women have participated in a class focusing more specifically on communicating with children from prison and understanding children's needs, and still others have completed courses at other institutions with content that is not well-known.

Support group. MILK participants in both institutions meet regularly with each other and an institutional sponsor. These meetings are meant to provide mothers with an opportunity to discuss challenges they are facing related to parenting from prison and receive support from others experiencing similar difficulties. In addition, the meetings are used to plan for upcoming visits and debrief after visits. Meetings may also include additional parenting instruction. Currently, group meetings at FCCW occur weekly and include a greater degree of emotional processing related to issues with children. Group meetings at VCCW occur bi-weekly and are more focused on logistics of upcoming visits.

Specialty visits. MILK participants and their children have regular, extended visits outside of the standard visitation room that occur four times per year at FCCW and six times per year at VCCW. The duration of visits varies between the two institutions. Visits at VCCW are seven hours in length, while visits at FCCW last for three hours. These 
visits include a combination of structured activities, such as arts and crafts, sports, and carnival games, which are designed and run by the inmates, and unstructured time for visiting. During each visit, mothers are able to share a meal with their children and their children's caregivers. The program was initially designed to facilitate "community visits" in which families were encouraged to interact with each other. Currently, this approach continues at FCCW; however, due to changes in regulations at VCCW, mothers are now discouraged from interacting with children other than their own, and mothers whose children are not visiting that day are not permitted to interact with other families at all.

Research objectives. The present study aims to add to the general understanding of combined parent training, parent support, and specialty visit interventions through an evaluation of the MILK program. Using both qualitative and quantitative methods, this investigation aims to achieve the following two goals: (1) to evaluate the efficacy of the MILK program as perceived by staff and inmate participants; and (2) to better understand the mechanisms of change that facilitate any perceived benefits. Research questions were developed using the hypothesized theory of change model as a guide and are presented accordingly below. Given the dearth of prior research in this area, all hypotheses are exploratory.

Proposed mechanism of change 1: Parent training and support in conjunction with specialty visits leads to healthier mother-child relationships via improved visit quality and increased visit frequency (see Figure 3).

Research Question 1a: Do mothers in the MILK program perceive improvement in relationships with their children as a result of MILK? If so, what is the nature of the improvement and to what do they attribute the change? 
Research Question 1b: Do mothers in the MILK program perceive improvement in the quality of in-person contact with their children as a result of MILK? If so, what is the nature of the improvement and to what do they attribute the change?

Research Question 1c: Do mothers in the MILK program perceive an increase in the frequency of visits from their children as a result of MILK? If so, to what do they attribute this increase?

\section{Proposed mechanism of change 2: Parent training and support in conjunction} with specialty visits leads to improved mother-caregiver alliance via improved quality and increased frequency of mother-caregiver in-person contact (see Figure 4).

Research Question 2a: Do mothers in the MILK program perceive improvement in parenting alliance with their children's caregivers as a result of MILK? If so, what is the nature of the improvement and to what do they attribute it?

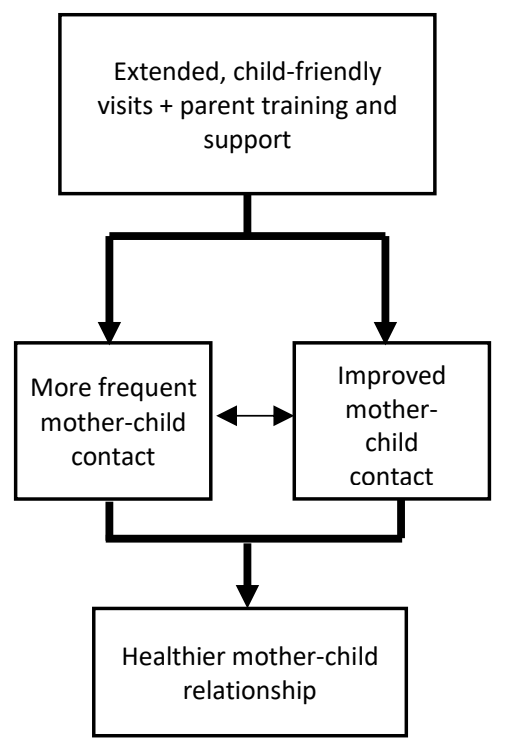

Figure 3. Hypothesized mechanism of change 1: The MILK program leads to healthier mother-child relationships via mother-child in-person contact of increased frequency and improved. 


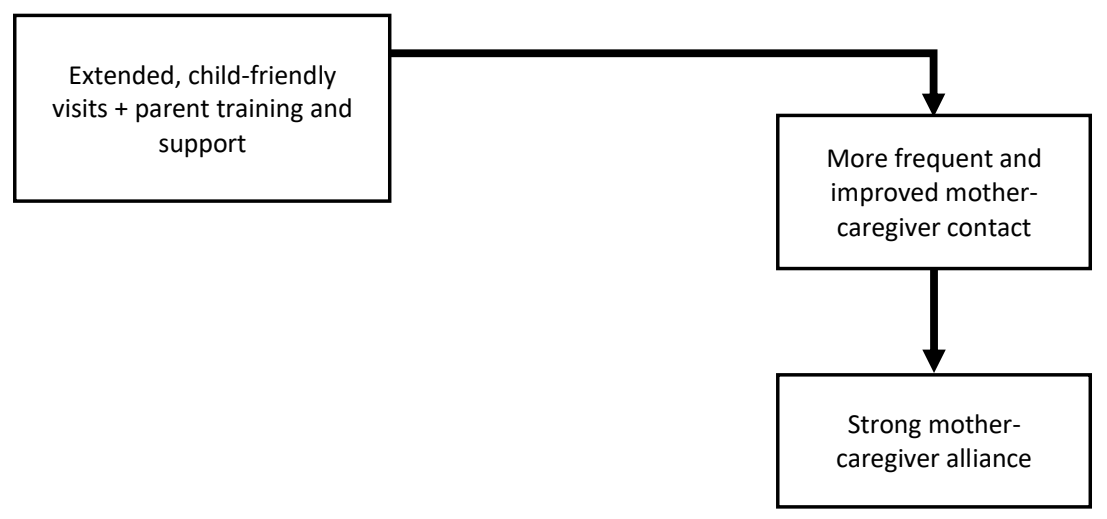

Figure 4. Hypothesized mechanism of change 2: The MILK program leads to improved mother-caregiver alliance via mother-caregiver in-person contact of increased frequency and improved quality.

Research Question 2b: Do mothers in the MILK program perceive improvement in the quality of in-person contact with their children's caregivers as a result of MILK? If so, what is the nature of this improvement and to what do they attribute the change?

Research Question 2c: Do mothers in the MILK program perceive an increase in the frequency of visits from their children's caregivers as a result of MILK? If so, to what do they attribute this increase?

\section{Proposed mechanism of change 3: Parent training and support in conjunction} with specialty visits leads to reductions in maternal parenting stress (see Figure 5).

Research Question 3: Do mothers in the MILK program perceive a reduction in parenting stress as a result of MILK? If so, to what do they attribute this improvement? 


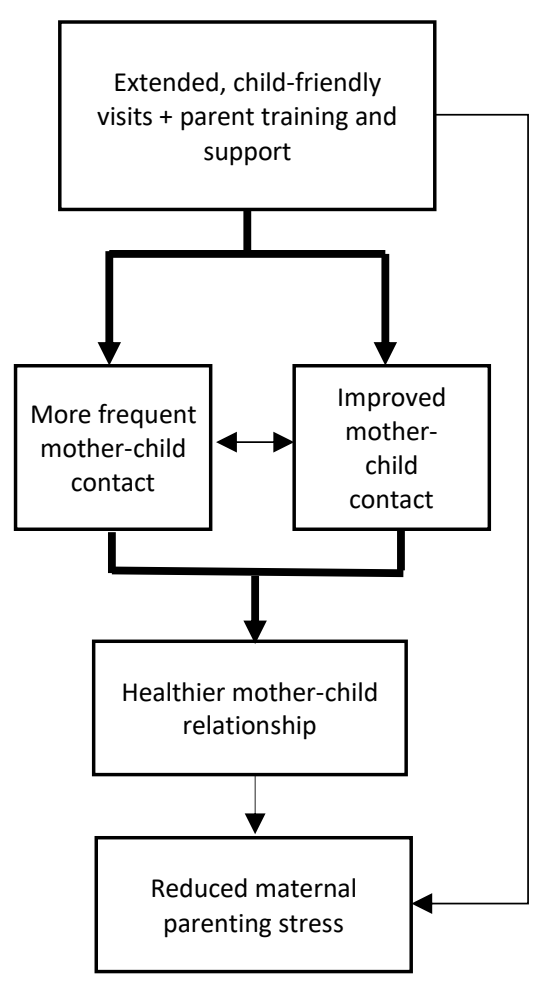

Figure 5. Hypothesized mechanism of change 3: The MILK program leads to reduced maternal parenting stress via increased perceived parenting competence, increased parenting support, and a healthier mother-child relationship.

Proposed mechanism of change 4: The MILK program leads to improved inprison behavior by incentivizing good behavior and through reductions in parenting stress (see Figure 6).

Research Question 4: Do mothers in the MILK program report improved in-prison behavior as a result of MILK? If so, to what do they attribute this change?

Proposed mechanism of change 5: The MILK program leads to institutional benefits via improved inmate behavior, improved inmate mental health, shorter sentences and reduced recidivism (see Figure 7). 
Research Question 5a: Do institutional representatives view MILK as a beneficial program for the institution?

Research Question 5b: Do institutional representatives perceive improvements in inmate behavior as a result of MILK? If so, what are the nature of these improvements and to what do they attribute them?

Research Question 5c: Do institutional representatives perceive improvement in inmates' well-being as a result of MILK? If so, what are the nature of these improvements and to what do they attribute them?

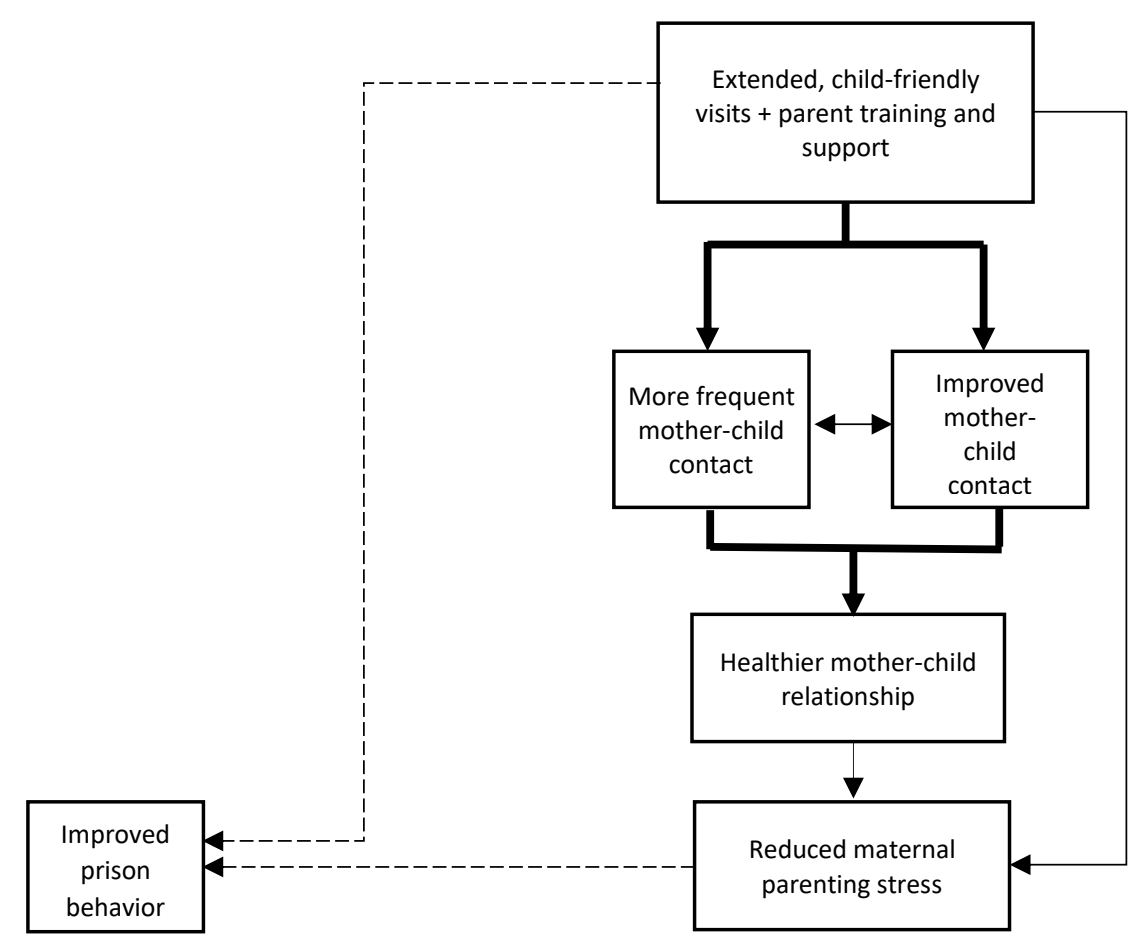

Figure 6. Hypothesized mechanism of change 4: The MILK program leads to improved inprison behavior via program incentives and reduced maternal parenting stress. 
Research Question 5d: Do institutional representatives perceive reductions in inmate sentence length as a result of MILK?

Research Question 5e: Do institutional representatives perceive reductions in recidivism among MILK participants?

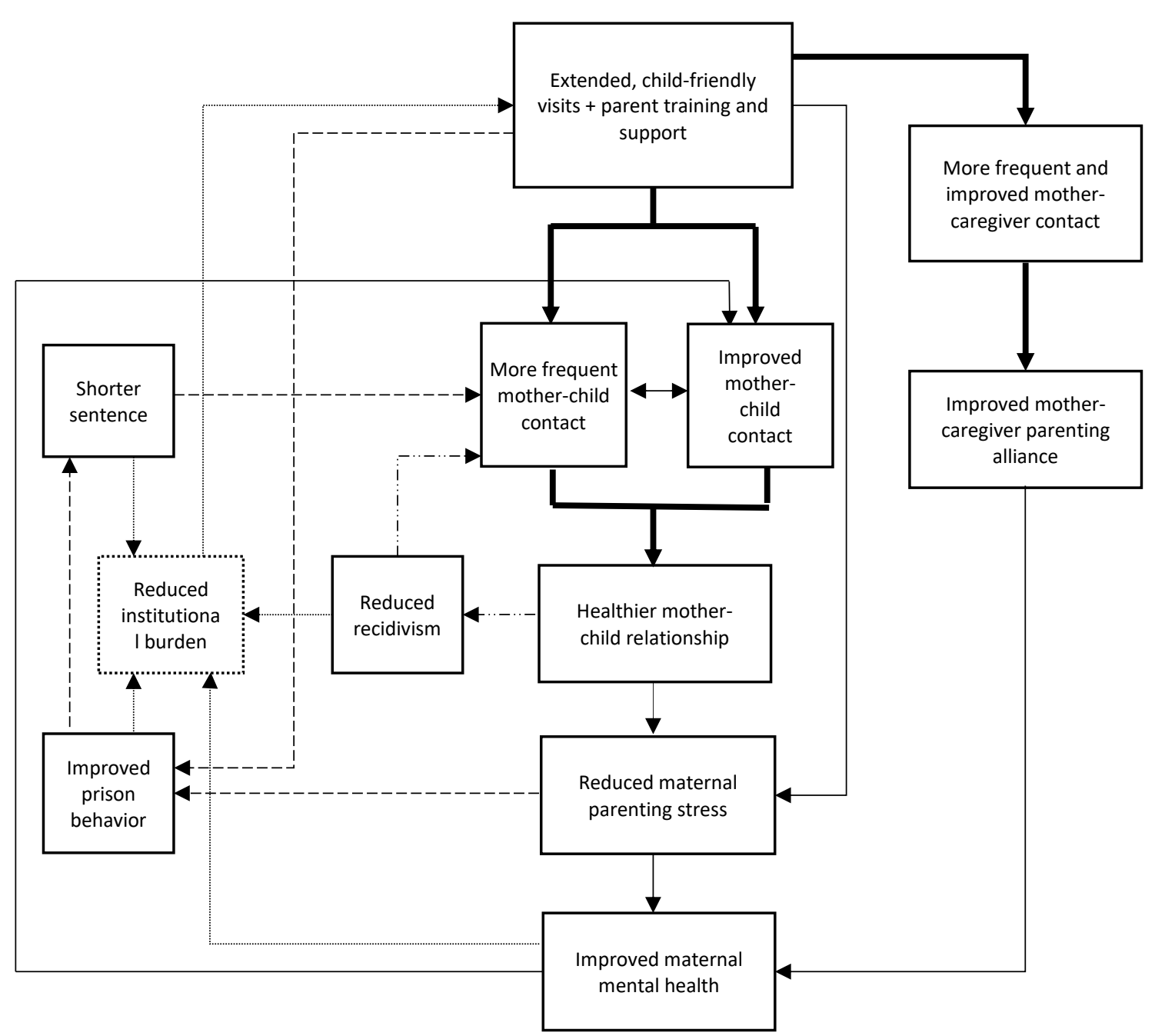

Figure 7. Hypothesized mechanism of change 5: The MILK program leads to institutional benefits via improved inmate behavior, improved inmate mental health, reduced recidivism, and shorter sentences. 


\section{CHAPTER III}

\section{Method}

\section{Participants}

Participants included select staff members identified by prison administrators as having first-hand knowledge of the MILK program as well as current inmate MILK participants at the two facilities.

Phase I: Staff. Staff with knowledge of the MILK program were identified during initial meetings at each institution between the research team and VADOC representatives, the warden or assistant warden, the director of institutional programming, and the MILK staff sponsor. All staff who were invited to participate agreed. In total, the following five staff members participated: the current staff sponsors of the MILK program at each institution, a correctional officer at VCCW who has worked during several MILK visits, a specialist in inmate programming from VADOC headquarters, and the director of institutional programming at VCCW.

Phase II: Inmate MILK members. All current members of the MILK program at both institutions were invited to participate in the study. At the time of the study, both institutions

allowed a total of 25 women to participate in the program. 24 women were participating in the program at $\mathrm{VCCW}$ and 15 were participating in the program at FCCW. According to the program sponsor at FCCW, this was a period of particularly low participation and she was anticipating a surge in membership following an upcoming period of enrollment.

$\boldsymbol{V C C W}$. Of the 24 current MILK participants who were invited to participate in the study, all agreed and completed the consent form and questionnaire. Of these 24 
women, 15 participated in the interview. Three women declined to participate in the interview during the consent process. One woman consented to the interview during the initial process, but declined to schedule the interview citing feelings that it would be "too upsetting." One woman declined to attend on the day of the interview for what appeared to be scheduling reasons (e.g., not wanting to miss work). An additional four inmates were released or transferred (information was not available on which of these had occurred for each inmate) before interviews began (due to scheduling issues, interviews at VCCW were conducted two months after the initial consent process).

FCCW. Of the 15 current MILK participants at FCCW who were invited to participate, all agreed and completed the consent form and questionnaire. Thirteen of these women participated in the interview. Of the two women who were not interviewed, one was expelled from the program in between consent and the interview date due to a behavior issue, and the other was released from prison during this interim.

Final sample. Between the two institutions, a total of 39 women participated in the study and $28(72 \%)$ of these participants were interviewed. There were no significant differences between the two institutions nor between the overall sample and interview sample on any demographic variable. Nor were there any significant differences between the overall sample and interviewed sample on perceptions of program effects as reported on the Background and Program Questionnaire (e.g., there was no significant difference between the groups on responses to the question "overall, how helpful has MILK been to you?"). Participants ranged in age from 23 to 54 with a mean age of $35.74(S D=7.11)$. The majority of participants identified as Caucasian (66.7\%) with the remainder identifying as African-American (33.3\%). Eighty-seven percent ( $n=34)$ of participants 
had a high school diploma or GED and ten percent of participants had a college degree.

The duration of participants' membership in the MILK program varied considerably from two months to 118 months (nine years, nine months). The mean length of membership was 24.82 months $(S D=26.61)$.

Participants had an average of $2.72(S D=1.41)$ children with a range of one to six. Ninety-two percent of mothers reported having lived with their children prior to incarceration and $82 \%$ planned to live with their children upon release. Thirty-six percent of participants reported that their children were living with the mother's parents (i.e., the children's maternal grandparents); 31\% reported that their children lived with their father; and, $18 \%$ reported that their children were living with both their father and their maternal grandparents. Participants also reported that children were being cared for by family members other than parents or grandparents (8\%) and foster parents $(5 \%)$. The majority of participants' children (72\%) lived within a one-to-three-hour drive of the prison. Ten percent of participants' children lived closer than a one-hour drive away, and $18 \%$ lived more than a five-hour drive from the prison.

\section{Measures}

Staff interview. The staff interview protocol was designed as part of a larger process evaluation focusing primarily on program implementation for VADOC. The interview contained structured, open-ended questions designed to elicit information related primarily to program implementation and secondarily to perceived efficacy. Questions were intended to encourage interviewer follow-up. Questions focused on program logistics and implementation as well as any barriers to implementation from an institutional perspective. Staff were also asked to reflect on institutional and individual 
benefits and challenges resulting from MILK. In accordance with standards of qualitative research, questions were designed to be as open-ended as possible. All staff interviews were conducted by the lead researcher. See Appendix A for a copy of the staff interview protocol.

Inmate interview. All inmate interviews were conducted by the lead researcher who was accompanied by a research assistant. The research assistant was a VADOC research staff member with a background in public policy who expressed interest in collaborating on the project in an effort to gain a better understanding of the program on behalf of VADOC. Despite the possibility that the presence of a VADOC representative might influence respondents during interviews, the decision to include this staff member in the interviews was made in order to facilitate access to the institutions and to allow for the use of a computer for transcription (only VADOC staff have access to government computers that are allowed inside the prisons). Moreover, given the nature of the staff member's position, she had little to no interaction with inmates in either of the prisons involved prior to the investigation. She also had no direct influence on the lives of inmates in her position as a researcher (i.e., she did not create regulations or have power to enact punishments or grant privileges). As such, I felt the impact of her presence on inmates would likely be minimal. Nevertheless, in order to reduce the possible influence of her presence on participants' reports, all participants were told that the staff member was there to help the research team gain an honest understanding of the program and its efficacy and that she would not be reporting directly to superiors regarding any one participant. In addition, participants were told that data would be presented to institution and VADOC personnel in a de-identified format and were encouraged to be honest in 
their responses. While it is possible that this staff member's presence limited what participants felt comfortable sharing, overall interviewees appeared to share both positive and negative experiences honestly.

The majority of interviews took approximately one hour, with a few taking closer to an hour and a half. Interviews were conducted in multi-purpose rooms at the prisons with closed doors. Only the inmate and the two researchers were present during the interviews. Inmates were scheduled for interviews and made aware of their appointment by prison staff. A written verbatim of each interview was taken by hand or computer by the research assistant. The research assistant was granted access to a VADOC-approved computer mid-way through the interviewing period. As such, approximately half of all interviews were recorded by hand and half were recorded by computer. Following each interview, the lead researcher and research assistant debriefed and reviewed the verbatim notes; if either recalled information that had not been recorded, it was added to the verbatim at that time. Verbatim interview transcripts were uploaded into Dedoose (2016), a qualitative data analysis software, for management and processing.

Two semi-structured interview protocols were used. The first protocol $(n=12)$ included a series of semi-structured questions designed to gather information from inmate mothers regarding their perceptions of and experiences in MILK. Questions were openended and intended to facilitate interviewer follow-up. Questions were designed to elicit information related to these research questions in two ways: by asking participants to reflect on circumstances before and after joining MILK (e.g., participants were asked to describe their relationships with children and caregivers prior to and after joining MILK) and by asking participants to directly reflect on the proposed mechanisms of change that 
drive the research questions (e.g., "Do you think your experience will be different when you go home because you participated in MILK? If so, how so?"). In addition, questions regarding program implementation were included as part of the larger process evaluation for VADOC. See Appendix B for a copy of the first inmate interview protocol.

Based on theoretical concerns regarding social desirability effects in response to the first interview protocol, a second protocol (see Appendix C) was developed and used for the remainder of interviews $(n=16)$. As a result, the second protocol was used for three of the interviews at VCCW and for all of the interviews conducted at FCCW. This second interview protocol asked participants to plot changes on a map (Futch \& Fine, 2014) in three domains across their prison stay: their relationship with their children, their relationship with their children's caregiver(s), and their own behavior. Interviewer follow-up was used to inquire into the perceived mechanisms involved when changes in these domains were reported. In this way, participants were asked to reflect on changes occurring before and during the program without the interviewer directly asking about perceived effects of the program itself.

Inmate questionnaires. Inmates were administered questionnaires to collect demographic and background information and to provide a quantitative complement to the qualitative interview.

The Background and Program Questionnaire. Participants were asked to provide basic demographic information as well as information related to their prison sentence and record on the Background and Program Questionnaire (see Appendix D). This questionnaire also included questions regarding the MILK program including length 
and nature of participation in the program and perceptions of program effects. Questions were designed by the research team to supplement information obtained in interviews. Questions that I believed would not require prompting or follow up were included in the questionnaire rather than the interview in order to limit interview duration. In some instances, questions were similar to those in the interview but asked the participant to choose answers from a response set. This provided quantitative information that offered a valuable supplement to the qualitative information collected through interviews.

The Adult Adolescent Parenting Inventory (AAPI-2). In order to describe the overall parenting style of the sample, participants completed the Adult-Adolescent Parenting Inventory, Version 2 (AAPI-2; Appendix E). The AAPI-2 is a commonly used, well-validated and reliable measure that assesses attitudes towards parenting (Bavolek \& Keene, 1999) and is written at a 5th grade reading level. The AAPI-2 provides the following sub-scale measures of parenting attitudes: Expectations of Children, Parental Empathy Towards Children's Needs, Use of Corporal Punishment, Parent-Child Family Roles, and Children's Power and Independence. Each sub-scale score is converted into a sten score (standard ten score) by comparing it to a set of established norms for adult parents provided by the AAPI-2 authors. Sten scores are then categorized into low, medium, and high risk categories indicating the degree to which the parent's attitudes in that domain are likely to put children at risk.

\section{Analysis}

Positionality. I am a white, female doctoral candidate in Clinical Psychology. Coming from a background of economic fortune and racial privilege, I have a strong 
desire to help those who were born into lives of adversity. As both a clinician and researcher, I have a particular interest in how family impacts the individual, and believe strongly in the power of the family to harm and to heal. I came to my work with incarcerated mothers by way of an interest in helping at-risk families. At the outset of this evaluation, I had been working with incarcerated women at a local jail and at the Fluvanna Correctional Center for Women for three years to help improve their parenting during incarceration. During this time, I developed both a sense of hope and a sense of frustration regarding the potential for these mothers to become better parents. I was surprised by how much promise some women showed in their ability to change, and by how intransigent problematic parenting approaches were in other women. When I learned of the MILK program, I believed it held considerable potential to catalyze change among incarcerated mothers; however, I also understood the difficulty of influencing longstanding relational dynamics in this population. With this in mind, I worked to approach data collection and analyses with a neutral stance toward the MILK program, although it is certainly possible that at times my hope for the success of the program and the participants influenced my work.

Coding. Interview transcripts were analyzed using Dedoose (2016), a web-based platform for management and analysis of mixed-methods data. Transcripts were thematically coded using first cycle and second cycle coding (Saldana, 2013) to capture perceived changes in behavior, wellbeing, and relationships with children and caregivers since beginning the pre-program parenting course and since joining the MILK program, and to identify perceived mechanisms of change. 
First cycle code development. During first cycle coding, deductive and inductive codes were used (Miles, Huberman, \& Saldana, 2014). Deductive codes were developed from the proposed theory of change model and resulting research hypotheses (e.g., mother-child relationship change, inmate behavior change). As data collection progressed and research team members began to read through and code interviews, emergent themes were proposed and discussed during research meetings. A series of inductive codes were developed through this process and subsequently applied to all interviews (e.g., benefit of one-on-one time with children, behavior change to meet expectations of prison community).

Deductive coding. During first cycle coding, hypothesis codes (Miles et al., 2014) derived from proposed mechanisms of change were applied to test the proposed theory of change model. Magnitude coding using weights on a single code was utilized when appropriate to indicate perceived direction of change; (e.g., improvement in the motherchild relationship was designated by a weight of +1 on the mother-child relationship change code while deterioration was designated with a weight of -1 on the same code). I began with the following broad hypothesis codes to capture changes predicted by the theory of change model: changes in mother-child relationship quality, mother-child contact quality, mother-child contact frequency, mother-caregiver relationship quality, mother-caregiver contact quality, mother-caregiver contact frequency, mother-caregiver parenting alliance, and participant behavior and wellbeing. The following hypothesis codes relating to proposed mechanisms of change were also applied: improved motherchild communication, improved parenting skill, opportunity to parent during visits, opportunity for physical contact during visits, child-friendly visits, improved knowledge 
of children, children see mother safe, improved mother-caregiver communication, improved understanding of caregiver experience, improved knowledge of caregiver, improved appreciation for caregiver, availability of support from other incarcerated mothers, improved behavior to enter MILK program, and improved behavior to maintain membership in MILK program. Lastly, first cycle coding also included coding of the following program components to identify aspects of the program to which participants attributed perceived changes: parenting class, specialty visits, and group support.

Inductive coding. Inductive codes were developed to capture emergent themes in the data and to refine codes derived from research hypotheses. Concepts that members of the research team identified in interviews but could not capture with existing codes were discussed during research meetings. If a concept was deemed to be theoretically significant and potentially illuminating to causal processes under investigation, a new code was created. The following codes were created to capture emergent themes related to mechanisms of change: developing connections with similar others (e.g., caregivers meeting other caregivers, inmates meeting other incarcerated mothers, and children meeting other children with an incarcerated mother), mother earning respect from children and caregiver through program participation, and improved in-prison behavior to meet expectations in greater prison culture. The following inductive sub-codes were developed to refine the "improved contact experience" codes by capturing specific elements of the specialty visits that participants identified as influential: activities, sense of normalcy, relaxed atmosphere, one-on-one time, increased visit duration, celebrating holidays, and interaction with other families (i.e., families of other program participants). 
Second cycle code development. Second cycle codes were developed and applied by the me during the analytic phase of the study to refine explanatory themes captured by first cycle codes. Second cycle codes identified more specific causal mechanisms involved in the mechanisms of change identified by first cycle codes. For example, the code capturing changes in communication with children was further coded based on distinct types of communication changes noted by participants (e.g., children sharing more, more discussion of difficult topics), in order to allow for a more robust description of this mechanism of change.

Mother-child relationship change codes. The following second cycle codes were developed to capture additional themes related to mother-child relationship improvements: improved communication with children due to improved skill discussing emotionally challenging topics, improved communication with children due to children sharing more, improved communication with children due to mother's increased patience and reduced negative language, and better knowledge of children as a result of observing developmental changes through more natural interactions.

Mother-caregiver relationship change codes. The following codes were added during second cycle coding to better capture themes related to mother-caregiver relationship improvements: improved communication with caregivers due to mother learning to listen and back down, improved comfort sharing parenting ideas with caregivers, improved parenting alliance via mother assisting caregiver with parenting burden, and improved parenting alliance via mother earning parental privileges from hesitant caregiver. 
Behavior change codes. Lastly, the following second cycle codes were developed to better explain themes related to improved participant behavior in prison: MILK as a catalyst for personal growth, and improved behavior motivated by increased dedication to family.

Code application. Four advanced undergraduate research assistants conducted first cycle coding. I trained research assistants on the initial coding manual during a coding workshop. Two research assistants independently coded each interview. Research assistants then met to reconcile any coding discrepancies and create a final coded interview. If research assistants could not reach agreement on a coding discrepancy, or if they were uncertain about the appropriateness of any code, the issue was discussed with the research team during a weekly research meeting and the group came to consensus on appropriate codes. Research assistants rotated coding partners every week so that each research assistant worked with every other research assistant at least twice. In addition, prior to analysis, I reviewed every interview for coding accuracy. 


\section{CHAPTER IV}

\section{Results}

\section{Research Question 1a: Do Mothers in the MILK Program Perceive Improvements in Relationships with Their Children as a Result of MILK? If So, What is the Nature of the Improvement and to What Do They Attribute the Change?}

Among participants interviewed, ninety-three percent $(n=26)$ perceived an improvement in relationships with their children since joining MILK. The two women who did not report improvements in the mother-child relationship since joining MILK had no contact with their children since joining the program as a result of conflicts with caregivers. Twenty-five (96\% of those reporting improvements and $89 \%$ of all participants interviewed) of the 26 mothers who noted improvements in relationships with children, attributed these improvements at least in part to their participation in the MILK program. Seventeen women attributed these improvements to the MILK program but not to the pre-program parenting course and 8 attributed the improvements to both the MILK program and the pre-program parenting course. One mother attributed improvements in her relationship with her children to the pre-program parenting course but not to the MILK program; notably, this mother had not received visits from her children during her time in MILK. Among the 26 women who reported improvements in relationships with children since joining MILK, nine also reported improvements in these relationships due to factors unrelated to the program (e.g., less expensive phone calls, caregivers moving closer to the prison). 


\section{Nature of mother-child relationship improvement.}

Improved communication. One of the most prominent mechanisms of change noted by mothers was the development of improved communication with children through MILK visits $(n=18 ; 64 \%)$. For example:

I bond more with my son in MILK; I can talk to him about my mistakes. You have time to do that with MILK. MILK helps by showing kids that prison is not the life. I feel closer to him and know what's going on in his life. Being able to move around and speak to them alone helps. It's one-on-one time. Regular visits are confining. It's better to interact with kids in MILK.

This mother outlined the two categories of communication change noted by many of the participants who described developing improved mother-child communication through MILK visits: increased honest discussion about emotionally challenging topics—often relating to the mother's incarceration and criminal history — and increased sharing from children about the lives they lead away from their mothers. She, like many other participants, attributed this healthier communication to elements of the MILK visits, specifically, increased time, the more relaxed environment, and the availability of oneon-one time.

Parenting skill. Of the 18 women who indicated improvements in communication, ten (36\% of women interviewed) specifically identified parenting skills learned in the parenting class and the MILK program as the catalyst of this improvement. For example:

Parenting [class] showed you how to parent and MILK allowed us the time and physical contact and connection once we got in it to practice what we learned. 
Parenting showed us what to do. Parenting taught us a way to still discipline and be a mother and not scare them the first time they see us. Like without parenting the first time I saw my son I might have yelled at him like "sit down.” But with parenting I learned that you don't want to yell like that the first time you're seeing them in so long.

This participant reflected on how the parenting skills she learned through the program and the parenting class improved her approach to communicating with her children. She specifically described learning a softened approach to parenting, which fostered an improved contact experience. Six of the 10 women who reported that improved parenting skills contributed to improved communication with children described a similar form of improved communication involving less negative interaction (e.g., punishment, chastising) and more patience and listening. Four of the women noted an improvement in how they talked to their children about difficult subjects — specifically, their incarceration, bullying, and sex — as a result of the parenting skills they had learned.

While this relatively small subset of participants noted learning a healthier approach to parenting, results from the Adult-Adolescent Parenting Inventory (AAPI-2) indicated that most MILK participants continued to hold problematic beliefs about parenting (see Table 1). In each of the five parenting constructs measured by the AAPI-2, the majority of participants described parenting beliefs that placed them in the "Medium Risk" category. 
Table 1

Parenting Attitudes of Participants Per the Adult-Adolescent Parenting Inventory (AAPI-2)

\begin{tabular}{|c|c|c|c|}
\hline \multirow[b]{3}{*}{ AAPI-2 Construct } & \multicolumn{3}{|c|}{ Risk level } \\
\hline & Low & Medium & High \\
\hline & $n(\%)$ & $n(\%)$ & $n(\%)$ \\
\hline A: Expectations of Children & $5(12.8)$ & $30(76.9)$ & $4(10.3)$ \\
\hline $\begin{array}{l}\text { B: Parental Empathy Towards } \\
\text { Children's Needs }\end{array}$ & $8(20.5)$ & $26(66.7)$ & $5(12.8)$ \\
\hline C: Use of Corporal Punishment & $3(7.7)$ & $34(87.2)$ & $2(5.1)$ \\
\hline D: Parent-Child Family Roles & $9(23.1)$ & $29(74.4)$ & $1(2.6)$ \\
\hline E: Children's Power and Independence & $8(20.5)$ & $18(46.2)$ & $13(33.3)$ \\
\hline
\end{tabular}

Note. The AAPI-2 assesses attitudes towards parenting (Bavolek \& Keene, 1999) and is written at a 5 th grade reading level. Sub-scale scores are converted into sten scores and categorized through comparison to established norms for same-aged parents.

Better knowledge of children. Twelve participants (43\% of those interviewed) described getting to know their children better as a result of the MILK program. These mothers described getting to know their children better in three ways. Participants described how MILK provided an opportunity to see children engage with a more typical environment than would be available during a regular prison visit, which allowed them to learn about their children's developing interests and personalities. For example:

We got to have time that I could walk around with my kids. All these years I have to sit down in regular visits. I couldn't move around with them, couldn't hold them. With MILK, I got to know their personalities. They are two totally different people. Being in MILK helps you learn what they like. With my son I got to learn 
that he's like into Legos and stuff and my daughter she's really into dancing. She is a wild one while he is more quiet and a lot a lot like me.

Second, mothers described how they were better able to see children's true selves because children were able to relax in the less stressful environment of MILK. For example:

In a regular visit [children] can't sit on your lap, it's very restrictive for both kids and parents. Now they can lay all over the floor and you can pick them up. It makes them more comfortable and that makes a better visit. You can talk privately without having an officer there; there is no way to get away during a regular visit. You can take one child away and speak with them separate from each other during a MILK visit.

This mother reflected not only on the influence of the more relaxed atmosphere on the children, but also on the third way in which mothers reported getting to know their children better: by talking to them alone, which encouraged more sharing.

Earned parental respect. Nine participants (32\% of women interviewed) described how their participation in the program helped them earn respect from their children and assume or re-assume parental status. Mothers focused on two primary parental roles that they were able to assume through MILK visits: disciplinarian and teacher. This mother described both of these roles:

When I first started I had no idea that my kids have so much energy. I learned how to deal with a meltdown. They are not gonna act perfect during a visit...I had to learn how to parent. They fight each other and my mom just tells me to deal 
with it. When it's the MILK visits it's like they're mine and she just gives me the kids and I deal with them the whole visits. It's like it's her time off... It's taught me a lot like when one wants to do one thing and the other wants to do another. I taught my son how to tie his shoe. He said we had to go under the table so no one would see, so I had to teach him under the table. I loved teaching him.

In addition, a small subset $(n=3)$ of mothers who reported earning respect from children through MILK attributed this in part to their participation in the planning and running of the visits. For example:

You do more activities with them, they see you more as mom. Like if I say my responsibility is craft table they see me take responsibility of the craft table. Cause I don't know what they think of us because they see us in here and not sure how they see us as mom.

\section{Research Question 1b: Do Mothers in the MILK Program Perceive Improvement in the Quality of In-Person Contact with Their Children as a Result of MILK? If So, What Is the Nature of the Improvement and to What Do They Attribute the Change?}

The most striking theme to emerge from the interviews was the essential role the specialty visits played in strengthening participants' relationships with their children. Of the 25 mothers who reported improved relationships with their children as a result of MILK, $100 \%$ noted improved contact quality during visits as the key factor in this relationship improvement. Mothers reported a variety of ways in which MILK visits facilitated improved in-person contact with their children. Below I review the elements of 
the MILK visits to which they attributed these relationship improvements and the types of improvements they connected to each element.

\section{Contributing factors to improved contact experiences during specialty visits.}

Activities. The availability of child-friendly activities was the element of visits most often noted by participants as influencing their relationships with children $(n=23$; $82 \%$ of interviewees). Mothers described several ways in which the activities facilitated connections with children. Nearly half of the mothers who mentioned activities when describing how MILK had led to improved contact experiences with children $(n=10)$, connected these activities to a sense of normalcy in MILK visits, which they felt enhanced the experience. Several mothers noted that being able to play outside with children felt particularly "normal.” In addition, mothers reported that activities helped them get to know their children. For example:

I've basically seen my baby grow up in here. You get to do different activities in the visits and I get to see her personality. We dance together and she teaches me things like how to do the "Nae Nae." It's like I know her, but it's like seeing her in a different environment at a MILK visit because at a regular visit you just sit there and talk.

Like this mother, several mothers specifically noted becoming aware of developmental changes in their children as a result of the activities. Mothers also reported that the activities helped children enjoy the visits, which fostered connection by helping children relax, facilitating a sense of normalcy, and contributing to mother-child interactions that were more positive in nature. Moreover, several women focused on the benefits of 
engaging in pleasurable activities with children, reflecting the importance of shared rewarding experiences in developing and sustaining relationships. For example:

All of the visits have been great. My son has won a lot at Bingo. He gets really excited and there's fun and laughing. When you feel like it's the end of the world and you get to experience laughter like this it feels like god is looking out for you.

A smaller subset of women specifically mentioned special holiday activities during MILK visits as important in developing or maintaining relationships with their children $(n=5)$. Several women described how special and normalizing it felt to eat Christmas dinner with their children during a MILK visit. And, one mother described the joy she felt giving her son his first Easter basket.

One-on-one time. After activities, the one-on-one time with children allowed in MILK visits was the most frequently noted aspect of the visits that women believed contributed to improved mother-child relationships $(n=13 ; 46 \%)$. For example, this mother described how this made MILK visits different from regular visits:

I wasn't able to get to know them in the regular visits because I couldn't sit with them alone and there was too much going on. Maybe [my son's] telling me something that he doesn't want the caregiver to know and being one-on-one with mom helps. I feel like they can feel closer to me and more open.

This mother highlights two of the many barriers to maintaining or developing a healthy parent-child relationship through typical prison visits: the chaotic environment and lack of privacy. She suggests that, in contrast to regular visits, MILK permits her to spend 
time alone with her son in a more relaxed environment, which allows her to fulfill the parental role of confidant and source of support despite her daily absence.

Physical contact. For a significant number of participants $(n=12 ; 43 \%$ of interviewees), the ability to have physical contact with children during MILK visits emerged as an important contributor to improved relationships. While many women made a direct connection between physical contact and an enhanced emotional connection with children, others provided more specific mechanisms of change. Some women described how the availability of physical contact with children created a greater sense of normalcy in which to develop a relationship. For example:

[During visits] we are able to go outside and touch them and take pictures. It's like being at home with them. There's no touching during regular visits. During MILK we can hug, kiss, play. It's like we're not even in prison for that day. Like it takes them back home for a little while. I wouldn't trade it for anything.

Others described how children felt more relaxed without the strict regulations on touching their parents that are imposed on them during regular prison visits.

Relaxed environment. The more relaxed environment of the MILK visits as compared to regular prison visits emerged as another factor mothers perceived as influential in improving relationships with their children ( $n=11 ; 39 \%$ of interviewees). Mothers noted several factors that contributed to the more relaxed atmosphere during MILK visits. The following mother described how the ability to move between spaces freely helped her family during visits - a theme that was reflected by several other participants: 
It helps everyone loosen up and relax. You don't get stuck in a rut. If one thing isn't working for you, you can move on to something else.

In addition, several mothers mentioned that the lower profile of the guards during MILK visits helped children feel more comfortable. For example:

[What made MILK visits better was] not having an officer walk around. My 14year-old quit coming to regular visits because she was uncomfortable. She came to the first MILK visit. We had a lot of fun, she told me a lot of stuff and ever since then she's been to every visit. It had been almost a year.

As both of these women alluded to, when describing the impact of the more relaxed environment on children, mothers noted that the atmosphere helped children feel safer and less intimidated by the prison setting, which facilitated increased comfort while interacting with their mothers, and, in some cases, fostered a desire to return to visits. In addition, several mothers described how their children spoke to them more openly during these visits because they felt more relaxed and less guarded.

Contact with other families. Seven women (25\%) felt as though the presence of other families facilitated improved contact experiences with children during MILK visits. These mothers focused on how having contact with other families improved the visit experience for children and thereby fostered connection. For example:

Seeing other kids in the program play together is great. My son plays with other boys his age. It's important for him; he's more outgoing with other boys than when he just stays with mom. It's fun to sit and watch the kids play together like 
if he were at home. And I've become friends with the other boys' moms. We've gotten really close.

This mother explains how being able to interact with other families allows her son to enjoy the visit more, creates a sense of normalcy, helps her get to know her son's personality better, and fosters connection between herself and other incarcerated mothers. In addition, a number of other mothers focused on the normalization and support children experienced by developing relationships with other children whose mothers were incarcerated.

\section{Research Question 1c: Do Mothers in the MILK Program Perceive an Increase in the Frequency of Visits from Their Children as a Result of MILK? If So, to What Do They Attribute This Increase?}

Seventy-four percent ( $n=29)$ of MILK participants who completed the questionnaire reported that they received the same number or fewer visits from their children since joining MILK (see Table 2 for additional information regarding visit frequency). Among mothers who participated in interviews, six $(21 \%)$ noted an increase in frequency of visits from children since joining MILK. Five of these six women reported an increase in visits because family began attending MILK visits when they previously did not visit at all or visited very infrequently, while one woman reported that her family began attending non-MILK visits more frequently as a result of the relationships they had developed through MILK. Participants described several factors that contributed to increased visit frequency (factors are not mutually exclusive): caregivers who had previously prevented regular visits allowing MILK visits due to their 
Table 2

Self-reported Visit Participation and Changes in Visit Frequency

$n(\%)$

Number of MILK visits attended

None

One to Three

$10(25.6)$

Four to Eight

$9(23.1)$

More than Eight

$9(23.1)$

Did any child attend most recent MILK visit?

Yes

No

$18(46.2)$

Change in number of visits from children since joining MILK

More visits

Same number

Fewer visits

$6(15.4)$

Note. Responses were provided on the Program and Background Questionnaire Appendix D) by MILK participants during group meetings at both facilities.

child-friendly nature $(n=3)$, caregivers becoming willing to travel for the longer MILK visits $(n=1)$, children being willing to attend MILK visits who refused to attend regular visits due to discomfort $(n=2)$ — one mother described how telling her son that he could "run around" during a MILK visit "persuaded" him to visit her-changes in legal visitation rights resulting from child-friendly MILK visits $(n=1)$, greater likelihood of visits due to the regular scheduling of MILK visits $(n=1)$, and family members feeling closer to the woman as a result of MILK visits and wanting to attend regular visits to see her more $(n=1)$. 
An additional six interviewees noted that MILK allowed them more contact with children through the increased duration of the visits (i.e., more contact through longer rather than more frequent visits). Another three women reported an increase in non-visit contact with children (e.g., phone calls, letters, emails), which they said resulted from the improved mother-child relationship developed in the MILK program. In total, 13 women $(46 \%)$ mentioned at least one form of increased contact with children as a result of their participation in the MILK program.

One woman reported a decrease in visit frequency as a result of joining MILK. She explained that her family no longer wanted to attend non-MILK visits after seeing how much more comfortable and enjoyable MILK visits were. This mother also reported an increase in time spent with children due to the longer MILK visits, and expressed a clear preference for less frequent yet higher quality (i.e., MILK) visits over more frequent, lower quality (i.e., non-MILK) visits.

\section{Research Question 2a: Do Mothers in the MILK Program Perceive Improvement in Relationships with Their Children's Caregivers as a Result of MILK? If So, What is the Nature of the Improvement and to What Do They Attribute It?}

According to questionnaire self-reports, most mothers in the MILK program felt as though they got along well with their children's caregivers $(54 \% ; n=21)$ and that caregivers respected their opinions about parenting (67\%; $n=26)$. In addition, fifty-one percent $(n=20)$ of mothers reported that caregivers allowed them some say in parenting 
decisions. For additional data on mother-caregiver relationships per questionnaire selfreports, see Table 3 .

Table 3

MILK Participant Self-reports of Relationships with Children's Caregivers

$n(\%)$

What is your relationship with your children's caregiver like?

We get along very well

We get along $\mathrm{OK}$

Neutral: neither good nor bad

We don't get along very well

We don't get along at all

Does the caregiver respect your opinions on parenting?

Yes, a lot

Yes, a little

Neither respects nor disrespects

No, not at all

How much say do you have in how your children are raised?

Total say

A good amount but not total say

Some say

Not much say

No say at all

$9(23.1)$

Note. Responses were provided on the Program and Background Questionnaire (Appendix D) by MILK participants during group meetings at both facilities. All 3 current participants at both facilities completed the questionnaire. 
Seventy-five percent of mothers interviewed $(n=21)$ perceived an improvement in relationships with their children's caregivers since joining MILK. Of these mothers, 14 attributed these improvements to the MILK program but not to the pre-program parenting course and 5 attributed the improvements to both the MILK program and the pre-program parenting course. One mother attributed improvements in her relationship with her children's caregiver to the pre-program parenting course but not to the MILK program; this mother attributed the change to her sister's feeling that she was putting more effort in just by signing up for the parenting course, not to anything learned in the course itself. One woman reported improvements in her relationship with her children's caregiver due entirely to factors other than the MILK program or parenting class. Among the 21 women who reported improvements in relationships with caregivers since joining MILK, five also reported improvements in these relationships due to factors unrelated to the program (i.e., four women reported improvements due to MILK and/or parenting as well as external factors while one woman reported improvements due entirely to external factors). Most of these five women described improvements in relationships with children's caregivers (often the woman's parent or parents) due to the passage of time and development of forgiveness.

\section{Nature of mother-caregiver relationship improvement.}

Participants perceived two distinct yet related categories of change in relationships with caregivers as a result of participating in MILK and/or the pre-program parenting class: Improved parenting alliance and a more general sense of improved connection and interpersonal dynamics not necessarily related to co-parenting. 
Improved parenting alliance. Thirteen mothers (46\% of interviewees) reported feeling an increased sense of parenting alliance with their children's caregivers as a result of the program and/or pre-program parenting class. MILK participants described developing a stronger parenting alliance with caregivers via two pathways: One group of women $(n=7)$ took on more parenting responsibilities per the request of caregivers who felt overburdened and overwhelmed by the parenting duties they had assumed. In contrast, another group of women had to work toearn co-parent status from caregivers who were more resistant to sharing parenting responsibilities as a result of doubting the mother's fitness to parent. Six mothers fell into this latter group. They reported that as a result of MILK and/or the pre-program parenting class, they were able to step into more of a co-parent role than had been previously permitted by their children's caregivers. For example:

He broke down about [my daughter's] medicine and listened to me. The parenting class told us that we have to respect our caregivers because they have our children. And if we don't have a good relationship with our caregivers then you aren't setting a good example for your kids. I basically started to respect him a lot more, showing my kids that you can't speak to him the way that I used to talk to him. That's when we were able to come to an agreement about my daughter's treatment and that's when he gave in.

In one of the most dramatic changes in parenting alliance reported by participants, this mother described being able to step so firmly into the role of co-parent that she had the final say in a complex medical decision for her daughter. 
In contrast to mothers who wanted more parenting responsibility than caregivers were inclined to allow, the other seven mothers who reported developing a better parenting alliance with caregivers described relieving some of the parenting burden from caregivers who wanted the help. For instance:

[My relationship with my mom] improved. It was just seeing her on a regular basis. And I guess she felt like I had more input with the kids, she wasn't just by herself. Because I actually had time to sit down and talk to the kids one-on-one, and some of it was off of her. She says they behave better after they leave here.

This mother described how the less restrictive and more family-oriented nature of MILK visits provided an opportunity for her to relieve some of the burden of parenting from her children's caregiver, which fostered an increased sense of shared responsibility for child rearing. In addition, most mothers in this group $(n=5 ; 71 \%$ of the seven reporting this change in dynamic) attributed their willingness and/or ability to relieve some of the parenting burden from caregivers to a process of maturation that involved taking an increased interest in family, which was facilitated by the MILK program and/or preprogram parenting course.

Opportunity to parent at MILK visits. Like the participant quoted above, five women attributed developing a greater sense of parenting alliance with caregivers to the opportunity they had to parent their children during the longer, more open MILK visits. For example:

Normally [their caregiver] acts like their mom, but during MILK she hands them to me and gives me a chance to be a mom. I tell her things I want to do with the 
kids parenting-wise, but she says, "I have to do this so let me do it my way. When you get out you can be in charge."

This participant painted a picture in which MILK visits provided the only opportunity she had to act as parent to her children. She described how even though her children's caregiver believed strongly that she should make all decisions if she was shouldering the daily burden of parenting, MILK visits provided a brief opportunity for her to relieve some of this burden from the caregiver. The other four women in this group described varying degrees of co-parenting both during and outside of MILK visits. While most of these women reported that MILK helped them co-parent because they were able to take over parenting from caregivers during the visit, one participant described how the familynature of the MILK visits allowed her to actually practice co-parenting with her child's caregiver:

I didn't have much say in parenting before MILK. Now I can speak to my son directly so it feels more like parenting. I can speak to both [my son and my mom] directly, so parenting is more shared. MILK brought us all closer as family.

This participant described how MILK helped her family achieve the ideal of coparenting - co-parents who interact in a healthy way in front of the child and are able to make decisions jointly in the child's presence and with the child's collaboration.

Improved communication with caregivers. Seven women (54\% of those reporting improved parenting alliance with caregivers; $25 \%$ of those interviewed) related a greater sense of parenting alliance with caregivers to changes they (the MILK participants) had made in the way they communicated with them (the caregivers). These changes fell into 
two main categories: expressing increased interest in the caregiver's experience and respect for his or her opinion $(n=5)$, and feeling more comfortable expressing ideas about parenting to caregivers $(n=2)$. These mothers attributed changes in communication with caregivers to several factors. One mother attributed the improvement to her own maturation and not to MILK or the pre-program parenting course directly. She described growing up and being able to take the perspective of others more easily. Two women reported learning how to communicate with caregivers about parenting from other mothers in the MILK program. One of these mothers related how other mothers helped her during a particularly challenging time with her child's caregiver:

One day he told me that he got married and had another baby and would not communicate with me at all about my child...MILK may have helped me because I would have handled it differently. I probably would have cussed him out, but MILK moms helped me understand that it's not about him, it's about my daughter. I'm there for my daughter, my main concern is for my daughter. He's her father, he should be taking care of her. I'm fortunate that he's there too because many kids don't have that...I get that it's about her, and the ruder I am to him the more it's going to hurt her.

This participant explained how the support of other participants who had experienced similar situations helped her develop arguably the most important perspective to have when co-parenting through conflict — that the child's wellbeing is what matters most. This is a concept many co-parents dealing with adversities far more minor than incarceration struggle to understand, and this participant was able to develop this challenging perspective through her relationships with other MILK participants. In 
addition, four of these seven women $(57 \%)$ reported that they learned how to communicate with caregivers more effectively in the pre-program parenting class. For example:

[My relationship with my sister improved]. We were arguing a lot in the beginning. She was feeling overwhelmed because my son was really small and she had a kid at the same time... We had a bumpy relationship before I got here too because of certain things in my past. But I started getting focused and showing them that I care. I had to make the push to be involved in the kids' lives, they weren't going to make the push. Through parenting [class] I learned that we had to be the ones to make a push and eventually they would come along... [The instructor] was telling us that we have made a mistake but they are still our kids and we deserve to be in their lives.

This mother identified several challenges that many incarcerated mothers and their children's caregivers face: a difficult pre-existing relationship, and the caregiver's resentment over having to assume the burden of parenting someone else's child. She then described how she learned two key concepts in the parenting course that helped her navigate these common obstacles to healthy parenting alliance. She learned that she had a right to be involved in her children's lives despite her incarceration, and, that given her role in creating the situation, she bore the burden of initiating and sustaining that communication.

Better understanding of caregiver's experience. Four mothers (14\% of those interviewed) reported developing a better understanding of their children's caregiver's experience as a result of participation in MILK or the parenting class. And, they all 
described this improved understanding as contributing to an improved sense of parenting alliance. Like the following mother explains, this better understanding often contributed to the improvements in communication outlined above:

When [the parenting class instructor] was talking to us about caregivers' struggles that was helpful. I didn't understand when I first got here I only thought about me and not that I'd just left my mom alone with an infant. Once I realized that I needed to look at it from my mom's side, things started to get better from there. It helped me be more empathetic and learn to ask how my mom was doing instead of focusing on myself. I also started to ask if there was anything I could do to help.

This mother reflected on how the parenting class helped her to develop a deeper understanding of the issues her mother may have been facing as a caregiver. She then described how she brought this understanding into communications with her mother, which improved their relationship. This participant was the only one to attribute this change in perspective to skills she had learned during the parenting class. The three other women who reported developing an increased understanding of caregivers' experiences attributed this change to the closer relationships they had developed with children through the MILK program. They described how time spent with children in MILK had helped them appreciate the challenges of parenting their children as well as feel a sense of gratitude towards caregivers. For example:

I think with me joining MILK it took a lot of the pressure off of [my children's caregiver] where I took notice of all the stuff that he has gone through. I see how much my daughter is to handle_-all the energy she has at the MILK visit. When 
they're at the MILK visit, he gets a break and I get to actually be a mom during the visit. I get to be in control and do the mom thing. Like say "sit down, no you can't have that."

Here, this mother explained how the opportunity to parent during MILK visits, which, as discussed above, a number of women $(n=9)$ reported was instrumental in developing a healthier relationship with children, was also important in improving parenting alliance with children's caregivers for a small, yet notable, group of women.

Earned respect. Five women (18\% of those interviewed) described how caregivers began to trust and respect them more as parents once they showed interest in becoming better parents and put effort into co-parenting. Some women reported that they earned this increased respect from caregivers simply by joining the parenting class and/or MILK program, while others tied these changes more directly to changes in their behavior as parents, like this participant:

[My relationship with my daughter's aunt] has improved because we were getting through some issues. She was talking to me more and getting to the realization that I was going to keep calling to talk to my kids. My daughter calls her mommy because she helped raised her. I think she can see a change in me. I've been taking this more seriously about being a mom. Joining MILK has been a really big thing for my family. They knew about it and wanted me to join the whole time I've been here.

This participant reflected how, for this group of women, joining MILK and then having the opportunity to step-up as a parent during MILK visits, was a way for them to 
demonstrate personal growth generally and growth as a parent more specifically to caregivers, which earned them the respect that is fundamental to a healthy parenting alliance.

Improved connection with caregivers. As mentioned above, in addition to describing the improvement in parenting alliance predicted by the theory of change model, participants also described developing a greater sense of interpersonal connection with caregivers more generally. This more general relationship improvement was likely transactionally related to improved parenting alliance among the seven women who reported both types of improved relationships with caregivers. However, another seven women described feeling closer to their children's caregiver as a result of MILK but did not describe developing a healthier parenting alliance. In sum, a total of fourteen women ( $50 \%$ of those interviewed) reported developing a closer relationship with their children's caregiver as a result of the program and/or parenting class, and 50\% of these women also described developing improved parenting alliance with caregivers.

The enhanced connection mothers reported developing with caregivers was characterized by a general sense of increased connection and greater comfort, as this mother reflects:

[My relationship with my mom] is good because now I can spend more time with her. My mom has cancer and is aging. She is more relaxed during MILK visits and there is more opportunity to spend time and talk together. It's like being at home; there's more natural interaction. 
Some women described developing this comfort with caregivers with whom they had previously had little to no relationship, while others described repairing conflictual relationships with caregivers. Most women in this latter group described repairing relationships with their own parents. For example:

My mom was my best friend for years so for her to be completely out of my life for that long, I think just us being around each other and me being clean and sober and us being able to be around each other and re-form that bond made everything so much better...I can't imagine what it was like for her to see me with my kids... She got so used to me being not worthy of trust or being positive. I feel like I'm back to being that person I was before. I hope that it leads to us being back together again.

This mother described how she was able to repair her relationship with her mother as a result of time spent together during MILK visits and her own personal growth, which may or may not have been related to her participation in the MILK program (I address this in greater detail in the next section).

MILK visits. The majority of women reporting improved connections with caregivers attributed this improvement in some part to the special nature of MILK visits $(n=11 ; 79 \%)$. They described the visits as fostering a pleasant environment that facilitated comfortable interactions and shared rewarding experiences, which enhanced mothercaregiver relationships just as it did mother-child relationships. For example:

Before [my relationship with my children's caregiver] was just cordial, now it's more on a family level. It's because they visit more and we spend more time 
together bonding. Regular visits are too restrictive. It's being able to hug and bond and have the entire day to spend with my family.

This participant, focused on the more comfortable environment as well as the longer duration of MILK visits as contributing to improved relationships with caregivers. Four other women specifically mentioned the longer duration of MILK visits as a contributing factor to improved mother-caregiver connection. Moreover, three women referenced the physical contact permitted during MILK visits as a significant factor in strengthening connections with caregivers, just as it did with children. This likely reflects the fact that most caregivers are family members of the incarcerated mothers. One participant reflected on how even a simple gesture made a difference in her relationship with her mother:

I love [my mom] even more. Being able to be expressive physically...allows me to be more appreciative. I feel like the transition [home] is going to be much easier because of MILK because the interactions are much more like what they would be on the outside...MILK makes interactions more realistic, like just being able to wipe something off of my mom's face.

This participant described how the physical contact allowed during MILK visits helped her feel closer to her mother, and, as the theory of change model predicted would happen as a result of stronger mother-child relationships, she noted a belief that her improved relationship with her mother would help adjustment after release.

Improved communication with caregivers. A much smaller group of women $(\mathrm{n}=3$; $21 \%$ of those reporting improved connection to caregivers and $11 \%$ of those interviewed) 
linked the improvement they perceived in connection with their children's caregivers to changes in the way the pair communicated. Two of these women described learning to listen to the caregiver and express care and consideration for their experience. These women both reported learning these more effective communication skills through the preprogram parenting course. The other woman in this group reported that she and her mother (also her children's caregiver) began discussing difficult issues from their past including the mother's incarceration during the MILK participant's own childhood. She described how the MILK visit facilitated this processing of emotionally challenging material:

[My mom] was at the MILK visit too and she saw the interaction between me and my baby and I talked to her about some of the things that me and my baby talked about and that opened up the relationship with my mom. It was seeing the interaction between me and my baby and how close we were. I think it triggered something in the past like how we weren't close growing up and I rehashed old feelings. We talked about things that we had never talked about; my mom was in prison when I was a kid. It brought a lot of old feelings up that had never been talked about that we needed to talk about.

Here she described how the family-style nature of MILK visits created an opportunity for multi-generational interactions, which facilitated a meaningful discussion about being a parent in prison and facilitated relationship repair. While this participant's story was not typical, it was notable in the profound impact she described MILK as having on her family. 


\section{Research Question 2b: Do Mothers in the MILK Program Perceive Improvement in the Quality of In-Person Contact with Their Children's Caregivers as a Result of MILK? If So, What is the Nature of This Improvement and to What Do They Attribute the Change?}

As mentioned above, mothers connected the MILK visits to improvements in relationships with caregivers in two primary ways: 1) the opportunity MILK afforded incarcerated mothers to parent children during visits fostered a greater sense of parenting alliance with caregivers; and, 2) the different atmosphere of MILK visits facilitated increased comfort, which contributed to a greater sense of connection with caregivers. In this section, I detail the elements of the MILK visits that mothers mentioned as contributing factors to this connection-building atmosphere.

Relaxed environment. Four women (14\% of those interviewed) tied improvements in relationships with caregivers to the more relaxed and enjoyable environment provided by MILK visits.

[My relationship with my child's caregivers] has been wonderful. They need my help as much as I need theirs. MILK helped because it gave us time and put my family at ease. Instead of visitation with guards watching, our interactions are more like how a family interacts — playing games, laughing, and making new memories.

This participant reflected on how a pleasant environment that allows for shared rewarding experiences has helped her family continue to develop their shared story despite her incarceration. Other women who noted the relaxed environment as important in 
improving their relationships with caregivers also referred to this sense of normalcy as an important factor in this change. Participants also described how the more relaxed environment made it easier to have positive interactions with caregivers who had felt tense during regular visitation.

Visit duration. Four women (14\% of those interviewed) noted the longer duration of MILK visits as important in improving relationships with children's caregivers. These women described having more time to "bond" as well as increased time for discussion about the children. One woman reflected on how the longer visits allowed her mother to "remember to tell [her] everything" about the children.

Physical contact. As briefly described above, three women reported that being able to have physical contact with their children's caregivers was important in developing a better relationship with them. The children of these women were all being cared for by very close family members (mothers for two of the women and a sister for the other). All three of these women tied the physical contact to a sense of normalcy in the relationship. As mentioned above, one woman mentioned how connected she felt to her sister when she was able to reach over and wipe something off of her face during a shared meal.

One-on-one time. Lastly, two women specifically mentioned being able to interact with their children's caregivers one-on-one as important in building their relationship. One mother described how this allowed her privacy to speak to her child's caregiver about difficult subjects that she feared would get her family in trouble, such as drug use. The other woman described how the one-on-one time contributed to a sense of connection with her own mother: 
I get to talk to her too, about a lot of stuff. It's more like we are at home together.

We just get a lot more time together. It's like we have our own time too.

\section{Research Question 2c: Do Mothers in the MILK Program Perceive an Increase in the Frequency of Visits from Their Children's Caregivers as a Result of MILK? If So, to What Do They Attribute This Increase?}

Among interviewees, five women (18\%) reported an increase in frequency of visits from children's caregivers as a result of the MILK program. Three of these women reported that their children's caregivers visited more often because they preferred MILK visits to regular visits, including one caregiver who only agreed to visit with the children once the mother had joined MILK. Several of the mothers indicated an increase in contact resulting from improved relationships with caregivers. Two mothers specifically reported that caregivers began attending non-MILK visits in between MILK visits as a result of developing a closer relationship through the MILK program. An additional two mothers reported an increase in phone contact with caregivers since joining the MILK program, which reflected an improved relationship. One of these mothers attributed this increased phone contact to an improved relationship with the caregiver, which she believed they developed through MILK visits. The other mother believed that her daughter's caregiver began answering her phone calls because she saw that she (the mother) was taking more responsibility and putting more effort into parenting as a result of her joining MILK. 


\section{Research Question 3: Do Mothers in the MILK Program Perceive a Reduction in Parenting Stress as a Result of MILK? If So, to What Do They Attribute This Improvement?}

Of the 39 women who completed the Background and Program Questionnaire, 38 responded to the multiple-choice question "Since joining MILK, how much stress do you feel about being a parent?" Sixty-eight percent $(n=26)$ of these mothers reported experiencing less parenting stress than they had before joining the program (see Table 4). Moreover, among the 28 women interviewed, 22 (79\%) reported experiencing some form of improved personal wellbeing as a result of the MILK program and/or the parenting class. Twelve of these women (43\% of those interviewed) specifically described feeling less stress related to at least one aspect of parenting. The other 10 women in this group reported general improvements in mood, motivation, and hopefulness as a result of the program, but did not relate these changes specifically to changes in their feelings about parenting.

Reduced parenting stress. Among the twelve women who reported feeling less parenting stress as a result of MILK and, for some, the parenting class, four themes captured the nature of the improvements described. One third of these twelve women $(n=4)$ reported feeling less stress about being a mother because they developed a greater sense of confidence as a parent through the MILK program. Three of these four women pointed to the opportunity MILK visits afforded them to act as mothers for an extended period as the root of this increased parenting confidence. For instance: 
Table 4

Self-reported Changes in Parenting Stress Since Joining MILK

\begin{tabular}{lr}
\hline Reported parenting stress & $n(\%)$ \\
\hline A lot less than before joining & $19(48.7)$ \\
A little less than before joining & $7(17.9)$ \\
The same amount as before joining & $10(25.6)$ \\
A little more than before joining & $1(2.6)$ \\
A lot more than before joining & $1(2.6)$ \\
\hline
\end{tabular}

Note. Answers represent multiple-choice responses to question: "Since joining MILK, how much stress do you feel about being a parent?" Responses provided on Program and Background Questionnaire (Appendix D), administered to all 39 participants during group meetings at both facilities.

MILK allows me to step back into the parental role. It does wonders for my kids and for my self-esteem. Self-esteem is my issue, and MILK gives me the opportunity to parent. You feel like less of a parent inside [prison], so MILK allows us to feel confirmation of parenting. It's inspired me to be a productive citizen once I'm on the outside.

This participant described how her self-esteem suffered when her maternal role was threatened by incarceration, and how MILK helped rebuild her sense of self by providing regular opportunities to step back into that role during visits. In addition, two women in this group described feeling more confident about their ability to approach different issues with their children as a result of the parenting skills they learned from other MILK mothers and the parenting class. 
Another theme to emerge was that of increased connection with children contributing to reduced parenting stress. Four women reported that they felt less stress about parenting simply because they felt closer to their children. For example:

[My daughter] has gotten to know me better. It's impacted my behavior a lot. I've always been worried that she wouldn't know me, but that's not the story. I'm less worried about my relationship with her.

All four of these women reported that the MILK visits were essential in improving connection with their children. One of these women also noted that she began to feel this increased connection during the parenting class because she learned the importance of frequent contact and subsequently began calling and writing her children more often. In addition, some women $(n=4)$ described feeling more hopeful about the future of their relationships with children as a result of the MILK program. Three of these women tied this hopefulness to seeing strong relationships between other MILK participants and their children, while one woman reported developing more hope about her relationship with her entire family through the parenting course. Lastly, two women reported learning to tolerate the pain of separation from children more easily through the MILK program. For example, this participant described how MILK helped her tolerate the fact that her daughter had not attended any visits:

Even though I don't see her [MILK has] made me realize a whole lot of other things. Before I couldn't bear not seeing her, now I can. It's mainly being able to see the other children and parents interact. And I know that she knows that I love her. Regardless she knows that I love and miss her. It makes it easier too when we 
are in the group and I can talk about it and difficult situations, that helps a whole lot. And to see other people that are in the same situation that can offer support.

As she described above, this participant gained strength through the support she received from other participants and through her interactions with other participants and their families during visits. The other woman reporting increased tolerance for separation described how spending more and higher quality time with her children during MILK visits stopped her pattern of "cry[ing] every day because [she] couldn't be with them."

General improvement in well-being. Another set of MILK mothers $(n=10 ; 36 \%$ of those interviewed) reported feeling a general sense of improved well-being as a result of MILK but did not tie this to a sense of reduced parenting stress. For instance, this participant described how her participation in MILK provided positive feelings that propelled her personal growth:

MILK gave me all them good feelings, but I wanted to feel more so I didn't stop at MILK. I came further like into college. If I didn't do MILK I probably would have had a chance of not even taking college classes. It gave me a boost, gave me a desire to want a better life. I wanted more than I was getting from MILK and my family; I wanted them to be really proud of me.

Like this participant, three other women described how joining MILK gave them something to feel proud of, which improved their self-esteem. Some women $(n=5)$ also pointed to the positive feelings they felt during visits as the force behind the improvements in mood they experienced after joining MILK. Lastly, four women 
mentioned the importance of support from other MILK participants in developing a greater sense of wellbeing. For example:

[My mood] went up because I was going through a little bit after I had my first few visits and $[\mathrm{MILK}]$ just made me do better. It made me open up in MILK [group meetings]; it made me speak out. It felt good and I felt like as if we were in here together as a MILK family. I got a little insight, this is what made [my mood] go up.

This mother described how MILK brought about difficult, yet important, emotions regarding her children and how she felt a sense of comradery with other MILK participants that helped her manage these challenging feelings. She, like several other women, described her fellow MILK members as a family-like team that supports each other through the hardships inherent in incarceration, and she noted feeling an improvement in her mood as a result of joining this "family."

\section{Research Question 4: Do Mothers in the MILK Program Report Improved In- Prison Behavior as a Result of MILK? If So, to What Do They Attribute This}

\section{Change?}

Behavior change to meet program requirements. According to self-report questionnaire data, seventy-four percent $(n=29)$ of MILK participants reported that they intentionally improved their behavior to get into MILK and 56\% $(n=22)$ reported receiving fewer disciplinary "tickets" since joining the program (see Table 5). Moreover, all but three of the MILK participants interviewed reported that participating in the MILK program had a positive influence on their behavior in prison $(n=25 ; 89 \%)$. Of these 25 
women, 22 (79\% of those interviewed) reported that their behavior had improved as a direct result of program requirements for entry or continued participation. The three women who did not endorse behavioral improvement related to MILK all described themselves as generally well-behaved and engaged before MILK and therefore as having little need to improve on their behavior before or during the program.

Fifteen women (54\% of those interviewed) reported that they had actively worked on improving their behavior in order to meet the entrance requirement of having no "charges" or "tickets" for at least six months. Sixteen women (57\% of those interviewed; nine of whom also reported changing behavior for program entry) reported that being able to stay in MILK and receive the associated privileges was their main motivation for remaining ticket-free following acceptance into the program. Nine (56\%) of these participants who reported maintaining good behavior in order to avoid losing MILK privileges focused on the loss they would feel if they could no longer participate in MILK visits. Like the following participant, these women described placing a high value on the MILK program and its role in their lives:

I enjoy being in MILK. I think it's essential to keeping up with my kids' growth. I got no more tickets. I haven't had a ticket in eight years and MILK is the most important part of that. I don't want to risk anything to get thrown out of MILK.

The other seven women who reported maintaining good behavior in order to avoid losing MILK privileges reported finding motivation to behave well not in their own potential losses, but rather, in the loss their children would experience if they were to lose MILK privileges. For example: 
Once I had my MILK visit it made me not even want a regular visit anymore. I had the extra time with my baby and it made me see her in a different light...It makes you think about what I'm messing up if I do get in trouble and go to seg. Not just for me but for my baby. Like if she doesn't come she wants to know what happened in the visit. That's not worth messing up over an argument with an officer.

This participant reflected on how her child looked forward to MILK visits and would be disappointed if she and her mother were prohibited from participating in one.

Table 5

Self-reported Behavior Change Among MILK Participants

\begin{tabular}{lr}
\hline Perceived behavior change & $n(\%)$ \\
\hline Did you work to get fewer tickets to get into MILK? & $22(56.4)$ \\
Yes, MILK was main motivation for getting fewer tickets & $7(17.9)$ \\
Yes, MILK was part of motivation for getting fewer tickets & $10(25.6)$ \\
No, I never got many tickets so it wasn't an issue & $3(7.7)$ \\
How many tickets have you received since joining MILK? & $8(20.5)$ \\
A few more than before joining & $2(5.1)$ \\
The same amount as before joining & $20(51.3)$ \\
A few less than before joining & \\
A lot less than before joining & \\
\hline
\end{tabular}

Note. Responses were provided on the Program and Background Questionnaire (Appendix D) by MILK participants during group meetings at both facilities. All 39 current participants at both facilities completed the questionnaire. 
While meeting program requirements emerged as the most significant motivator for developing and/or maintaining good behavior, a number of women also highlighted other aspects of the MILK program that facilitated this positive behavior. Below, I review four additional influences on behavior identified by interviewees.

MILK as a catalyst for personal growth. Nine women (32\% of those interviewed) painted a picture of personal progress in which MILK served as a catalyst for change by providing an opportunity to work towards and achieve a goal which then served as a source of pride. For example:

[My behavior has] tremendously changed. You have an incentive to carry yourself positively. It's easy to succumb to surroundings here. MILK gives a reason to carry yourself well and gives you something to work on. It's very important in here to always strive for something and avoid complacency. I like giving back and being a MILK mom. I take pride in taking pictures in the compound, and I want my attitude to reflect what I'm working for and to be an example to others that aren't in MILK.

This mother described how being a MILK mom improved her self-concept by giving her a sense of meaning and self-confidence. Moreover, she explained how maintaining this admirable identity provided her with motivation to act in a prosocial manner in an environment that pulls for antisocial behavior. Other women focused more on how their participation in MILK facilitated participation in other activities that promoted their personal development. For example: 
[My behavior] improved. I just started doing better things, I got a full-time job at the library, got a college scholarship. Things just got progressively better. If it wasn't for MILK and being able to have that time with the group and the children I wouldn't have been as hopeful.

This participant reflected a common theme that emerged among the mothers: MILK provided a sense of hope for the future, and that hope fueled more participation in other healthy activities and discouraged negative behaviors.

Meeting community expectations. Eight women (29\% of those interviewed) described how other inmates as well as prison staff had higher expectations for the behavior of MILK participants, as they were seen as role models. Like the following participant, these women reported making changes in their behavior in order to meet these higher expectations:

I've always felt like I tried to keep myself out of trouble. Being in MILK though you feel like people look at you different if you are a MILK mom, like they expect something more or different from you if you are a MILK mom. I believe that MILK moms are held to a higher standard than everyone else. So, I'm less opinionated, more laid back, because of MILK and college.

Support from other members. Six women (21\% of those interviewed) cited the support they received from other MILK participants both in and outside of MILK-related activities as an important influence on their behavior. For example, the following participant described how she was inspired to engage in more prosocial activities by her fellow MILK participants: 
I slipped a bit once I got in [to MILK] but the other moms pulled me up and I've been infraction-free since then. Other MILK moms were taking college classes and I was very interested. So, that's when I got into every program that I could possibly get in. I got my Associate's and am working on my Bachelor's...And now I've been an influence on other moms because now I'm one of the oldest MILK moms. They were a positive influence on me and now I've become a positive influence on others.

While this mother reported finding motivation to pursue her goals in her peers, other participants focused on how peers in the program helped remind them to refrain from negative behaviors. One mother reflected on how she actively tried to help other MILK participants in this way:

I've seen a lot of MILK moms change. They come in very young and wild and then change. If I see another MILK mom getting in trouble I walk up to them and say "come on" or we just say "MILK, MILK" as a reminder. I'll say "Do you want even more time, do you want to tell your child why you're not coming home on time, or why she can't come to the milk visit?"

This mother explained how, for some participants, the relationships they developed with other MILK members during MILK-related activities served as an important protective factor outside of these activities when it was most difficult to avoid trouble with other inmates. She reflected on how some MILK members served as checks on each other's behavior by helping each other foresee how the behavior would negatively impact participation in the MILK program and their children. 
Focus on family. Lastly, five women (18\% of those interviewed) described how the closer relationships they had developed with family through the MILK program helped them maintain good behavior. For example, this participant explained how she had worked on her patience with others in an effort to address behaviors that had previously interfered in her relationships with her family, including drug use:

I realized that spending more time with my kids and mom and grandmother, I've just realized everything that I'm going to have to take on when I get home. It's really pushing me to explore lots of different ways of confronting issues that caused me to use [drugs] before. It's all coming together to...I mean I very rarely get short with people, but even less so now...It's all coming together to make things a lot better for me.

Moreover, two participants in this group specifically noted that the pre-program parenting class helped them understand the importance of prioritizing their children. For example:

When I first got here I didn't like the way the officers treated you so I was getting tickets for talking back. But when I got into parenting [class] I realized that this is how it is. I just have to deal with it and talking back will get me nowhere. Parenting helped me realize you have to put your kids first.

This mother described how the parenting class helped her understand that prioritizing her children would sometimes mean refraining from behaviors that would bring more immediate satisfaction (i.e., responding to a rude comment from an officer).

\section{Research Questions 5a-5e: Do Institutional Representatives View MILK as a Beneficial Program for the Institution, Perceive Improvements in Inmate Behavior}




\section{and Well-Being as a Result of MILK, and/or Perceive Reductions in Sentence Length and/or Recidivism Among MILK Participants?}

Staff interviews were conducted in an earlier stage of the evaluation during which the project was geared towards a study of program implementation rather than the perceived efficacy of the MILK program and mechanisms of change. As such, staff interviews provided rather limited insight into program effects. However, staff interviews did provide validation for inmate perceptions in several important areas.

Program efficacy and mechanisms of change. All of the staff members interviewed $(n=5)$ expressed support for MILK as a program that benefitted both inmates and the institution. This attitude was reflected poignantly by the director of institutional programming at VCCW:

The first time I saw a visit I got a warm feeling. It was very rewarding to see the excitement in the offenders' eyes and their happiness and joy.

Moreover, in support of participants' perceptions, staff members also identified perceived effects in three of the main proposed areas of change: improvement in the mother-child relationship, improvement in the mother-caregiver relationship, and improvement in behavior. None of the staff interviewed specifically noted perceived changes in inmate wellbeing other than the happiness experienced during visits, as is reflected above. Only one staff member mentioned the impact of the program on recidivism; the director of institutional programming at VCCW believed that MILK "enables [participants] to focus on reentry by focusing on the mother role. It keeps the connection and the seed planted about feeling like a real mom one day." No information was available on actual 
recidivism among MILK participants. Similarly, staff did not have information related to sentence length. Below I detail the three mechanisms of change on which staff were able to elaborate.

Mother-child relationship. Similarly to participants, all five staff members mentioned the role the program played in strengthening or maintaining mother-child bonds as key to its efficacy. For example, the programming specialist from VADOC noted:

It's important to continue the bond with children during incarceration. [MILK is] one tool in that process. It encourages the presence of mothers in their children's lives and fosters love.

Staff echoed participants' reports that the specialty visits were the primary means through which the program influenced mothers' relationships with their children $(n=5)$. For example, when asked how she believed the visits fostered improved mother-child relationships, the MILK sponsor at VCCW stated:

It's the one-on-one nature of the visits, there's more interacting throughout the visit, there's shared meals, and joy for moms, they get to learn about children's likes and dislikes. They can really enjoy themselves - not like in the quiet, crowded normal visit. They get more freedom. The visit allows more time with children and allows them to see how they handle the child. They get an idea of how they will react on the outside.

Here, the program sponsor - the only staff member whose presence is required at every MILK visit - points to the importance of several aspects of the visits that also emerged as 
important mechanisms of change among participant reports: one-on-one time with children, shared rewarding activities, the more relaxed environment (i.e., more freedom), increased time together, and the opportunity to parent. Additionally, the director of institutional programming at VCCW underscored the importance of the relaxed environment, as did many MILK participants:

Interactions [between mothers and children] are easier because it's a relaxed atmosphere. The regular visit room is difficult—-there's not a lot of contact, you have to be seated, no games. It's harder to keep children well behaved in a regular visit room. In MILK they can be more like children.

Furthermore, like a number of MILK participants, a security guard who had worked many MILK visits pointed to the respect mothers earned from children during MILK visits as important to the development of the mother-child relationship:

MILK is popular. [Participants want to do it] so they don't lose the bond with their kid. You can easily lose your bond with a child in here. Visits allow them to show their children that they are trying to better themselves to come home to them. They can show them that mom is working hard.

In addition, the VADOC program specialist noted the importance of physical touch during the visits, as did so many participants interviewed:

During visits kids can see mom with their own eyes. They can crawl in mom's lap, smell and touch her. They remember all those little things. Touch means so much. 
In sum, in reference to the mother-child relationship, themes that emerged among staff who provided detail regarding perceived mechanisms of change closely matched those reported by MILK participants themselves.

Mother-caregiver relationship. In support of participants' reports, four of the five staff members interviewed (80\%) specifically noted a perception that MILK had a positive impact on mothers' relationships with their children's caregivers. Again, staff focused primarily on how the mother-caregiver relationship was improved through the specialty visits. With regard to the visits, staff noted similar mechanisms of change to those that emerged among participants. The MILK sponsor at VCCW described caregivers as "more open" during visits because "they can step away to have private conversations," again pointing to the importance of one-on-one time. She also pointed to the freedom mothers had to parent children as important in that it "gives caregivers a break." She specifically noted seeing caregivers "observing" mothers and children from the side lines at visits. Moreover, the security guard interviewed provided a unique look into the perspective of caregivers (she reported speaking to caregivers at many visits):

Caregivers say they like the women seeing what it's like to have the kids all day long. The caregivers sit back and let mom see what it's like so they can see. It helps some of the moms appreciate the caregiver.

Here, she provided some evidence that caregivers themselves find the MILK visits helpful in two important ways: they provide a break from the children and they allow mothers to understand the caregiver's experience and potentially approach the caregiver with more appreciation. This is potentially indication that the improvements in parenting alliance reported by participants may be felt by caregivers as well. Lastly, the director of 
institutional programming at VCCW pointed to a mechanism of change he perceived to be at play in the development of the mother-caregiver relationship that was not mentioned by any participants, nor hypothesized in the theory of change model. He noted that in order to have a highly-coveted MILK visit with their children, mothers had to interact effectively with caregivers for coordination of scheduling. He was referring to the fact that, whereas regular visits are offered continuously, allowing visitors to attend without coordinating with the inmate, MILK visits are set far in advance and are only available on specific days, which requires more coordination of schedules. He felt that this encouraged mothers to put effort into building a better relationship with their children's caregivers.

Behavior. All staff members interviewed $(n=5)$ noted the impact of MILK on participants' in-prison behavior, confirming participants' reported improvements. The director of institutional programming at VCCW noted that "getting charges doesn't happen often in MILK." He hypothesized that women in MILK have better behavior because "it encourages the mom to be a better person; in order to be in the program, they have to be good." The MILK sponsor at VCCW noted that "95\% of the [MILK participants] control their behavior well;" however, she also noted that "five of the 25 participants are currently on the borderline of having too many charges." It was unclear what accounted for this discrepancy. She echoed participant reports when describing the mechanisms of change she perceived to be influencing participant behavior:

They have to walk the straight and narrow in population to get visits. They are more closely watched. They have to meet criteria to stay in the program and are very upset if they get a charge that threatens MILK participation. MILK gives 
them structure and boundaries. And they don't want other MILK members to know.

Here, the sponsor pointed to the following mechanisms of change related to improved participant behavior: meeting expectations the community has of MILK participantsinterestingly she described this as being "more closely watched"-meeting the expectations of other MILK participants, and behavior requirements to stay in the program. The sponsor at FCCW underscored how influential the expectations of other MILK participants can be on participant behavior. She described noticing this increasingly as older members have been transitioning out and newer members have become the majority in her group.

Most in MILK see it as a privilege. But it's harder for that to happen without old timers to season the new offenders so that it's not entitlement. I have a current issue with offenders feeling like they are entitled to MILK because they worked really hard to get charge free. Some people totally get it and are happy with whatever they get, others feel entitled to visits.

Here, she outlined the role veteran members typically played in setting the expectations that all members would treat visits as a privilege to be valued and protected by behaving appropriately. She described watching this mechanism of change weaken as veterans of the program have left (typically due to their children aging out). This may point to the importance of fostering a culture of respect for the program in order to facilitate improvements in inmate behavior. Lastly, in contrast to participants, none of the staff members interviewed noted the influence of entrance requirements on inmate behavior. 


\section{CHAPTER V}

\section{Discussion}

This study sought to shed light on the Mothers Inside Loving Kids (MILK) program - a specialty visitation and parenting training and support program for inmate mothers that has been active in two Virginia state prisons for over 30 years. I proposed a complex theory of change model (see Figure 2) detailing the hypothesized mechanisms of change through which a program of this nature might contribute to a variety of positive outcomes for incarcerated mothers, their children, and their children's caregivers. I then used in-depth qualitative interviews with MILK participants and a small number of institutional staff, in combination with a selection of quantitative measures, to explore program efficacy and relevant mechanisms of change as perceived by those directly involved in the program. Below, I compare findings against each proposed mechanism of change.

\section{Mechanisms of Change}

Mechanism of change 1. In "Mechanism of Change 1," (represented by Pathway A in Figure 2) I proposed that the program might lead to healthier mother-child relationships via improved visit quality and increased visit frequency. The following findings contributed to a more nuanced understanding of perceived effects and the specific program components to which participants attributed changes, which is visually

depicted in Figure 8. In keeping with the limited research in this area (Snyder et al., 2001), results clearly indicate that MILK members perceived improvements in relationships with their children as a result of their participation in the MILK program, 
with $89 \%$ of participants interviewed directly connecting improved relationships with children to their participation in MILK. More specifically, mothers reported developing healthier communication with children (64\%), getting to know children better (43\%), and achieving more appropriate parent-child roles (32\%) as a result of the program. Moreover, as hypothesized, improved visit quality was instrumental in this perceived relationship improvement with 100 percent of the women who reported improved relationships with children since joining MILK describing the specialty visits as the key factor in this improvement.

Although I have no direct evidence of child outcomes related to MILK visits, this finding is in keeping with Poehlmann et al.'s (2010) assertion that the context of visitation with incarcerated parents is key in determining the influence it has on children. Poehlmann et al. (2010) suggested that negative outcomes observed in children following visitation with incarcerated parents were likely related to frightening visit conditions and strict regulations on behavior that precluded children from feeling safe and/or comfortable rather than from exposure to the incarcerated parent, as some have suggested. The perceptions of the incarcerated mothers I interviewed support this hypothesis. The majority of the participants interviewed reflected specifically on the fear and discomfort they saw in their children during regular visits, and noted how this interfered in their ability to connect with them. Moreover, $46 \%$ attributed a sense of improved connection with their children to the fact that MILK visits were held in an environment in which children could feel comfortable and even enjoy themselves, which they held in contrast to regular visitation conditions. 
Participants identified the following as factors that contributed to children's comfort and enjoyment during MILK visits: the ability to physically touch each other, availability of child-friendly activities, ability to speak with mothers privately, the presence of other children, reduced chaos and noise (as compared to regular visitation areas), lack of restrictions on movement, presence of "friendly" officers, and availability of outdoor space (only available during some visits). Of these factors, the allowance of physical contact, availability of child-friendly activities, and ability to interact one-on-one emerged as the factors cited most often by participants as facilitating a comfortable experience for children. Moreover, results indicate that according to $36 \%$ of participants interviewed, MILK visits were so successful in reducing the discomfort associated with prison visitation that they allowed for a sense of normalcy among their family. For this group of participants, this sense of ease and normalcy were important in several ways. Participants reported that it allowed them to get to know their children as they are during normal activities of daily life. In addition, it facilitated shared rewarding experiences between mother and child as the atmosphere was conducive to positive interactions and offered opportunities for joint activities.

These results clearly indicate the perceived benefits of a more relaxed, childfriendly environment for visitation between children and their incarcerated parents. However, I posited that in order to foster a healthy relationship between an incarcerated mother and her children, simply creating a better visitation environment might be insufficient. Given evidence that incarcerated parents, namely fathers, demonstrate problematic parenting approaches (Kjellstrand \& Eddy, 2011) which might preclude healthy interactions during visitation, I suggested that a specialty visitation program 
without a parenting intervention of some kind might have limited benefit for children. I posited that a parenting intervention in combination with specialty visitation would provide an opportunity to learn and then practice newly acquired skills—a suggestion bolstered by prior findings that gains in skills were limited among incarcerated parents taking a parenting course as they were unable to engage with children outside of the classroom (Block et al., 2014). The MILK program is a step towards this ideal. All MILK participants are required to complete a parenting course prior to program entry. However, there is no standardized course and as such, participants have completed a variety of different courses making an evaluation of this pre-program component difficult. MILK also provides indirect parenting interventions through group support and weekly meetings which mothers are afforded the opportunity to discuss parenting issues with each other. In

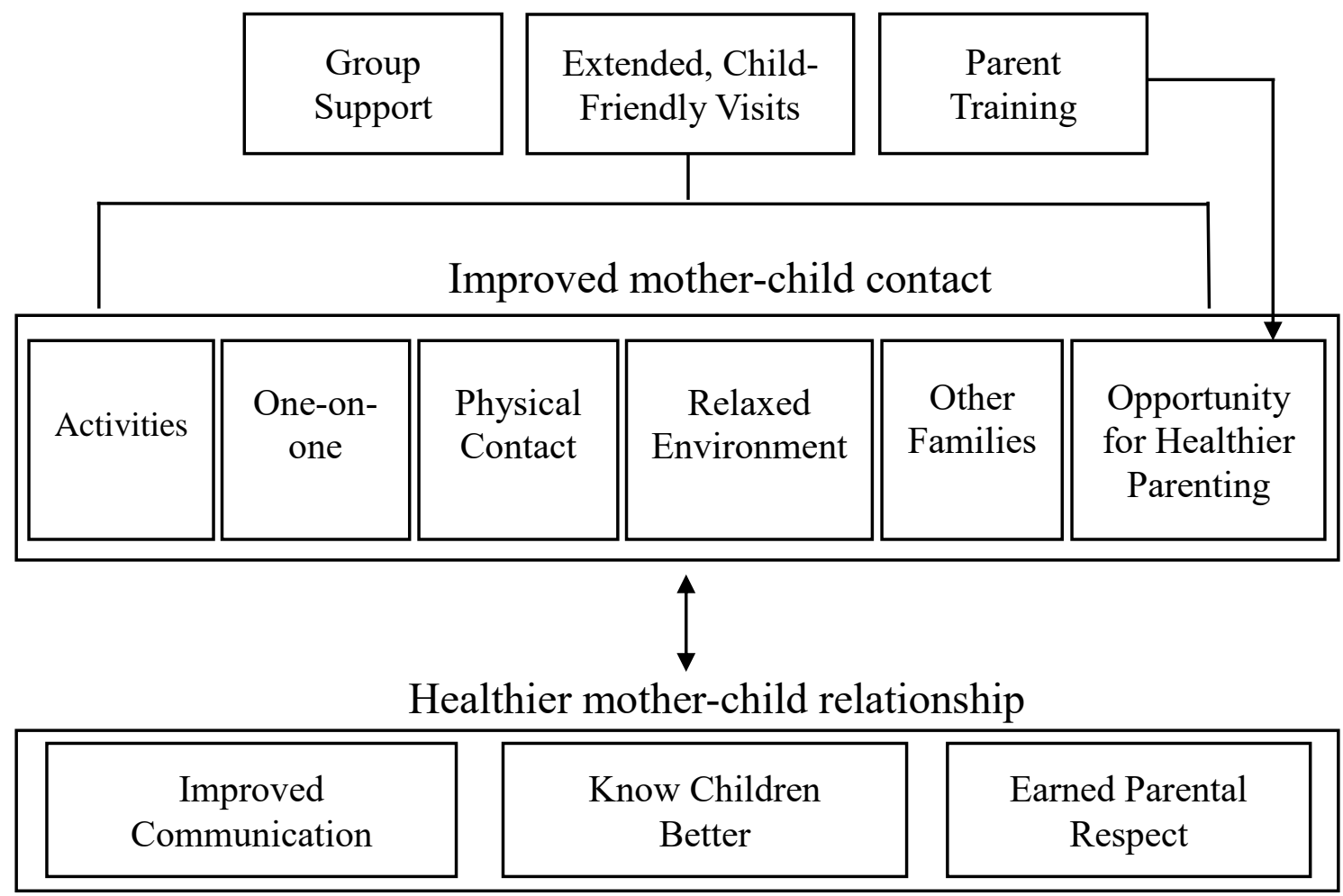

Figure 8. Visual representation of perceived changes in mother-child relationships and contributing program elements according to inmate MILK participants. 
support of my hypothesis, a number of participants described how MILK visits provided an opportunity to act like a parent and thus develop a healthier relationship with their children in which they felt more respected as the parent. Unlike regular visitation, the laxer MILK visits allow parents to interact with children privately (i.e., away from caregivers). Nine mothers (32\%) described how being alone with children allowed them to step into the role of parent and provide instruction and discipline as needed during activities. Moreover, several mothers reported that caregivers took advantage of these laxer regulations and explicitly stepped back from parenting encouraging mothers to take over during MILK visits. In addition, thirteen of the 28 mothers interviewed (46\%) pointed to the opportunity for private interactions as a key contributing factor to improved communication and a deepening of relationships with children. And, a small, yet notable, group of participants were aware of bringing newly learned parenting skills to these private interactions with children; ten women (36\%) specifically noted that they were better equipped to manage interactions with children as a result of learning healthier parenting skills during the pre-program parenting course.

However, findings on the parenting attitudes of participants caution against overinterpretation of these self-reports; the majority of MILK participants reported parenting beliefs in the "medium-risk" range on all parenting attitude domains measured by the AAPI-2 (see Table 1; Bavolek \& Keene, 1999). As such, despite participants' beliefs that the one-on-one interactions afforded by visits were a boon to the mother-child relationship, it remains unclear whether or not the opportunity to parent children away from caregivers is actually beneficial to children participating in MILK visits. These results are perhaps unsurprising given the wide variety of parenting courses participants 
took to meet program prerequisites, and the increased difficulty of changing parenting skills and attitudes among this particularly challenging population (Loper \& Novero, 2010). Unfortunately, I am unable to provide information regarding impactful and less- or non-impactful elements of the parenting training participants received as a careful study of the various parenting courses taken was beyond the scope of this evaluation. As a result, it is possible that the ten women who endorsed the parenting course as helpful in improving relationships with children all took the same course and that those who did not endorse this took different courses that were less effective. Alternatively, a host of other factors may have influenced which participants were able to make improvements in their parenting approach. For instance, participants who improved their parenting abilities may have been those who had stronger relationships with children prior to incarceration, or who received more visits and therefore had more opportunities to practice newly acquired parenting skills. I am not able to make these distinctions with this data.

It is also possible that participants gained improved parenting skills, as a result of the parenting class or the MILK group, of which they were unaware or that they failed to mention during the interview. Moreover, it is possible that participants developed improved parenting skills that were not captured by the AAPI-2; evidence for this comes from the only other evaluation of the MILK program (Moore \& Clement, 1998), which found that while participants showed no significant improvements in parenting attitudes as measured by the AAPI, they did demonstrate significant improvements in their understanding of behavioral management techniques. Given that the measure has never been validated with an incarcerated sample, these findings may reflect issues with the AAPI-2's validity among this population, which is known to be distinct from the general 
population of parents in several ways (e.g., increased incidence of limited cognitive abilities and difficult family background, as well as limited exposure to children). For example, it may be that incarcerated parents have considerably less insight into their own parenting beliefs given a host of factors, which may undermine the validity of the selfreport measure.

In addition to my hypothesis that the MILK program would lead to improved visit quality, I hypothesized that this improvement in the contact experience would lead to increased visit frequency and that this relationship would be recursive. Results provided considerably limited support for this hypothesis: only 21 percent $(n=6)$ of women interviewed reported that their children visited them more frequently since joining MILK. Of these six women, five reported that their families had not visited at all or had visited very infrequently prior to joining MILK and had become more willing to visit as a result of the improved visits offered by the program. Given the considerable obstacles to visitation facing the majority of families of incarcerated women (i.e., financial stress, long distances from prisons, lack of transportation; Christian et al., 2006) it is possible that families of the women interviewed did experience an increase in the desire to visit but could not overcome these obstacles in order to act on this. After all, while the program may increase motivation to visit, at this point in time it in no way reduces the financial burden associated with visitation (at the program's onset, community members provided free transportation to family members). It is also possible that family members did not experience MILK visits as positively as the incarcerated mothers I interviewed and were therefore not motivated to attend visits more frequently. 
Mechanism of change 2. In "Mechanism of Change 2," (also represented by Pathway A in Figure 2), I proposed that the program would lead to an improved parenting alliance (Weissman \& Cohen, 1985) between participating mothers and their children's caregivers via improved visit quality and increased visit frequency between incarcerated mothers and caregivers to children's wellbeing (Loper et al., 2009; Loper et al., 2012; Poehlmann et al., 2008). According to Weissman and Cohen (1985) co-parents with a strong parenting alliance are mutually invested in children, value each other's involvement with children and judgments related to them, and communicate with each other about childrearing in healthy ways. I suggested that these ideals may be particularly difficult for incarcerated mothers and caregivers to achieve given a plethora of barriers including dysfunctional relationship history, limitations on contact and communication, uneven division of responsibility and labor, and the incarcerated mother's lack of exposure to the children. I posited that the MILK program might encourage a greater degree of alliance between participating mothers and their children's caregivers by reducing these barriers.

As depicted in Figure 9, which illustrates perceived changes reported by participants and associate program elements, these findings provide some support for this hypothesis with $46 \%$ of mothers interviewed reporting that they strengthened at least one aspect of the parenting alliance with their children's caregiver as a result of the MILK program and/or the pre-program parenting course. As expected, these women described how various aspects of the program and pre-program parenting course helped reduce the barriers to a healthy parenting alliance with children's caregivers. They reported that increased contact with children as well as learning about the challenges facing caregivers 
in the parenting course and, in some cases, from other MILK participants, improved their understanding of the caregiver's experience, which led to increased respect. Moreover, participants reported that the opportunity they had to parent children during MILK visits contributed to a sense of shared responsibility with caregivers. In addition, mothers reported developing healthier communication with caregivers as a result of skills learned in the parenting course and from other MILK participants who had experienced similar challenges. Notably, of all the mechanisms of change examined, the parenting course emerged as most influential on the mother-caregiver relationship. Lastly, a small group of

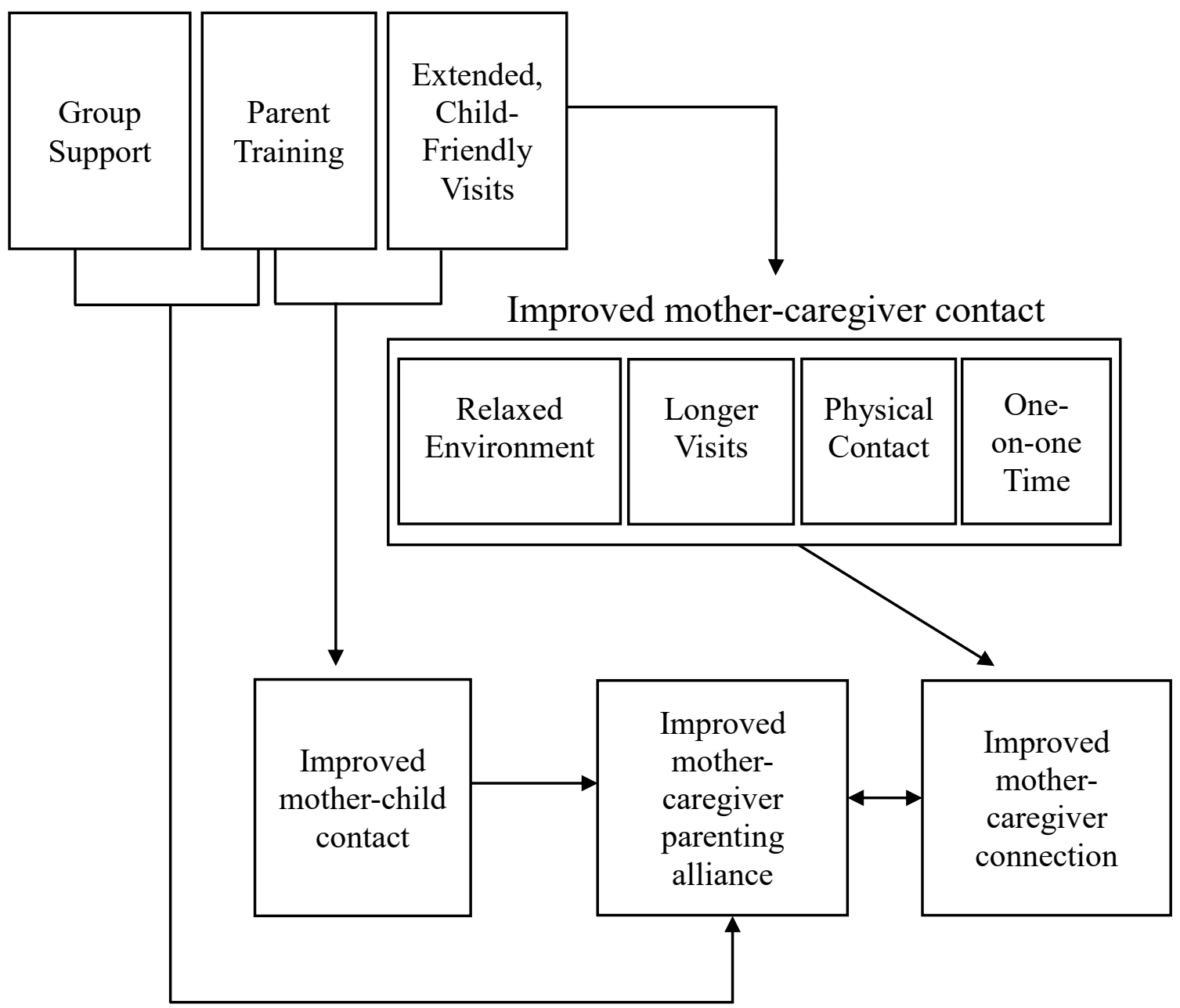

Figure 9. Visual representation of perceived changes in mother-caregiver relationships and contributing program elements according to inmate MILK participants. 
mothers reported that through their participation in the MILK program, caregivers saw them as more invested in their children, which strengthened the sense of mutual investment that is key to a healthy parenting alliance.

While less than half of participants believed that the MILK program and/or parenting course contributed to an improved sense of parenting alliance with caregivers, a sizable minority indicated that this intervention does in fact improve perceived parenting alliance for some mother-caregiver dyads. Moreover, seven women reported that they developed an improved connection with caregivers as a result of the program but did not speak directly to the parenting alliance. However, they provided evidence that the program helps participants reduce a considerable barrier to parenting alliance - the oftendysfunctional pre-existing relationship between the mother and caregiver. These mothers attributed this improved connection primarily to the relaxed environment of the MILK visits, which fostered positive interactions, echoing the perceived benefits of this visit environment on the mother-child relationship, although this evidence was not as robust.

As I had with the mother-child relationship, I hypothesized that the improvement in contact experience between mothers and caregivers would lead to increased visit frequency and that this relationship would be recursive. And, as I found regarding the mother-child relationship, there was very limited support for this hypothesis with only five women (18\%) reporting that caregivers visited more since joining MILK. In contrast to the results regarding visit frequency with children, this finding is perhaps expected given that less than $50 \%$ of participants interviewed noted improved visit experiences with caregivers, while $100 \%$ noted improved visit experiences with children. If it is the case that the improved visit environment has less impact on mother-caregiver 
relationships than on mother-child relationships, as the perceptions of the mothers interviewed might suggest, this could explain the discrepancy between the number of women noting improvements in visit quality with children and the number noting increased visits with children. For, children cannot get to visits without their caregivers. Alternatively, as I suggested previously, this may be a reflection of the many barriers to visitation among the families of the incarcerated.

Mechanism of change 3. In "Mechanism of Change 3," represented by Pathway B in Figure 2, I hypothesized that an intervention targeting improved and more frequent contact experiences between incarcerated mothers and their children as well as their children's caregivers would contribute to improved wellbeing among incarcerated mothers. This hypothesis stemmed from evidence that stress related to parenting (e.g., worries about children's wellbeing, guilt about parenting competence) is prevalent among incarcerated mothers and contributes to depression and anxiety (Houck \& Loper, 2002; Loper et al., 2009), as well as evidence linking increased contact with children, improved relationships with children, and stronger parenting alliances with children's caregivers to reduced parenting stress among incarcerated women (Loper et al., 2009).

Results provide relatively strong support for this hypothesis, and suggest that reductions in parenting stress experienced by participants stemmed mainly from interactions they had with children during the specialty visits. Sixty-seven percent of mothers who completed the Background and Program Questionnaire reported experiencing less parenting stress than they had before joining the program. And, among interviewees, $43 \%$ specifically noted feeling less stress about parenting. In particular, half of these women reported feeling more competent as a parent as a result of having the 
opportunity to parent their children during MILK visits. Additionally, as the literature suggested (Loper et al., 2009), a smaller group of women $(n=4)$ linked reductions in parenting stress to feeling more connected with children, which they all attributed to the specialty visits. There was also evidence that the group setting of the MILK program (i.e., regular group meetings and repeated shared visits with the same women and their families) helped some mothers manage stress related to separation and uncertainty about their family's future. Women who made this connection described how seeing other women have positive interactions with children fostered a sense of hope even when their own relationships with children were sources of stress. Lastly, two women made note of how the group members provided support that helped them tolerate the pain of separation from their children.

Findings also indicate a direct pathway from the program to improved wellbeing among participants that is not necessarily mediated by a reduction in parenting stress. Thirty-six percent of women interviewed perceived an improvement in their overall happiness as a result of participating in MILK. As has been true throughout these findings, most women in this group tied improvements in their happiness to the MILK visits and the positive mood they experienced during these experiences. Additionally, the group support involved in the program again emerged as a notable contributing factor with four women pointing to this as the source of their improved mood. In addition, some women focused not on the nature of the program itself, but on joining MILK as an achievement that led to improved self-esteem and an increased sense of meaning and direction. As depicted in Figure 10, taken together, these findings provide some evidence that the MILK program contributes to improved maternal wellbeing by reducing 
parenting stress, as I predicted, as well as more directly by providing positive, selfesteem-building experiences, which was not part of my original model. However,in contrast to my prediction, participants did not report feeling less parenting stress or experiencing a boost in overall wellbeing as a result of improved relationships with children's caregivers. Instead, they connected these improvements to relationships with their children and/or the other MILK participants. Given findings indicating that for some the MILK program contributed to improved relationships with children's caregivers, the fact that women did not mention this as a source of reduced stress is surprising. It is

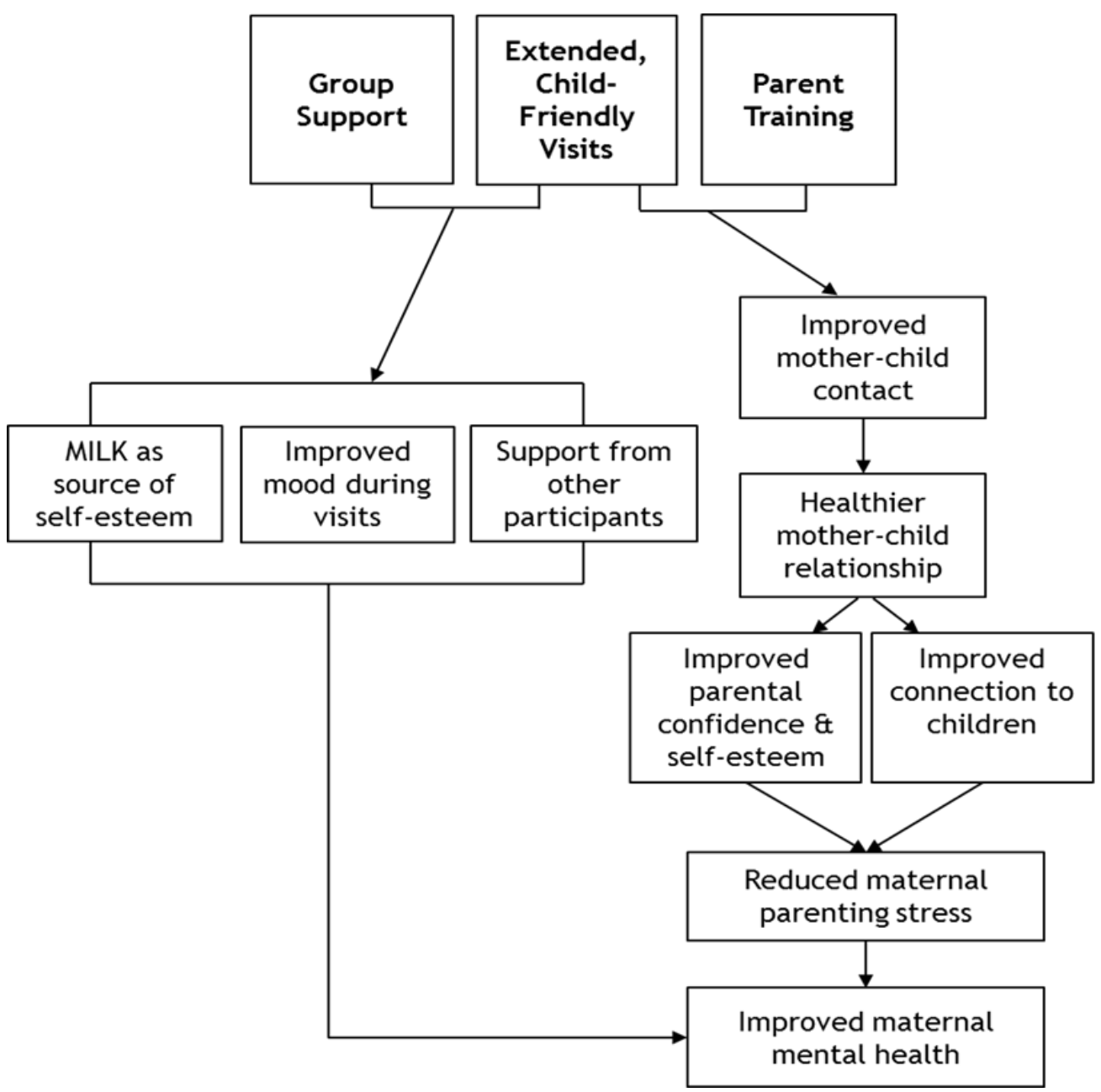

Figure 10. Visual representation of perceived changes in participant wellbeing and contributing program elements according to inmate MILK participants. 
possible that experiences and relationships with children are so much more impactful than experiences with caregivers that interviewees focused on this to the exclusion of their relationships with children's caregivers, which may have contributed more mildly to improved wellbeing.

Mechanism of change 4. "Mechanism of change 4," illustrated by Pathway C in Figure 2, represents the predicted positive impact of the MILK program on participant's in-prison behavior. I predicted that a program of this nature would contribute to improved behavior among its members given evidence linking increased contact with children to improved inmate behavior (Loper et al., 2009; McClure et al., 2015) as well as institutional requirements for inmate behavior to enter and maintain status in the program. Inmates must be "ticket free" for at least six months prior to entry and must remain ticket-free in order to receive MILK visits. Moreover, if women commit serious

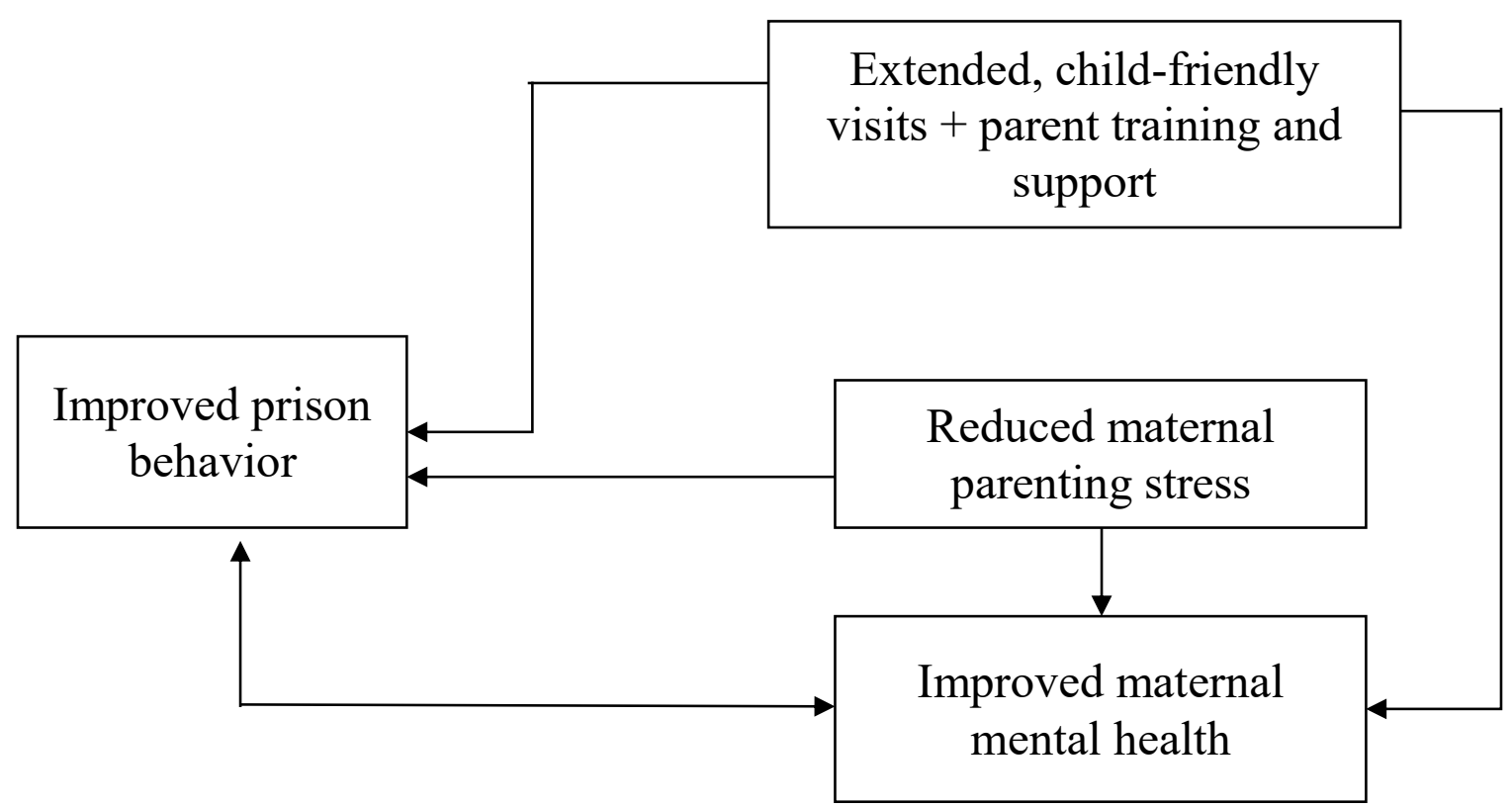

Figure 11. Visual representation of perceived changes in participant behavior and contributing program elements according to inmate MILK participants. 
infractions or receive a number of more minor tickets, they are dismissed from the program entirely. Results indicate that the MILK program had a significant influence on the behavior of many participants: On the Background and Program Questionnaire, seventy-four percent of all MILK members reported that they had intentionally improved their behavior in order to be eligible for program entry.

And, fifty-six percent reported receiving fewer tickets since entering the MILK program. Moreover, $89 \%$ of participants interviewed reported that their behavior had improved as a direct result of their participation in MILK. The majority of these participants focused on being able to attend MILK visits as their primary motivation for maintaining good behavior. Interestingly, nearly half of these women found motivation in the loss their children would experience if they lost visitation privileges in MILK, rather than the loss they themselves would feel. This was not a mechanism of change I had anticipated and suggests that for some women, MILK helped them see the impact of their negative behavior on their children — insight that eludes many inmate parents — which motivated good behavior.

As depicted in Figure 11, reports from interviewees confirmed my hypothesis that behavioral improvements among participants would stem from program requirements as well as improvements in relationships with children; however, program requirements emerged as a much more influential factor as only five women specifically pointed to improved relationships with children as contributing to improved behavior. Given findings that the majority of interviewees perceived improvements in relationships with children and that a significant number of participants perceived improvements in mood and overall wellbeing, which they attributed to positive experiences in MILK, it is 
somewhat surprising that improvements in behavior would not follow a similar pattern. However, this is perhaps less surprising when considering the more direct and intentional nature of the relationship between program requirements and behavior changes made to meet those requirements, as compared to behavior changes made, possibly unknowingly, as a result of improvements in relationships with children. Again, this may reflect a more obvious motivator of change overshadowing a contributing factor that is less obvious to participants themselves. Of course, it is also possible that the majority of participants interviewed did in fact see no connection between improved relationships with their children and their own improved behavior.

Results also provided information about additional mechanisms influencing participant behavior that I had not anticipated. Perhaps most surprising among these unforeseen mechanisms of change was the influence of higher expectations for MILK members' behavior held by the general prison community. Twenty-nine percent of women interviewed $(n=8)$ as well two staff members described how MILK participants are seen as role models in the prison community and how this expectation and responsibility helped them maintain good behavior. This finding echoes a substantial body of research demonstrating how expectations of others, are significant predictors of individual behavior and achievement (Nickerson, 1998; Rist, 1970; Snyder, Tanke, \& Berscheid, 1977). Additionally, just as a number of women reported regarding the influence MILK had on their mood, nine women (32\% of interviewees) described how joining MILK was the first step in a journey of personal growth, which first involved decreasing antisocial behaviors to enter the program and eventually involved engaging in more prosocial behaviors to improve quality of life (i.e., leaving one's cell more, taking 
classes, getting a job). In other words, these women described how their initial efforts to meet program requirements transformed into more meaningful behavior change as they built on this initial success. Lastly, in another finding similar to those regarding mood and wellbeing, a number of women $(n=6)$ pointed to the support of other MILK members as instrumental in their improved behavior. These women described how other members provided motivation to engage more in rehabilitative activities (e.g., classes and work programs), as well as provided support during difficult times in general population, which helped them avoid getting into trouble.

Mechanism of change 5. In "Mechanism of Change 5," I hypothesized that the MILK program would lead to institutional benefits via improved inmate behavior, improved inmate mental health, shorter sentences and reduced recidivism. This hypothesis was explored through interviews with institutional staff, which occurred during a prior phase of data collection. Unfortunately, staff members who participated in interviews had little information regarding recidivism or sentence length, although one program administrator hypothesized that the program reduced recidivism by helping mothers focus on their role as parent. Nevertheless, these findings provide no clear evidence either way regarding this particular hypothesis. Staff also provided little information on inmate wellbeing relating to MILK. However, findings from staff interviews regarding the influence of MILK on inmate behavior echoed findings from inmate interviews indicating that MILK has a significant influence on the behavior of many participants. As such, while there is evidence that participation in MILK reduces institutional burden by improving participant behavior, hypotheses related to sentence length and recidivism cannot be proved or disproved by this investigation. I am left to 
speculate that the personal growth described in combination with the improved connections to family described by many participants protects against recidivism as the literature suggests it would (Bales \& Mears, 2008; Hlavka et al., 2015).

\section{Revised Theory of Change Model}

Based on these findings, I revised the original hypothesized theory of change model, originally depicted in Figure 2. The original model identified three primary pathways: Pathway A represented the hypothesized influence of the MILK program on mother-child and mother-caregiver relationships via improved and more frequent contact experiences. Pathway B represented the hypothesized influence of the program on maternal parenting stress and mental health via the expected improvements in relationships with children and caregivers as well as the availability of group support. And, Pathway $\mathrm{C}$ represented a hypothesized improvement in inmate behavior as a result of program requirements and reduced parenting stress. All three major pathways are retained in the revised model (Figure 12) with varying degrees of modification.

While the original model combined program elements, this revised model is structured around the three components of the program-specialty visits, parenting class, and group support - in order to delineate program elements to which participants attributed perceived changes. As depicted in Figure 8, participants attributed improvements in relationships with children to the specialty visits and, to a much lesser extent, to skills learned in the parenting class, but not to group support. In contrast, all three program elements emerged as factors that participants perceived as contributing to improved relationships with caregivers. However, according to findings, the program components seem to contribute to the relationship in distinct ways. In order to capture 
this, I have separated improvement in parenting alliance from more general improvements in connection with caregivers. As the diagram shows, participants attributed improvements in parenting alliance with caregivers to the parenting class and support of the other members who offered advice based on personal experience. In addition, they described how the specialty visits afforded the opportunity to parent their children, which increased their appreciation for caregivers. As such, I added a direct arrow from "Improved mother-child contact" to "Improved mother-caregiver parenting alliance." The figure also depicts the connection participants made between the more relaxed, enjoyable visits, and the greater sense of connection they were able to develop with caregivers. Lastly, with regard to Pathway A, I removed "More frequent motherchild contact" and "More frequent mother-caregiver contact" from the model to reflect the finding that few participants reported that family visited more often as a result of their participation in the MILK program.

While my hypotheses regarding the impact of the program on participants' wellbeing were mostly confirmed, I have made one change to Pathway B to reflect results. In addition to the pathway linking specialty visits and group support to improved mental health by way of the healthier mother-child relationship and reduction in parenting stress these components facilitate, I have added a direct pathway from both visits and group support to maternal mental health. This addition reflects participants' reports that simply participating in the visits and having the support of other mothers were boons to their wellbeing independent of the impact they had on their relationships 


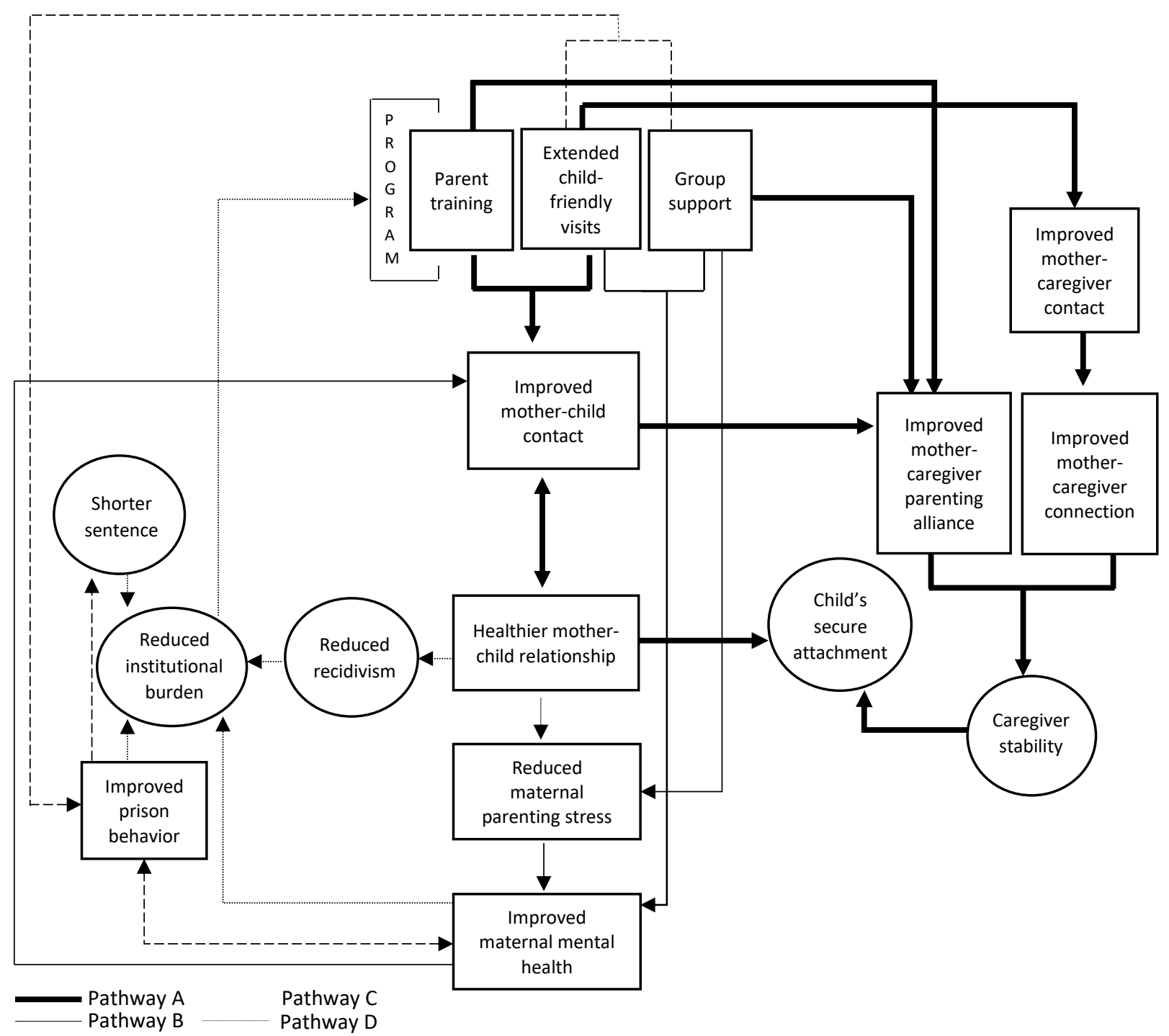

Figure 12. Revised theory of change model for MILK program based on participant reports. Primary and non-primary pathways are represented by distinct line types as described in the legend. Revisions described in Chapter V.

with children. In addition, I removed the originally proposed pathway from "Improved mother-caregiver relationship," to "Reduced maternal parenting stress" to reflect the lack of support for this connection in the data; participants seldom noted changes in relationships with caregivers as a contributing factor to reductions in parenting stress, and 
were instead focused on changes in relationships with children and in their own feelings about themselves as parents.

With regard to Pathway $\mathrm{C}$, which represents the impact of the program on participant behavior, I have refined the direct pathway from the program to improved behavior to reflect results indicating that participants were most motivated to improve behavior by the visits themselves and were also helped to maintain good behavior by the support of other group members. As the figure depicts, there was no indication that the parenting class contributed to improved behavior. Additionally, I have added a recursive arrow between "Improved maternal mental health" and "Improved prison behavior" to represent the journey of personal growth that a number of participants described in which initial behavior change motivated by program entry spurred personal improvement and eventually improved mental health. The arrow is recursive to indicate the transactional relationship between behavior and mood. Lastly, in order to distinguish hypothesized changes for which I found support in the results from those I can neither confirm nor disprove with the data, I created circles to represent changes that remain theoretical following this investigation.

\section{Recommendations}

These findings point to certain recommendations for correctional institutions and policy makers. The results of this study suggest that improving relationships between incarcerated women and their children holds promise as an avenue to decreasing behavior problems and improving wellbeing among inmates. As such, programs aimed at improving these relationships are likely to be fruitful investments for correctional institutions. Moreover, this study suggests that programs of this nature will likely be able 
to influence mother-child relationships with little investment of time or money. My findings indicate that while few women received a greater number of visits from their children as a result of the MILK program, most perceived improvements in relationships with children as a result of having visits of a higher quality that allowed for healthy, attachment-building interactions. This suggests that institutions have the power to influence these relationships by making simple changes to the nature of visitation.

According to the women I interviewed, there are many elements that create an improved visit experience for mothers and their children; however, there are three relatively simple changes that are likely to have a particularly strong impact on the mother-child relationship. First, the availability of child-friendly activities at visits is likely to facilitate more "normal" interactions and allow for healthy bonding in which mothers will be better able to get to know their children and see their development. Second, providing a space for mothers to interact with children away from other children and/or caregivers is likely to facilitate attachment by providing more intimacy in the relationship. And, third, allowing mothers to touch their children will likely allow for the physical bonding that is integral to healthy attachment. Based on my findings, environments that include these three elements are likely to be most successful in facilitating healthy mother-child relationships and thus are most likely to see improvements in inmate behavior and wellbeing.

\section{Limitations}

Findings from this investigation should be interpreted within the context of its limitations. First, given the self-report nature of the data, these findings may be influenced by several factors. Social desirability may have encouraged more positive 
portrayals of the program. More specifically, given the clear affinity participants had for the MILK program, and the pleasure it brought them in an otherwise aversive environment, they may have been consciously or unconsciously motivated to exaggerate the program's impact. However, I took several steps to minimize this possible effect. Most importantly, I revised the interview protocol to include a mapping procedure (Futch $\&$ Fine, 2014) such that participants were asked to focus on their relationships and behavior over time first, and then to reflect on causal mechanisms that explained changes in these areas. Fifty-seven percent of interviewees participated in this updated interview, and, importantly, there were no systematic differences in responses elicited by the different interview protocols. Moreover, participants often provided concrete examples of change rather than vague assertions of improvement, which spoke to the validity of their responses.

In addition, the degree to which participants' perceptions of improvements in relationships with children and caregivers reflect the feelings of these children and caregivers themselves is uncertain. There is some evidence that incarcerated mothers tend to underestimate the challenges experienced by their family members as a result of their incarceration (Loper et al., 2009). As such, it is possible that participants' perceptions of improvements in relationships with children and caregivers are somewhat inflated. In particular, given the very limited nature of the mothers' contact with their children, participants' perceptions that through MILK they were able to relieve some of the parenting burden from caregivers may point to this limited insight. Investigations focusing on the perceptions of family members themselves will be important in developing a full understanding of program effects; however, this was beyond the scope 
of this study. Lastly, participant reports represent perceptions of program effects during their participation in the program, which did not allow for investigation into duration of perceived effects. Longitudinal follow-up studies will be needed to address this.

Second, selection effects and attrition, which is a given when studying incarcerated populations, may have skewed results related to participants' perceptions of the program. While analyses of the Background and Program Questionnaire did not suggest that the five participants who declined the interview viewed the program less favorably, there may be differences in their perceptions of the program that I was not able to measure. Moreover, there were two participants who did not participate in interviews for reasons that suggest that their perceptions may have in fact been less favorable: One woman was expelled from the program before the interview occurred as a result of bad behavior, and another woman declined the interview stating that it would be "too hard" to talk about her children. There is no way to know how these two women perceived the program, but there is certainly reason to suspect that it may not have had the same positive impact on them as it had on many of the participants. There were also five participants who were either transferred or released prior to interviews (no information was available regarding who was transferred and who was released). Given the many possible reasons for transfer and release, it is not possible to speculate as to how this may have impacted the final sample.

Third, the generalizability of these findings is limited by the fact that the investigation focused on one program across two institutions. This is especially true given the wide variability in programs of this nature. Fourth, I did not investigate individual and program factors that may facilitate or impede program effects (e.g., pre- 
incarceration mother-child and mother-caregiver relationships, time spent in program, duration of visits, structure of weekly group meetings). While specific analyses of this nature are beyond the scope of this study, there are important questions that remain unanswered regarding differential experiences of participants based on background and nature of program participation. In particular, there was considerable variability in the length of program participation among participants, which may have impacted perceptions. Future studies examining possible interaction effects of program dosage on outcomes would enhance understanding of these interventions. Fifth, and last, I was not able to calculate an effect size for improvements reported by participants, which limits my ability to fully understand the influence, or lack thereof, of the MILK program.

\section{Conclusions and Future Directions}

Despite these limitations, these findings offer important information regarding interventions aimed at helping incarcerated parents in the US and the nearly two million children they have left behind (Glaze \& Maruschak, 2008). These findings provide support for the MILK program - a multisystemic parenting training, parent support, and specialty visitation program — and indicate that participants perceive benefits from all three components of the program (parenting class, specialty visits, and group support).

Most notably, these results provide strong support for the hypothesis that not all in-person contact experiences between incarcerated mothers and their family members, especially children, are created equal. As many experts in the field have argued, results suggest that the degree to which visitation between children and their incarcerated mothers impacts their relationship and benefits children depends on the degree to which the visit offers an opportunity for healthy mother-child interactions in a setting that facilitates feelings of 
security. These results indicate that the following factors are important to the creation of such a visit for both the mother-child and mother-caregiver relationship: opportunity for shared activities, physical contact, and one-on-one time, as well as a more relaxed environment (i.e., more space and fewer regulations), and the presence of other incarcerated mothers and their children. Results also showed that these visits contributed to perceived improvements in inmate behavior and emotional wellbeing as they provided strong motivation for good behavior and fostered improvements in hopefulness and mood. These results indicate that the MILK program seems to have found a recipe for success in their specialty visits and future program development efforts would likely benefit from close replication of this format.

Results were less clear regarding the parenting course and group support elements of the MILK program. While perceived effects were not nearly as evident as those related to the specialty visits, for a number of women, the pre-program parenting course contributed to improvements in several areas. Parenting instruction played an important role in some participants' ability to utilize the more conducive visit environment to facilitate the healthy interactions with both children and caregivers that strengthen relationships. Furthermore, the parenting class appeared to strengthen the parenting alliance between a number of participants and their children's caregivers by improving their understanding of the challenges facing caregivers. However, these results also indicate that the majority of MILK participants retain problematic beliefs about parenting, which suggests that the parenting training most participants received prior to joining MILK had limited efficacy. Programs are likely to have more success improving mother-child relationships if the parenting training component involves empirically- 
validated interventions, however, very few of these exist for the prison population. As such, given the potential for problematic parenting attitudes to undermine healthy interactions with children during specialty visits, gaining a better understanding of what does and does not work in courses for inmate parents is essential to future program development.

The group support component of the MILK program was the least often cited mechanism of change. However, a notable number of participants felt that having the support of other incarcerated mothers contributed to reduced parenting stress, improved mental health, improved behavior, and improved parenting alliance with children's caregivers. There was no evidence that participants perceived the support of the group as contributing to improved relationships with children. Given findings supporting the efficacy of interparent support when managing challenging familial adversities comparable to parental incarceration in its uniqueness (e.g., having a child with a disability; Davies \& Hall, 2005; Singer et al., 1999), these results seem to reflect a missed opportunity. Further investigation into the nature of the group meetings and comparison to other validated parent-to-parent support programs may shed light on why group support was less influential for MILK participants. Future program development efforts would benefit from careful investigation of parenting support groups with proven efficacy and consideration of how these interventions may be adapted for the prison setting.

Taken together, these findings suggest that multi-systemic programs that include all three of these components have promising potential to strengthen mother-child and mother-caregiver relationships as well as to improve the behavior and mental health of 
participants, especially if all three components are maximized for efficacy. Continued study of programs of this nature is necessary to fully understand the magnitude of the effects as well as how to maximize benefits for participants and their families (e.g., providing more effective parent training). Moreover, perhaps the most obvious direction for future studies is investigation of whether or not effects perceived by inmate participants are echoed qualitatively by their children and their children's caregivers, as well as quantitatively especially in measures of children's wellbeing. Studies of this nature will hopefully build upon and refine these findings in order to create more targeted and thus effective interventions for a group of parents and children who truly need them. 


\section{References}

Adamsons, K., \& Pasley, K. (2006). Coparenting following divorce and relationship dissolution. In M. A. Fine \& J. H. Harvey (Eds.) Handbook of divorce and relationship dissolution (pp. 241-261). New York: Routledge.

Ainsworth, M. S. (1979). Infant-mother attachment. American psychologist, 34, 932-937.

Arditti, J. A. (2003). Locked doors and glass walls: Family visiting at a local jail. Journal of Loss \& Trauma, 8, 115-138. doi: 10.1080/15325020305864.

Arditti, J. A., \& Few, A. L. (2006). Mothers' reentry into family life following incarceration. Criminal Justice Policy Review, 17, 103-123. doi: $10.1177 / 0887403405282450$.

Bachman, H., \& Chase-Lansdale, P. (2005). Custodial Grandmothers' Physical, Mental, and Economic Well-Being: Comparisons of Primary Caregivers from LowIncome Neighborhoods. Family Relations, 54, 475-487. doi: 10.1111/j.17413729.2005.00334.x.

Bakermans-Kranenburg, M. J., \& van IJzendoorn, M. H. (2009). The first 10,000 Adult Attachment Interviews: Distributions of adult attachment representations in clinical and non-clinical groups. Attachment \& human development, 11, 223-263. doi: $10.1080 / 14616730902814762$.

Bales, W. D. \& Mears, D. P. (2008). Inmate social ties and the transition to society: Does visitation reduce recidivism? Journal of Research in Crime and Delinquency, 45,287-321. doi: 10.1177/0022427808317574.

Bavolek, S. (1990). Research and Validation Report of the Adult-Adolescent Parenting Inventory. Park City, UT: Family Development Resources, Inc. 
Bavolek, S., \& Keene, R. G. (1999). Adult-Adolescent Parenting Inventory-AAPI-2: Administration and Development Handbook. Park City, UT: Family Development Resources. Inc.

Benoit, D., \& Parker, K. C. (1994). Stability and transmission of attachment across three generations. Child development, 65, 1444-1456.

Block, K. J., \& Potthast, M. J. (1998). Girl Scouts Beyond Bars: Facilitating parent-child contact in correctional settings. Child Welfare, 77, 561-578.

Bocknek, E. L., Sanderson, J., \& Britner IV, P. A. (2009). Ambiguous loss and posttraumatic stress in school-age children of prisoners. Journal of Child and Family Studies, 18, 323-333. doi: 10.1007/s10826-008-9233-y.

Boudin, C., Stutz, T., \& Littman, A. (2014). Prison Visitation Policies: A Fifty State Survey. Available at SSRN: http://ssrn.com/abstract=2171412

Bowlby, J. (1953). Some pathological processes set in train by early mother-child separation. The British Journal of Psychiatry, 99(415), 265-272.

Bowlby, J. (1969). Attachment and loss, Vol. 1: Attachment. New York: Basic Books.

Bowlby, J. (1982). Attachment and loss: Vol. 1. Attachment (2nd ed.). New York: Basic Books.

Braman, D. (2004). Doing time on the outside: Incarceration and family life in urban America. Ann Arbor, MI: University of Michigan Press.

Bretherton, I., \& Munholland, K. A. (2008). Internal working models in attachment relationships: Eleborating a central construct in Attachment Theory. In J. Cassidy and P. R. Shaver (Eds). Handbook of attachment: Theory, research, and clinical applications (2nd ed.) (pp. 666-697). New York: Guilford Press. 
Casey-Acevedo, K., \& Bakken, T. (2002). Visiting women in prison: Who visits and who cares?. Journal of Offender Rehabilitation, 34, 67-83. doi: 10.1300/J076v34n03_05.

Catalano, R. F., Haggerty, K. P., Oesterle, S., Fleming, C. B., \& Hawkins, J. D. (2004). The importance of bonding to school for healthy development: Findings from the Social Development Research Group. Journal of School Health, 74(7), 252-261. doi: 10.1111/j.1746-1561.2004.tb08281.x.

Chipman, S., Olsen, S. F., Klein, S., Hart, C. H., \& Robinson, C. C. (2000). Differences in Retrospective Perceptions of Parenting of Male and Female Inmates and NonInmates. Family Relations, 49, 5-11. doi: 10.1111/j.1741-3729.2000.00005.x.

Cho, R. M. (2010). Maternal incarceration and children's adolescent outcomes: Timing and dosage. Social Service Review, 84, 257-282. doi: 10.1086/653456.

Christian, J., Mellow, J., \& Thomas, S. (2006). Social and economic implications of family connections to prisoners. Journal of Criminal Justice, 34, 443-452. doi: 10.1016/j.jcrimjus.2006.05.010.

Connell, A. M., \& Goodman, S. H. (2002). The association between psychopathology in fathers versus mothers and children's internalizing and externalizing behavior problems: A meta-analysis. Psychological Bulletin, 128, 746-773. doi:10.1037//0033-2909.128.5.746.

Crnic, K., \& Low, C. (2002). Everyday stresses and parenting. In M. H. Bornstein Handbook of Parenting Volume 5: Practical Issues in Parenting (pp. 242-267). New Jersey: Lawrence Erlbaum. 
Dallaire, D. H. (2007). Incarcerated mothers and fathers: A comparison of risks for children and families. Family relations, 56, 440-453. doi: 10.1111/j.17413729.2007.00472.x.

Dallaire, D. H., Ciccone, A., \& Wilson, L. C. (2010). Teachers' experiences with and expectations of children with incarcerated parents. Journal of Applied Developmental Psychology, 31, 281-290. doi:10.1016/j.appdev.2010.04.001.

Dallaire, D. H., Ciccone, A., \& Wilson, L. C. (2012). The family drawings of at-risk children: Concurrent relations with contact with incarcerated parents, caregiver behavior, and stress. Attachment \& Human Development, 14, 161-183. doi: $10.1080 / 14616734.2012 .661232$.

Dallaire, D. H., \& Wilson, L. C. (2010). The relation of exposure to parental criminal activity, arrest, and sentencing to children's maladjustment. Journal of Child and Family Studies, 19, 404-418. doi: 10.1007/s10826-009-9311-9.

Dallaire, D., Zeman, J., \& Thrash, T. (2015). Differential effects of type of children's contact with their jailed mothers and children's behavior problems. In J. Poehlmann-Tynan (Ed.) Children's contact with incarcerated parents: Implications for policy and intervention (pp. 23-38). Urbana, Il : SpringerBriefs in Psychology

Dannerback, A. M. (2005). Differences in parenting attributes, experiences, and behaviors of delinquent youth with and without a parental history of incarceration. Youth Violence and Juvenile Justice, 3, 199-213. doi:10.1177/1541204005276260. 
Davies, S., \& Hall, D. (2005). “Contact A Family”: Professionals and parents in partnership. Archives of Disease in Childhood, 90, 1053-1057. doi: 10.1136/adc.2004.070706.

Deater-Deckard, K. (2005). Parenting stress and children's development: Introduction to the special issue. Infant and Child Development, 14, 111-115. doi: 10.1002/icd.383.

Dedoose Version 7.5.4, web application for managing, analyzing, and presenting qualitative and mixed method research data (2016). Los Angeles, CA: SocioCultural Research Consultants, LLC (www.dedoose.com).

Dozier, M. (2005). Challenges of foster care. Attachment \& human development, 7, 2730. doi: 10.1080/14616730500039747.

Eddy, J. M., Kjellstrand, J., Martinez, C. R., \& Newton, R. (2010). Theory-based multimodal parenting intervention for incarcerated parents and their children. In J. M. Eddy and J. Poehlmann (Eds.) Children of incarcerated parents: A handbook for researchers and practitioners (pp. 237-261). Washington, DC: Urban Institute Press

Eddy, J. M., Martinez, C. R., Schiffmann, T., Newton, R., Olin, L., Leve, L.,... \& Wu Shortt, J. (2008). Development of a multisystemic parent management training intervention for incarcerated parents, their children and families. Clinical Psychologist, 12, 86-98. doi: 10.1080/13284200802495461.

Eddy, J. M., \& Reid, J. B. (2003). The adolescent children of incarcerated parents. In J. Travis \& M. Waul (Eds.) Prisoners once removed: The impact of incarceration 
and reentry on children, families and communities (pp. 233-258). Washington, DC: Urban Institute.

Edin, K., Nelson, T. J., \& Paranal, R. (2004). Fatherhood and incarceration as potential turning points in the criminal careers of unskilled men. In M. Pattillo, D. F. Weiman, \& B. Western (Eds.), Imprisoning America: The social effects of mass incarceration (pp. 46-75). New York: Russell Sage Foundation.

Equit, M., Klein, A., Braun-Bither, K., Gräber, S., \& Gontard, A. (2013). Elimination disorders and anxious-depressed symptoms in preschool children: A populationbased study. European Child \& Adolescent Psychiatry, 23, 417-423. doi: 10.1007/s00787-013-0468-9.

Fergusson, D. M, \& Woodward L. J. (2002). Depression \& school underachievement: Mental health, educational, and social role outcomes of adolescents with depression. Archives of General Psychiatry, 59, 225-231. doi:10.1001/archpsyc.59.3.225.

Futch, V. A., \& Fine, M. (2014). Mapping as a method: History and theoretical commitments. Qualitative Research in Psychology, 11, 42-59. doi.org:10.1080/14780887.2012.719070.

Gasper, J. A., Stolberg, A. L., Macie, K. M., \& Williams, L. J. (2008). Coparenting in intact and divorced families: Its impact on young adult adjustment. Journal of Divorce \& Remarriage, 49, 272-290. doi: 10.1080/10502550802231924.

Gaudin Jr, J. M., \& Sutphen, R. (1993). Foster care vs. extended family care for children of incarcerated mothers. Journal of Offender Rehabilitation, 19, 129-147. 
Geller, A., Garfinkel, I., Cooper, C. E., \& Mincy, R. B. (2009). Parental incarceration and child well-being: Implications for urban families. Social science quarterly, 90, 1186-1202. doi:10.1111/j.1540-6237.2009.00653.x.

Geller, A., Garfinkel, I., \& Western, B. (2011). Paternal incarceration and support for children in fragile families. Demography, 48, 25-47. doi: 10.1007/s13524-0100009-9.

Geller, A., Cooper, C. E., Garfinkel, I., Schwartz-Soicher, O., \& Mincy, R. B. (2012). Beyond absenteeism: Father incarceration and child development. Demography, 49, 49-76. doi:10.1007/s13524-011-0081-9.

Gendreau, P., Little, T., \& Goggin, C. (1996). A meta-analysis of the predictors of adult offender recidivism: What works. Criminology, 34, 575-608.

Gerard, J., \& Buehler, C. (2004). Cumulative Environmental Risk and Youth Problem Behavior. Journal or Marriage and Family, 66, 702-720. doi: 10.1111/j.00222445.2004.00048.x.

Glaze, L. E., \& Maruschak, L. M. (2008). Bureau of Justice statistics special report: Parents in prison and their minor children. Washington, DC: Bureau of Justice Statistics.

Glaze, L. E., \& Parks, E. (2011). Correctional populations in the United States, 2011. Population, 6, 8-18.

Greene, J. (2013). FCC tackles cost of prison phone calls. The Blog of Legal Times. Available at: http://legaltimes.typepad.com/blt/2013/07/fcc-tackles-cost-ofprison-phone-calls.html. (July). 
Greenfeld, L. A., \& Snell, T. L. (1999). Women offenders. Washington, DC: US Department of Justice, Office of Justice Programs, Bureau of Justice Statistics.

Hairston, C. F. (1998). The forgotten parent: Understanding the forces that influence incarcerated fathers' relationships with their children. Child Welfare, LXXVII, $617-638$.

Hanlon, T. E., Blatchley, R. J., Bennett-Sears, T., O'Grady, K. E., Rose, M., \& Callaman, J. M. (2005). Vulnerability of children of incarcerated addict mothers: Implications for preventive intervention. Children and Youth Services Review, 27, 67-84. doi:10.1016/j.childyouth.2004.07.004.

Harm, N. J., \& Phillips, S. D. (2001). You can't go home again: Women and criminal recidivism. Journal of Offender rehabilitation, 32, 3-21. doi: 10.1300/J076v32n03_02.

Henry, K. L., Oetting, E. R., \& Slater, M. D. (2009). The role of attachment to family, school, and peers in adolescents' use of alcohol: A longitudinal study of withinperson and between-persons effects. Journal of Counseling Psychology, 56, 564572. doi:10.1037/a0017041.

Hlavka, H., Wheelock, D., \& Jones, R. (2015). Ex-offender accounts of successful reentry from prison. Journal of Offender Rehabilitation, 54, 406-428. doi: $1080 / 10509674.2015 .1057630$

Houck, K. D., \& Loper, A. B. (2002). The relationship of parenting stress to adjustment among mothers in prison. American Journal of Orthopsychiatry, 72, 548. doi: 10.1037/0002-9432.72.4.548. 
Huebner, B. M., \& Gustafson, R. (2007). The effect of maternal incarceration on adult offspring involvement in the criminal justice system. Journal of Criminal Justice, 35, 283-296. doi:10.1016/j.jcrimjus.2007.03.005.

Johnson, S. M., \& Greenberg, L. S. (1985). Differential effects of experiential and problem-solving interventions in resolving marital conflict. Journal of Consulting and Clinical Psychology, 53, 175-184. doi: 10.1037/0022006X.53.2.175

Kampfner, C. J. (1995). Post-traumatic stress reactions in children of imprisoned mothers. In K. Gabel \& D. Johnston (Eds.) Children of incarcerated parents (pp. 89-100). New York: Lexington Books.

Kennon, S. (2003). Developing the parenting skills of incarcerated parents: A program evaluation. Unpublished manuscript, Master's Thesis, Virginia Commonwealth University.

Kinner, S. A., Alati, R., Najman, J. M., \& Williams, G. M. (2007). Do paternal arrest and imprisonment lead to child behaviour problems and substance use? A longitudinal analysis. Journal of Child Psychology and Psychiatry, 48, 11481156. doi:10.1111/j.1469-7610.2007.01785.x.

Kjellstrand, J. M., \& Eddy, J. M. (2011). Parental incarceration during childhood, family context, and youth problem behavior across adolescence. Journal of Offender Rehabilitation, 50, 18-36. doi: 10.1080/10509674.2011.536720.

Kupers, T. (1999). Prison madness: The mental health crisis behind bars and what we must do about it. San Francisco: Jossey-Bass Publishers. 
La Vigne, N. G., Naser, R. L., Brooks, L. E., \& Castro, J. L. (2005). Examining the effect of incarceration and in-prison family contact on prisoners' family relationships. Journal of Contemporary Criminal Justice, 21, 314-335. doi: $10.1177 / 1043986205281727$.

Landreth, G. L., \& Lobaugh, A. F. (1998). Filial therapy with incarcerated fathers: Effects on parental acceptance of child, parental stress, and child adjustment. Journal of Counseling \& Development, 76, 157-165. doi: 10.1002/j.15566676.1998.tb02388.x.

Loper, A. B., Carlson. L. W., Levitt, L., \& Scheffel, K. (2009). Parenting stress, alliance, child contact, and adjustment of imprisoned mothers and fathers. Journal of Offender Rehabilitation, 48, 483-503. doi: 10.1080/10509670903081300.

Loper, A. B., \& Novero, C. (2010). Parenting programs for prisoners. In J. M. Eddy and J. Poehlmann (Eds.) Children of incarcerated parents: A handbook for researchers and practitioners (pp. 189-215). Washington, DC: Urban Institute Press.

Loper, A. B., Phillips, V., Nichols, E. B., \& Dallaire, D. H. (2014). Characteristics and effects of the co-parenting alliance between incarcerated parents and child caregivers. Journal of Child and Family Studies, 23, 225-241. doi: 10.1007/s 10826-012-9709-7.

Loper, A. B., \& Tuerk, E. H. (2011). Improving the emotional adjustment and communication patterns of incarcerated mothers: Effectiveness of a prison parenting intervention. Journal of Child and Family Studies, 20, 89-101. doi:10.1007/s 10826-010-9381-8. 
Lupien, S., McEwen, B., Gunnar, M., \& Heim, C. (2009). Effects of stress throughout the lifespan on the brain, behaviour and cognition. Nature Reviews Neuroscience, 10, 434-445. doi:10.1038/nrn2639

Lyons-Ruth, K., \& Jacobvitz, D. (2008). Attachment disorganization: Genetic factors, parenting contexts, and developmental transformation from infancy to adulthood. In J. Cassidy and P. R. Shaver (Eds). Handbook of attachment: Theory, research, and clinical applications (2nd ed.) (pp. 666-697). New York: Guilford Press.

Mackintosh, V. H., Myers, B. J., \& Kennon, S. S. (2006). Children of incarcerated mothers and their caregivers: Factors affecting the quality of their relationship. Journal of Child and Family Studies, 15, 579-594. doi: 10.1007/s10826-0069030-4.

Maddox, S. J., \& Prinz, R. J. (2003). School bonding in children and adolescents: Conceptualization, assessment, and associated variables. Clinical Child and Family Psychology Review, 6, 31-49. doi:10.1023/A:1022214022478.

Main, M., \& Solomon, J. (1990). Procedures for identifying infants as disorganized/disoriented during the Ainsworth Strange Situation. In M. Main, J. Solomon, M. T. Greenberg, D. Cicchetti, D., \& E. M. Cummings (Eds) Attachment in the preschool years: Theory, research and intervention (pp.121160). Chicago: University of Chicago Press.

Makariev, D. W., \& Shaver, P. R. (2010). Attachment, parental incarceration and possibilities for intervention: An overview. Attachment \& human development, 12, 311-331. doi: 0.1080/14751790903416939. 
McClure, H. H., Shortt, J. W., Eddy, J. M., Holmes, A., van Uum, S., Russell, E.,...\& Martinez Jr., C. R. (2015). Associations among mother-child contact, parenting stress, and mother and child adjustment related to incarceration. In J. PoehlmannTynan (Ed.) Children's contact with incarcerated parents: Implications for policy and intervention (pp. 59-82). Urbana, Il: SpringerBriefs in Psychology.

McIntosh, K., Horner, R. H., Chard, D. J., Dickey, C. R., \& Braun, D. H. (2008). Reading skills and function of problem behavior in typical school settings. The Journal of Special Education, 42, 131-147. doi: 10.1177/0022466907313253.

Meyer, D., \& Moriarty, C. (1995). Rebonding and Rebuilding (A parenting curriculum) ( $4^{\text {th }}$ ed.). Los Angeles: Hacienda La Puenta.

Moore, A., \& Clement, M. J. (1998). Effects of parenting training for incarcerated mothers. Journal of Offender Rehabilitation, 27, 57-72. doi: 10.1300/J076v27n01_05.

Mumola, C. J. (2000). Incarcerated parents and their children. Washington, DC: Bureau of Justice Statistics.

Murray, J., \& Farrington, D. P. (2005). Parental imprisonment: Effects on boys' antisocial behaviour and delinquency through the life-course. Journal of Child Psychology and Psychiatry, 46, 1269-1278. doi:10.1111/j.14697610.2005.01433.x.

Murray, J., \& Farrington, D. P. (2008a). The effects of parental imprisonment on children. Crime and Justice, 37, 133-206. doi: 10.1086/520070. 
Murray, J., \& Farrington, D. P. (2008b). Parental imprisonment: Long-lasting effects on boys' internalizing problems through the life course. Development and Psychopathology, 20, 273-290. doi:10.1017/S0954579408000138.

Murray, J., Farrington, D. P., \& Sekol, I. (2012). Children's antisocial behavior, mental health, drug use, and educational performance after parental incarceration: A systematic review and meta-analysis. Psychological Bulletin, 138, 175-210. doi:10.1037/a0026407.

Murray, J., \& Murray, L. (2010). Parental incarceration, attachment, and child psychopathology. Attachment and Human Development, 12, 289-309. doi: $10.1080 / 14751790903416889$.

Myers, B. J., Smarsh, T. M., Amlund-Hagen, K., \& Kennon, S. (1999). Children of incarcerated mothers. Journal of Child and Family Studies, 8, 11-25. doi: 10.1023/A:1022990410036.

Nesmith, A., \& Ruhland, E. (2008). Children of incarcerated parents: Challenges and resiliency, in their own words. Children and Youth Services Review, 30, 11191130. doi: 10.1016/j.childyouth.2008.02.006.

Nichols, E. B., Loper, A. B., \& Meyer, J. P. (2015). Promoting Educational Resiliency in Youth with Incarcerated Parents: The Impact of Parental Incarceration, School Characteristics, and Connectedness on School Outcomes. Journal of Youth and Adolescence, published online, 1-20. doi: 10.1007/s10964-015-0337-6.

Nickerson, R. S. (1998). Confirmation bias: A ubiquitous phenomenon in many guises. Review of General Psychology, 2, 175-220. 
Parke, R. D., \& Clarke-Stewart, K. A. (2003). The effects of parental incarceration on children. J. Travis \& M. Waul (Eds.), Prisoners once removed: The impact of incarceration and reentry on children, families and communities (pp. 189-232). Washington, DC: Urban Institute.

Patterson, G. R., DeBaryshe, B. D., \& Ramsey, E. (1989). A Developmental Perspective on Antisocial Behavior. American Psychologist, 44, 329-335.

Phillips, S. D., Burns, B. J., Wagner, H. R., Kramer, T. L., \& Robbins, J. M. (2002). Parental incarceration among adolescents receiving mental health services. Journal of Child and Family Studies, 11, 385-399. doi:10.1023/A:1020975106679.

Phillips, S. D., \& Zhao, J. (2010). The relationship between witnessing arrests and elevated symptoms of posttraumatic stress: Findings from a national study of children involved in the child welfare system. Children and Youth Services Review, 32, 1246-1254. doi:10.1016/j.childyouth.2010.04.015.

Pitts, J., Griffin, O., \& Johnson, W. (2013). Contemporary prison overcrowding: Shortterm fixes to a perpetual problem. Contemporary Justice Review, 17, 124-139. doi: 10.1080/10282580.2014.883844.

Poehlmann, J. (2005a). Incarcerated mothers' contact with children, perceived family relationships, and depressive symptoms. Journal of Family Psychology, 19, 350357. doi: 10.1037/0893-3200.19.3.350.

Poehlmann, J. (2005b). Representations of attachment relationships in children of incarcerated mothers. Child Development, 76, 679-696. doi: 10.1111/j.14678624.2005.00871.x. 
Poehlmann, J., Dallaire, D., Loper, A. B., \& Shear, L. D. (2010). Children's contact with their incarcerated parents: Research findings and recommendations. American Psychologist, 65, 575-598. doi: 10.1037/a0020279.

Poehlmann, J., Shlafer, R. J., Maes, E., \& Hanneman, A. (2008). Factors associated with young children's opportunities for maintaining family relationships during maternal incarceration. Family Relations, 57, 267-280. doi: 10.1111/j.17413729.2008.00499.x.

Rist, R. (1970). Student social class and teacher expectations: The Self-Fulfilling Prophecy in ghetto education. Harvard Educational Review, 40, pp. 411-451. doi: 10.17763/haer.40.3.h0m026p670k618q3.

Rothbaum, F., \& Weisz, J. R. (1994). Parental caregiving and child externalizing behavior in nonclinical samples: A meta-analysis. Psychological Bulletin, 116, 55-74. doi: 10.1037/0033-2909.116.1.55.

Roxburgh, S., \& Fitch, C. (2013). Parental status, child contact, and well-being among incarcerated men and women. Journal of Family Issues, 35, 1394-1412. doi: 10.1177/0192513X13498593.

Sameroff, A., Gutman, L. M., \& Peck, S. C. (2003). Adaptation among youth facing multiple risks: Prospective research findings. In S. S. Luthar (Ed.), Resilience and vulnerability: Adaptation in the context of childhood adversities (pp. 364391). New York: Cambridge University Press.

Sandifer, J. L. (2008). Evaluating the efficacy of a parenting program for incarcerated mothers. The Prison Journal, 88, 423-445. doi: 10.1177/0032885508322533. 
Shlafer, R. J., Loper, A. B., \& Schillmoeller, L. (2015). Introduction and literature review: Is parent-child contact during parental incarceration beneficial? In J. Poehlmann-Tynan (Ed.) Children's contact with incarcerated parents: Implications for policy and intervention (pp. 1-22). Urbana, Il : SpringerBriefs in Psychology.

Shlafer, R. J., \& Poehlmann, J. (2010). Attachment and caregiving relationships in families affected by parental incarceration. Attachment \& Human Development, 12, 395-415. doi: 10.1080/14616730903417052.

Simons, R. L., Whitbeck, L. B., Conger, R. D., \& Wu, C. I. (1991). Intergenerational transmission of harsh parenting. Developmental Psychology, 27, 159-171. doi: 10.1037/0012-1649.27.1.159.

Singer, G. H., Marquis, J., Powers, L. K., Blanchard, L., DiVenere, N., Santelli, B., ... \& Sharp, M. (1999). A multi-site evaluation of parent to parent programs for parents of children with disabilities. Journal of Early Intervention, 22, 217-229. doi: $10.1177 / 105381519902200305$.

Snyder, Z. K., Carlo, T. A., \& Mullins, M. M. C. (2002). Parenting from prison: An examination of a children's visitation program at a women's correctional facility. Marriage \& Family Review, 32, 33-61. doi: 10.1300/J002v32n03_04.

Snyder, M., Tanke, E. D., \& Berscheid, E. (1977). Social perception and interpersonal behavior: On the self-fulfilling nature of social stereotypes. Journal of Personality and Social Psychology, 35, 656-666. doi: 10.1037/00223514.35.9.656. 
Steele, H., Steele, M., \& Fonagy, P. (1996). Associations among attachment classifications of mothers, fathers, and their infants. Child development, 67, 541555.

Tennessee Department of Corrections - Planning and Research Section. (1995, April). The children and families of incarcerated felons: A status report and demographic inquiry. Tennessee Department of Corrections Planning and Research Section Report.

Trice, A. D., \& Brewster, J. (2004). Effects of maternal incarceration on adolescent children. Journal of Police and Criminal Psychology, 19, $27-35$. doi:10.1007/BF02802572.

Weissman, S. H., \& Cohen, R. S. (1985). The parenting alliance and adolescence. Adolescent psychiatry.

Wiebush, R., Freitag, R., \& Baird, C., (2001). Preventing delinquency through improved child protection services. OJJDP Juvenile Justice Bulletin. Washington, D.C.

Wildeman, C. (2010). Paternal incarceration and children's physically aggressive behaviors: Evidence from the Fragile Families and Child Wellbeing Study. Social Forces, 89, 285-309. doi: 10.1353/sof.2010.0055.

Young, D., \& Smith, C. J. (2000). When moms are incarcerated: The needs of children, mothers, and caregivers. Families in Society: The Journal of Contemporary Social Services, 81, 130-141. doi: 10.1606/1044-3894.1007.

Yun, I., \& Lee, J. (2013). IQ and delinquency: The differential detection hypothesis revisited. Youth Violence and Juvenile Justice, 11, 196-211. doi:10.1177/1541204012463410. 
Zuckerman, B. (1994). Effects on parents and children. In D. J. Besharov (Ed.), When drug addicts have children: Reorienting child welfare's response (pp. 49-61). Washington, DC: Child Welfare League of America. 


\section{Appendix A}

\section{Staff Interview Protocol}

Hello, our names are and we are researchers from the University of Virginia.

Thank you for agreeing to meet with us. We are interested in gathering information about the MILK program to find out how the MILK program is being implemented at [your institution]. We are interested in learning about the institutional elements that impact the program and how MILK is helping inmates and their families. Your ideas will help us to make suggestions for how to continue to improve this program. The results of our work will be shared with other Department of Corrections staff and administrators as they consider how to best use and improve this program. There are no right or wrong answers - we just want to know what you think.

ROLE OF RESPONDENT - First let me know a bit about you:

1. What is your role and involvement in the MILK program?

a. Probe to gain particulars about specific kinds of activities the staff member does in relation to milk.

2. How long have you been involved in MILK? How did you first get involved?

3. Did you have to do any special training to become involved with this program?

a. IF YES: What was involved? How long did it take?

4. Are you currently working directly with any MILK groups?

a. If yes, query how many women are in the group.

b. If yes, query how frequently women transition in and out of the group.

CONTENT OF THE PROGRAM - MILK has been here for a long time,

1. What do you know about the history of MILK here in Virginia? 
PROGRAM COSTS - I have some questions now about the cost of the program.

1. What space(s) are needed for the weekly meetings

2. What space (s) are needed for the special visits?

3. How many staff members are present during (weekly) MILK meetings? Do staff members work overtime, or is this within the usual load?

4. How many staff are needed for the family visits? Do staff members work overtime, or is this within the usual load?

5. What security staff requirements are needed for the visits? Do officers work overtime, or is this within the usual load?

6. What materials are needed for the weekly meetings? How are those paid for?

7. What materials are needed for the visits? How are those paid for?

8. Are there any materials that you routinely use, such as guides or manuals that are distributed to the mothers? How are these paid for?

9. Have you ever personally purchased materials for the program? Can you give us an estimate of what those were and how much you spent?

CONTENT OF THE PROGRAM - I would like to get a better sense of the day-to-day operations of MILK

1. Many inmates seem to be interested in joining MILK. Why do you think that is?

2. What is the enrollment process like for mothers to become involved in MILK?

a. Follow up as needed to understand the logistics for enrollment. Any impediments such as individual histories, etc.

3. Do most inmates who want to join MILK end up participating? 
a. If NO: What keeps them from participating? (PROBE FOR BARRIERS TO ENTRY)

4. We know inmates are involved in running MILK, how does that work?

5. IF NOT ALREADY ANSWERED: How are leaders chosen among the women?

6. Are there ever any issues around selecting leaders?

7. How often do MILK members meet with each other?

8. What typically happens at these meetings?

9. Are there any other activities that occur at meetings, even if not frequently?

10. How do MILK participants get along with one another and with staff? PROBE FOR HOW CONNECTED/TRUSTING MEMBERS ARE.

11. Some members of MILK may be very active, while others may take a less active role. What are the things that you have observed that seem to either encourage or discourage mothers from being actively engaged?

CONTENT OF THE PROGRAM - Now I would like to get a better idea about the usual activities during the special MILK visits with children and caregivers

1. MILK has special visits when children come for special activities. Have you ever been present at one of these meetings? If so, what were your impressions and thoughts about it?

2. How often do these special visits occur?

3. What are the typical activities that happen during a MILK visit with family members?

4. Mothers, children and caregivers may experience MILK visits in different ways. What do you think are the things that make this day better or worse for moms? 
a. FOR ANY ISSUES MENTIONED PROBE: Are there things that MILK does during these special days to address these challenges?

b. FOR ANY POSITIVES MENTIONED PROBE: Are there things that MILK does to encourage this?

5. What do you think makes this day go better or worse for caregivers?

a. For any issues mentioned PROBE: Are there things that MILK does during these special days to address these challenges?

b. For any positives mentioned PROBE: Are there things that MILK does to encourage this?

6. What do you think makes this day go better for children?

a. For any issues mentioned PROBE: Are there things that MILK does during these special days to address these challenges?

b. For any positives mentioned PROBE: Are there things that MILK does to encourage this?

7. In your own experience with MILK, have there ever been events that made you concerned or worried about this program? If so describe.

8. In your own experience with MILK, have there ever been events that made you feel very positive about this program? If so describe.

PERCEPTIONS OF GOALS, BARRIERS, AND OUTCOMES

9. What do you think are the main goals of the program? (Create list of goals indicated). IF NEEDED PROBE FOR GOALS FOR MOMS, KIDS, CAREGIVERS, \& INSTITUTION)

10. Which of these goals do you feel that MILK is meeting? 
a. For each goal listed PROBE: What happens in MILK to make that goal happen?

11. Which of these goals do you feel like MILK is NOT meeting?

a. FOR EACH GOAL PROBE: What happens in MILK that gets in the way of meeting that goal. 
Appendix B

Initial Inmate Interview Protocol

Hi, our names are and we are members of the prisoners and their families lab at the University of Virginia. Thank you for agreeing to meet with us. Today, we're interested in learning about your experience in MILK. The results of our work will be shared with the Department of Corrections staff and administrators to help them improve the program. There are no right or wrong answers - we just want to know what you think. Do you have any questions before we get started? Okay, let's get started. If you have any questions at any point, please let me know.

\section{MECHANISM: IMPROVED RELATIONSHIP WITH CHILDREN}

1. How many children do you have? How old are they? Can you tell me a little about what life was like with them before you got here?

2. Now I'd like you to think back to the time when you were in prison but not in MILK. What was your relationship like with your children then?

3. And what has your relationship been like with your children since you joined MILK?

\section{MECHANISM: IMPROVED RELATIONSHIP WITH CAREGIVER}

4. Who is taking care of your children? Thinking back to your time here before you joined MILK, what was your relationship like with him/her/them then?

5. And what has your relationship been like with him/her/them since you joined MILK?

MECHANISM: IMPROVED FAMILY CONNECTION REDUCES RECIDIVISM

6. How much time do you have left on your sentence? 
7. Do you think your experience will be different when you go home because you participated in MILK? If yes, how so?

\section{MECHANISM: IMPROVED IN-PRISON BEHAVIOR}

8. Do you feel that being in MILK has changed your experience in prison? If so, how? If only addresses visits, probe: Has MILK changed your experience even when you aren't in a visit? If so, how?

PROGRAM IMPLEMENTATION AND POTENTIAL AVENUES FOR ADDITIONAL INTERVENTION

I know that several different things happen in MILK, I'd like to get a sense of how you feel about each of these different activities.

9. Let's start with the visits. How do you feel about the MILK visits?

10. I imagine that some visits go well and others don't go so well. What sorts of things do you think make the visit day better or worse? Probe for factors important for children, mothers, and caregivers.

11. Is there anything you would like to change about the visits?

12. Next, I'd like to talk about your meetings with the other MILK moms. What are these meetings and the activities you do in them like for you?

13. What do you like most about these meetings and the activities you do in them?

14. What do you dislike or want to change?

\section{PROGRAM ACCESSIBILITY}

15. Think back to before you were in MILK, what made you want to join MILK?

16. What was the application process like to get into MILK? 
IF NEEDED PROBE: How many times did you try to join MILK before you got in?

17. Is there anything else you would like to share with us about MILK? 


\section{Appendix C}

Inmate Interview Protocol Revised

Hi, our names are and we are members of the prisoners and their families lab at the University of Virginia. Thank you for agreeing to meet with us. Today, we're interested in learning about your experience in MILK. The results of our work will be shared with the Department of Corrections staff and administrators to help them improve the program. There are no right or wrong answers - we just want to know what you think.

Do you have any questions before we get started? Okay, let's get started. If you have any questions at any point, please let me know.

1. I'd like to start by talking about your relationship with your children. We're going to use this map to track your relationship with your child(ren) at different points before and during your time inside. So, on this map you'll rate how close you felt to them using this scale where 5 is the closest, -5 is the least close, and 0 is right in the middle. Before we do this, I want to get a sense of what it means to you to feel close to your children. So, what does it mean to be close to your child?

2. OK, so on this graph here, I want to define what being close to your children at a 5,0 , and 5 mean to you and I'll write it on our graph. Let's pick 2 or 3 words to describe what a 5 , the closest, would be like?

3. OK, and let's pick 2 or 3 words to describe a -5 , the least close possible.

4. OK, and now let's pick 2 or 3 words to describe the middle of a 5, which is the closest, and -5, which is the least close? We'll put that at 0 . 
5. Ok, great. Now that we have our scale, I'd like you to rate how close you felt to your child at these different points here. So the first is after you got here but before you took the parenting class or joined MILK. How close did you feel to your child(ren) then using this scale? You can use this marker to put a dot there.

6. OK, and then you took the parenting class. Where would you rate how close you were with your children then?

7. OK, and then you joined MILK. Where would you rate how close you were with your children when you joined MILK?

8. OK, and how long have you been in MILK? OK, so now I'd like you to think back to about half way through your time in MILK, so that would have been __ mo/yrs, right? At that point, where would you rate how close you were with your children?

9. OK, and now let's rate how close you are with your children today. Where would you put that?

REVIEW OF CHANGES - CHILD

10. Before parenting class to Parenting class (circle one): IMPROVED WORSE NO CHANGE (If not noted prompt for changes related to class)

11. Parenting class to Start of MILK (circle one): IMPROVED WORSE NO CHANGE (If not noted prompt for changes related to class, visits, meetings with moms)

12. Start of MILK to Mid-MILK (circle one): IMPROVED WORSE NO CHANGE (If not noted prompt for changes related to class, visits, meetings with moms)

13. Mid-Milk to Current (circle one): IMPROVED WORSE NO CHANGE 
(If not noted prompt for changes related to class, visits, meetings with moms)

\section{CAREGIVER MAP}

14. Now I'd like to do the same thing on this graph, but this time I'd like you to rate how close you felt to the person taking care of your children. So, who takes care of your children? (WRITE ON GRAPH) OK, and what does it mean to you to be close to your children's caregiver?

15. OK, so on this graph here, I want to define what being close to your children's caregiver at a $-5,0$, and 5 mean to you and I'll write it on our graph. Let's pick 2 or 3 words to describe what a 5, the closest, would be like.

16. $\mathrm{OK}$, and let's pick 2 or 3 words to describe a -5 , the least close possible.

17. OK, and now let's pick 2 or 3 words to describe the middle of a 5, which is the closest, and -5 , which is the least close? We'll put that at 0 .

18. Ok, great. Now that we have our scale, we'll do the same ratings for how close you were with your children's caregiver at these different points. So the first is after you got here but before you took the parenting class or joined MILK. How close did you feel to your child(ren)'s caregiver then using this scale? You can use this marker to put a dot there.

19. OK, and then you took the parenting class. Where would you rate how close you were with your children's caregiver then?

20. OK, and then you joined MILK. Where would you rate how close you were with your children's caregiver when you joined MILK?

21. OK, so half-way through your time in MILK, so remember that's about $\mathrm{mo} / \mathrm{yrs}$, where would you rate how close you were with your children's caregiver? 
22. OK, and now let's rate how close you are with your children's caregiver today. Where would you put that?

\section{REVIEW OF CHANGES - CAREGIVER}

23. Before parenting class to parenting class (circle one):

\section{IMPROVED WORSE NO CHANGE}

(If not noted prompt for changes related to class)

24. Parenting class to Start of MILK (circle one):

\section{IMPROVED WORSE NO CHANGE}

(If not noted prompt for changes related to class, visits, meetings with moms)

25. Start of MILK to Mid-MILK (circle one): IMPROVED WORSE NO CHANGE (If not noted prompt for changes related to class, visits, meetings with moms)

26. Mid-Milk to Current (circle one): IMPROVED WORSE NO CHANGE (If not noted prompt for changes related to class, visits, meetings with moms)

\section{BEHAVIOR MAP}

27. OK, now we're going to do one last graph. On this graph I'd like you to rate your behavior in prison where a 5 is really good behavior, getting no tickets, and a -5 is the worst your behavior has ever been since you got here. So the first time point is after you got here but before you took the parenting class or joined MILK. How was your behavior then?

28. OK, and then you took the parenting class. Where would you rate your behavior then?

29. OK, and then you joined MILK. Where would you rate your behavior then? 
30. OK, so half-way through your time in MILK, so remember that's about $\mathrm{mo} / \mathrm{yrs}$ where would you rate your behavior then?

31. OK, and now let's rate your behavior today. Where would you put that?

\section{REVIEW OF CHANGES - BEHAVIOR}

32. Before parenting class to Parenting class (circle one):

IMPROVED WORSE NO CHANGE

(If not noted prompt for changes related to parenting class)

33. Parenting class to Start of MILK (circle one):

IMPROVED WORSE NO CHANGE

(If not noted prompt for changes related to class, visits, meetings with moms)

34. Start of MILK to Mid-MILK (circle one): IMPROVED WORSE NO CHANGE (If not noted prompt for changes related to class, visits, meetings with moms)

35. Mid-Milk to Current (circle one): IMPROVED WORSE NO CHANGE (If not noted prompt for changes related to class, visits, meetings with moms)

36. Anything else you'd like to share with us about your experience in MILK? 


\section{Appendix D}

\section{Background and Program Questionnaire}

Participant ID:

Date:

We'd like to ask you some questions to help us understand your experiences. Please answer these questions as honestly as possible. Your responses will be kept confidential.

1. How old are you?

2. Are you Hispanic or Latino? (CIRCLE ONE) YES NO

3. What is your race? (CIRCLE ONE)

\begin{tabular}{|c|c|c|c|c|c|}
\hline $\begin{array}{c}\text { African- } \\
\text { American/Bla } \\
\text { ck }\end{array}$ & $\begin{array}{c}\text { Asia } \\
\mathrm{n}\end{array}$ & $\begin{array}{c}\text { Caucasian/Whi } \\
\text { te }\end{array}$ & $\begin{array}{c}\text { American } \\
\text { Indian/Alask } \\
\text { an Native }\end{array}$ & $\begin{array}{c}\text { Native } \\
\text { Hawaiian/Pacif } \\
\text { ic Islander }\end{array}$ & OTHER \\
\hline
\end{tabular}

4. What is the highest level of education you have completed? (CIRCLE ONE)

\begin{tabular}{|c|c|c|c|c|}
\hline $\begin{array}{c}\text { Less than high } \\
\text { school }\end{array}$ & $\begin{array}{c}\text { High school } \\
\text { diploma/GED }\end{array}$ & $\begin{array}{c}\text { Some college/ } \\
\text { Associate's } \\
\text { degree }\end{array}$ & $\begin{array}{c}\text { College } \\
\text { degree }\end{array}$ & $\begin{array}{c}\text { Post-graduate } \\
\text { degree }\end{array}$ \\
\hline
\end{tabular}

5. I have been in MILK Moms for years and months

6. Think back to the time before you were involved in MILK. How did you hear or learn about MILK? (PLEASE CIRCLE ONE)

\begin{tabular}{|c|c|c|c|c|}
\hline From a C.O. & $\begin{array}{c}\text { From another staff } \\
\text { member (counselor, } \\
\text { etc.) }\end{array}$ & $\begin{array}{c}\text { From another } \\
\text { MILK } \\
\text { participant }\end{array}$ & $\begin{array}{c}\text { From a } \\
\text { flyer }\end{array}$ & Other \\
\hline
\end{tabular}

7. Did you find it difficult to get in to MILK?

\begin{tabular}{|c|c|c|c|c|}
\hline Not at all & $\begin{array}{c}\text { Neither difficult } \\
\text { nor easy }\end{array}$ & A little difficult & $\begin{array}{c}\text { Somewhat } \\
\text { difficult }\end{array}$ & Very difficult \\
\hline
\end{tabular}

8. My role in MILK Moms is (e.g., member, president, etc.):

9. How many MILK Mom visits have you participated in with your children?

10. At the last visit, did one or more of your children come? (CIRCLE ONE) YES NO 
If YES: Who came with the child/children? (CIRCLE ONE)

\begin{tabular}{|c|c|c|c|c|c|}
\hline $\begin{array}{c}\text { Child's } \\
\text { grandparent(s) }\end{array}$ & $\begin{array}{c}\text { Child's } \\
\text { father or } \\
\text { other parent }\end{array}$ & $\begin{array}{c}\text { Other family } \\
\text { member(s) }\end{array}$ & $\begin{array}{c}\text { A family } \\
\text { friend }\end{array}$ & $\begin{array}{c}\text { Child's foster } \\
\text { parent(s) }\end{array}$ & OTHER \\
\hline
\end{tabular}

If NO: Did anyone from your family come? YES NO

If YES: Who?

11. How many children do you have?

12. My children's ages are (fill in as many as apply for all of your children, even if they do not attend MILK):

13. How far away from the prison do your kid(s) live?

\begin{tabular}{|c|c|c|c|c|}
\hline $\begin{array}{c}\text { A plane ride } \\
\text { away }\end{array}$ & $\begin{array}{c}\text { More than a 10- } \\
\text { hour drive away }\end{array}$ & $\begin{array}{c}\text { More than a 5- } \\
\text { hour drive away }\end{array}$ & $\begin{array}{c}\text { A 1 to 3 hour } \\
\text { drive away }\end{array}$ & $\begin{array}{c}\text { Less than an } \\
\text { hour drive } \\
\text { away }\end{array}$ \\
\hline
\end{tabular}

14. How long is your current sentence?

15. How much of the sentence have you already served?

16. In all, how many times have you been in prison or in jail?

17. Did you live with your children immediately before this incarceration? (CIRCLE ONE) : YES NO

18. Do you plan to live with your children after you leave prison? (CIRCLE ONE) : YES $\mathrm{NO}$

19. My child/children live with

\begin{tabular}{|l|c|c|c|c|c|}
\hline My parent(s) & Their father & $\begin{array}{c}\text { Their father's } \\
\text { parent(s) }\end{array}$ & $\begin{array}{c}\text { A friend or } \\
\text { other family } \\
\text { member }\end{array}$ & $\begin{array}{c}\text { Foster } \\
\text { care/state } \\
\text { care }\end{array}$ & Other: \\
\hline
\end{tabular}

20. What is your relationship like with your child/children's caregiver?

\begin{tabular}{|c|c|c|c|c|}
\hline $\begin{array}{c}\text { We get along } \\
\text { VERY WELL }\end{array}$ & $\begin{array}{c}\text { We get along } \\
\text { OK }\end{array}$ & $\begin{array}{c}\text { Neutral: neither } \\
\text { good nor bad }\end{array}$ & $\begin{array}{c}\text { We DON'T get } \\
\text { along very well }\end{array}$ & $\begin{array}{c}\text { We DON'T } \\
\text { get along at } \\
\text { all }\end{array}$ \\
\hline
\end{tabular}

21. How many times have you spoken to your child's/children's caregiver in the last month (phone or in person)?

22. How many letters have you received from your child's/children's caregiver in the last month? 
IF NONE: How many have you received in the last year?

23. How many times has your child/children's caregiver asked for your opinion on parenting in the last month?

IF NONE: How many times has s/he asked for your opinion on parenting in the last year?

24. Do you feel like your child/children's caregiver respects your opinion about parenting? (circle one):

\begin{tabular}{|c|c|c|c|c|}
\hline Yes, a lot & Yes, a little & $\begin{array}{c}\text { Neither respects nor } \\
\text { disrespects }\end{array}$ & No, not much & $\begin{array}{c}\text { No, not at } \\
\text { all }\end{array}$ \\
\hline
\end{tabular}

25. Currently, how much of a say do you have in how your children are raised?

\begin{tabular}{|c|c|c|c|c|}
\hline Total say & $\begin{array}{c}\text { A good } \\
\text { amount, but not } \\
\text { total say }\end{array}$ & Some & Not much & None at all \\
\hline
\end{tabular}

26. How many letters have you written to your child/children in the last month? 27. How many letters have you written to your child/children in the last year?

28. How many times have you phoned your kid(s) in the last month?

29. How many times have you phoned your kid(s) in the last year?

30. On average, how long do phone calls with your child/children last? $\min$

31 . How many times have your children visited you in the last year?

32. Since you joined MILK Moms, how often do your kid(s) visit you, on average?

\begin{tabular}{|c|c|c|c|c|c|c|}
\hline Never & $\begin{array}{c}\text { Less than } \\
\text { once a } \\
\text { year }\end{array}$ & $\begin{array}{c}\text { About once } \\
\text { a year }\end{array}$ & $\begin{array}{c}\text { About } \\
\text { twice a } \\
\text { year }\end{array}$ & $\begin{array}{c}\text { About } \\
\text { every 2-3 } \\
\text { months }\end{array}$ & $\begin{array}{c}\text { Every } \\
\text { month }\end{array}$ & $\begin{array}{c}\text { Every } \\
\text { week }\end{array}$ \\
\hline
\end{tabular}

33. Before you joined MILK Moms, how often did your kid(s) visit you, on average?

\begin{tabular}{|c|c|c|c|c|c|c|}
\hline Never & $\begin{array}{c}\text { Less than } \\
\text { once a } \\
\text { year }\end{array}$ & $\begin{array}{c}\text { About once } \\
\text { a year }\end{array}$ & $\begin{array}{c}\text { About } \\
\text { twice a } \\
\text { year }\end{array}$ & $\begin{array}{c}\text { About } \\
\text { every 2-3 } \\
\text { months }\end{array}$ & $\begin{array}{c}\text { Every } \\
\text { month }\end{array}$ & $\begin{array}{c}\text { Every } \\
\text { week }\end{array}$ \\
\hline
\end{tabular}

34. Since joining MILK Moms, how much stress do you feel about being a parent?

\begin{tabular}{|l|l|l|c|c|}
\hline $\begin{array}{c}\text { A lot more than } \\
\text { before I joined }\end{array}$ & $\begin{array}{l}\text { A little more } \\
\text { than before I } \\
\text { joined }\end{array}$ & $\begin{array}{c}\text { The same amount } \\
\text { as before I joined }\end{array}$ & $\begin{array}{c}\text { A little less } \\
\text { than before I } \\
\text { joined }\end{array}$ & $\begin{array}{c}\text { A lot less than } \\
\text { before I joined }\end{array}$ \\
\hline
\end{tabular}

35. Did you work to get fewer charges/tickets in order to be eligible for MILK? 


\begin{tabular}{|c|c|c|}
\hline $\begin{array}{c}\text { YES, MILK was the main } \\
\text { motivation for me to get } \\
\text { fewer charges/tickets }\end{array}$ & $\begin{array}{c}\text { YES, MILK was part of the } \\
\text { motivation for me to get fewer } \\
\text { charges/tickets }\end{array}$ & $\begin{array}{c}\text { NO, I never got many } \\
\text { charges/tickets so it } \\
\text { wasn't an issue }\end{array}$ \\
\hline
\end{tabular}

36. Since you joined MILK Moms, how many tickets have you gotten?

\begin{tabular}{|c|c|c|c|c|}
\hline $\begin{array}{c}\text { A lot more } \\
\text { tickets than } \\
\text { before }\end{array}$ & $\begin{array}{c}\text { A few more } \\
\text { tickets than } \\
\text { before }\end{array}$ & $\begin{array}{c}\text { The same amount } \\
\text { of tickets as before }\end{array}$ & $\begin{array}{c}\text { A few less } \\
\text { tickets than } \\
\text { before }\end{array}$ & $\begin{array}{c}\text { A lot less } \\
\text { tickets than } \\
\text { before }\end{array}$ \\
\hline
\end{tabular}

37. Overall, how helpful has MILK Moms been to you?

\begin{tabular}{|c|c|c|c|c|}
\hline $\begin{array}{c}\text { It has been } \\
\text { VERY helpful } \\
\text { to me }\end{array}$ & $\begin{array}{c}\text { It has been } \\
\text { SOMEWHAT } \\
\text { helpful to me }\end{array}$ & $\begin{array}{c}\text { It's been neither } \\
\text { helpful nor } \\
\text { unhelpful }\end{array}$ & $\begin{array}{c}\text { It has been } \\
\text { ONLY A } \\
\text { LITTLE helpful } \\
\text { to me }\end{array}$ & $\begin{array}{c}\text { It has NOT } \\
\text { been helpful to } \\
\text { me AT ALL }\end{array}$ \\
\hline
\end{tabular}

38. Please list the three best things that happen in your life because of MILK?

1.

2.

3.

39. If you could make 3 changes to MILK, what would you change?

1.

2.

3. 


\section{Appendix E}

Adult-Adolescent Parenting Inventory (AAPI-2)

Stephen J. Bavolek, Ph.D. and Richard G. Keene, Ph.D.

Instructions: Please circle ONE response that best describes how you feel about each statement

\begin{tabular}{|c|c|c|c|c|c|}
\hline & $\begin{array}{l}\text { Strongly } \\
\text { Agree }\end{array}$ & Agree & Disagree & $\begin{array}{l}\text { Strongly } \\
\text { Disagree }\end{array}$ & Uncertain \\
\hline $\begin{array}{l}\text { 1. Children need to be allowed freedom } \\
\text { to explore their world in safety. }\end{array}$ & SA & $A$ & $D$ & SD & $U$ \\
\hline $\begin{array}{l}\text { 2. Time-out is an effective way to } \\
\text { discipline children. }\end{array}$ & SA & $A$ & $D$ & SD & $U$ \\
\hline $\begin{array}{l}\text { 3. Children who are one-year-old should } \\
\text { be able to stay away from things that } \\
\text { could harm them. }\end{array}$ & SA & $A$ & D & SD & U \\
\hline $\begin{array}{l}\text { 4. Strong-willed children must be taught } \\
\text { to mind their parents. }\end{array}$ & SA & $A$ & D & SD & $U$ \\
\hline $\begin{array}{l}\text { 5. The sooner children learn to feed and } \\
\text { dress themselves and use the toilet, the } \\
\text { better off they will be as adults. }\end{array}$ & SA & A & $D$ & SD & U \\
\hline $\begin{array}{l}\text { 6. Spanking teaches children right from } \\
\text { wrong. }\end{array}$ & SA & $A$ & $D$ & SD & $U$ \\
\hline $\begin{array}{l}\text { 7. Babies need to learn how to be } \\
\text { considerate of the needs of their } \\
\text { mother. }\end{array}$ & SA & $A$ & D & SD & U \\
\hline $\begin{array}{l}\text { 8. Strict discipline is the best way to } \\
\text { raise children. }\end{array}$ & SA & $A$ & $D$ & SD & $U$ \\
\hline $\begin{array}{l}\text { 9. Parents who nurture themselves } \\
\text { make better parents. }\end{array}$ & SA & A & D & SD & U \\
\hline $\begin{array}{l}\text { 10. Children can learn good discipline } \\
\text { without being spanked. }\end{array}$ & SA & $A$ & $D$ & SD & U \\
\hline
\end{tabular}




\begin{tabular}{|c|c|c|c|c|c|}
\hline $\begin{array}{l}\text { 11. Children have a responsibility to } \\
\text { please their parents. }\end{array}$ & SA & $A$ & $\mathrm{D}$ & SD & $U$ \\
\hline $\begin{array}{l}\text { 12. Good children always obey their } \\
\text { parents. }\end{array}$ & SA & $A$ & $\mathrm{D}$ & SD & $U$ \\
\hline $\begin{array}{l}\text { 13. In father's absence, the son needs to } \\
\text { become the man of the house. }\end{array}$ & SA & A & $\mathrm{D}$ & SD & $U$ \\
\hline 14. A good spanking never hurt anyone. & SA & $A$ & $\mathrm{D}$ & SD & $U$ \\
\hline $\begin{array}{l}\text { 15. Parents need to push their children } \\
\text { to do better. }\end{array}$ & SA & A & $\mathrm{D}$ & SD & $U$ \\
\hline $\begin{array}{l}\text { 16. Children should keep their feelings } \\
\text { to themselves. }\end{array}$ & SA & A & $\mathrm{D}$ & SD & $U$ \\
\hline $\begin{array}{l}\text { 17. Children should be aware of ways to } \\
\text { comfort their parents after a hard day's } \\
\text { work. }\end{array}$ & SA & A & $\mathrm{D}$ & SD & $U$ \\
\hline $\begin{array}{l}\text { 18. Children learn respect through strict } \\
\text { discipline. }\end{array}$ & SA & $A$ & $\mathrm{D}$ & SD & $U$ \\
\hline $\begin{array}{l}\text { 19. Hitting a child out of love is different } \\
\text { than hitting a child out of anger. }\end{array}$ & SA & $A$ & $\mathrm{D}$ & SD & $U$ \\
\hline $\begin{array}{l}\text { 20. A good child sleeps through the } \\
\text { night. }\end{array}$ & SA & $A$ & $D$ & SD & $U$ \\
\hline $\begin{array}{l}\text { 21. Children should be potty trained } \\
\text { when they are ready and not before. }\end{array}$ & SA & $A$ & $D$ & SD & $U$ \\
\hline $\begin{array}{l}\text { 23. A certain amount of fear is } \\
\text { necessary for children to respect their } \\
\text { parents. }\end{array}$ & SA & $A$ & $D$ & SD & $U$ \\
\hline $\begin{array}{l}\text { 24. Children who feel secure often grow } \\
\text { up expecting too much. }\end{array}$ & SA & $A$ & $D$ & SD & $U$ \\
\hline $\begin{array}{l}\text { 25. There is nothing worse than a } \\
\text { strong-willed two-year-old. }\end{array}$ & SA & $A$ & $D$ & SD & $U$ \\
\hline $\begin{array}{l}\text { 26. Sometimes spanking is the only } \\
\text { thing that will work. }\end{array}$ & SA & $A$ & $D$ & SD & $U$ \\
\hline
\end{tabular}




\begin{tabular}{|c|c|c|c|c|c|}
\hline $\begin{array}{l}\text { 27. Children who receive praise will } \\
\text { think too much of themselves. }\end{array}$ & SA & $A$ & $\mathrm{D}$ & SD & $U$ \\
\hline $\begin{array}{l}\text { 28. Children should do what they're told } \\
\text { to do when they're told to do it. It's that } \\
\text { simple. }\end{array}$ & SA & A & $\mathrm{D}$ & SD & $U$ \\
\hline $\begin{array}{l}\text { 29. Children should be taught to obey } \\
\text { their parents at all times. }\end{array}$ & SA & $A$ & $\mathrm{D}$ & SD & $U$ \\
\hline $\begin{array}{l}\text { 30. Children should know what their } \\
\text { parents need without being told. }\end{array}$ & SA & $A$ & $\mathrm{D}$ & SD & $U$ \\
\hline $\begin{array}{l}\text { 31. Children should be responsible for } \\
\text { the well-being of their parents. }\end{array}$ & SA & A & $\mathrm{D}$ & SD & $U$ \\
\hline 32. It's OK to spank as a last resort. & SA & $A$ & $\mathrm{D}$ & SD & $U$ \\
\hline $\begin{array}{l}\text { 33. Parents should be able to confide in } \\
\text { their children. }\end{array}$ & SA & A & $\mathrm{D}$ & SD & $U$ \\
\hline $\begin{array}{l}\text { 34. Parents who encourage their } \\
\text { children to talk to them only end up } \\
\text { listening to complaints. }\end{array}$ & SA & A & $\mathrm{D}$ & SD & $U$ \\
\hline $\begin{array}{l}\text { 35. Children need discipline not } \\
\text { spanking. }\end{array}$ & SA & $A$ & $\mathrm{D}$ & SD & $U$ \\
\hline $\begin{array}{l}\text { 36. Letting a child sleep in the parents' } \\
\text { bed every now and then is a bad idea. }\end{array}$ & SA & $A$ & $\mathrm{D}$ & SD & $U$ \\
\hline $\begin{array}{l}\text { 37. A good spanking lets children know } \\
\text { parents mean business. }\end{array}$ & SA & $A$ & $\mathrm{D}$ & SD & $U$ \\
\hline $\begin{array}{l}\text { 38. A good child will comfort both } \\
\text { parents after they have argued. }\end{array}$ & SA & $A$ & $D$ & SD & $U$ \\
\hline $\begin{array}{l}\text { 39. "Because I said so" is the only } \\
\text { reason parents need to give. }\end{array}$ & SA & $A$ & $D$ & SD & $U$ \\
\hline $\begin{array}{l}\text { 40. Children should be their parents' } \\
\text { best friend. }\end{array}$ & SA & $A$ & $D$ & SD & $U$ \\
\hline
\end{tabular}

